\title{
Chromosome instability
}

Citation for published version (APA):

Bergshoeff, V. E. (2017). Chromosome instability: a biomarker of progression in premalignant head and neck lesions. [Doctoral Thesis, Maastricht University]. Datawyse / Universitaire Pers Maastricht. https://doi.org/10.26481/dis.20170615vb

Document status and date:

Published: 01/01/2017

DOI:

10.26481/dis.20170615vb

Document Version:

Publisher's PDF, also known as Version of record

\section{Please check the document version of this publication:}

- A submitted manuscript is the version of the article upon submission and before peer-review. There can be important differences between the submitted version and the official published version of record.

People interested in the research are advised to contact the author for the final version of the publication, or visit the DOI to the publisher's website.

- The final author version and the galley proof are versions of the publication after peer review.

- The final published version features the final layout of the paper including the volume, issue and page numbers.

Link to publication

\footnotetext{
General rights rights.

- You may freely distribute the URL identifying the publication in the public portal. please follow below link for the End User Agreement:

www.umlib.nl/taverne-license

Take down policy

If you believe that this document breaches copyright please contact us at:

repository@maastrichtuniversity.nl

providing details and we will investigate your claim.
}

Copyright and moral rights for the publications made accessible in the public portal are retained by the authors and/or other copyright owners and it is a condition of accessing publications that users recognise and abide by the legal requirements associated with these

- Users may download and print one copy of any publication from the public portal for the purpose of private study or research.

- You may not further distribute the material or use it for any profit-making activity or commercial gain

If the publication is distributed under the terms of Article $25 \mathrm{fa}$ of the Dutch Copyright Act, indicated by the "Taverne" license above, 


\section{Chromosome instability:}

a biomarker of progression

\section{in premalignant head and neck lesions}

Ewa Bergshoeff

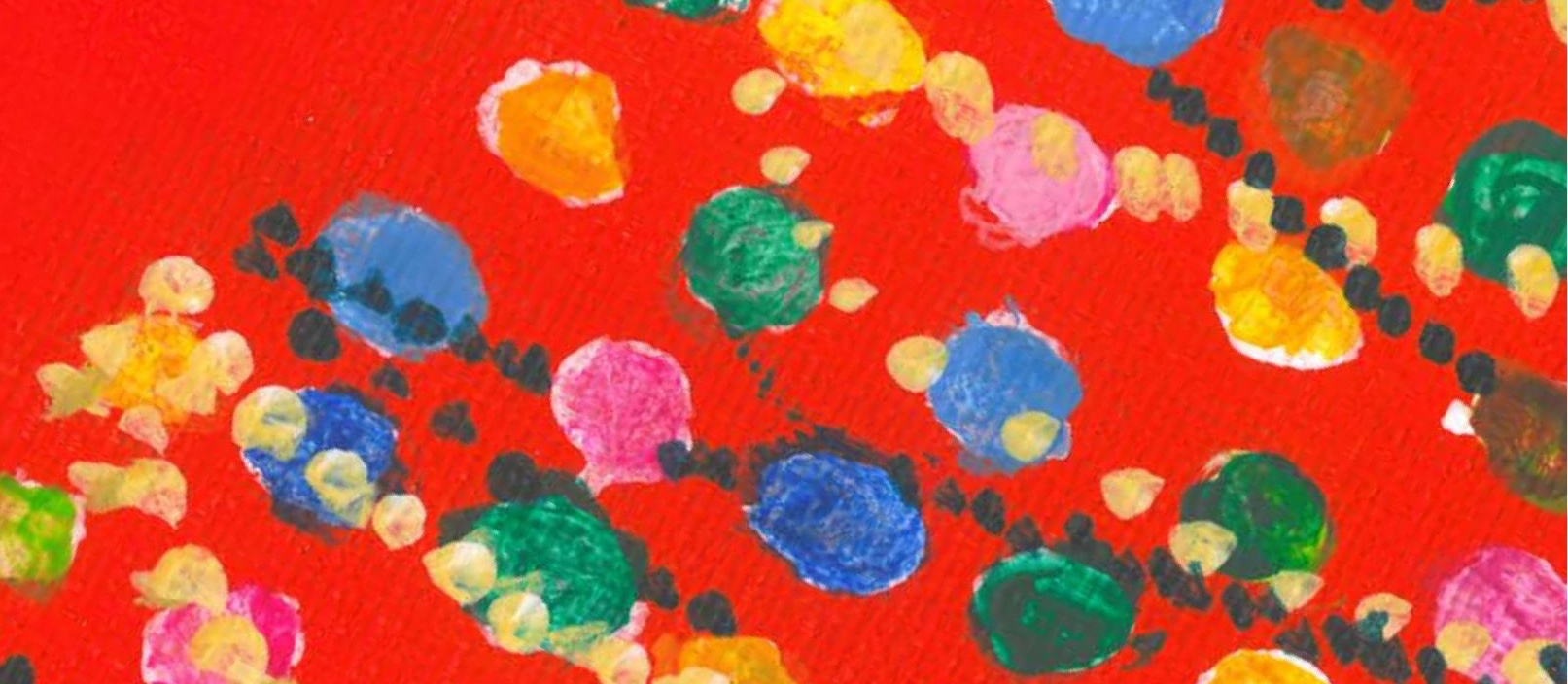


Copyright Ewa Bergshoeff, Maastricht 2017

Layout: Tiny Wouters

Cover Design: Datawyse

Production: Datawyse - Universitaire Pers Maastricht ISBN: 9789461597007 


\title{
Chromosome instability:
}

\section{a biomarker of progression in}

\section{premalignant head and neck lesions}

\author{
PROEFSCHRIFT \\ Ter verkrijging van de graad van doctor aan de Universiteit Maastricht, \\ op gezag van de Rector Magnificus, \\ Prof. dr. Rianne M. Letschert \\ volgens het besluit van het College van Decanen, \\ in het openbaar te verdedigen op \\ donderdag 15 juni 2017 om 12:00 uur
}

door

Verona Ewa Bergshoeff 


\section{Promotores:}

Prof. dr. B. Kremer

Prof. dr. E-J. M. Speel

Prof. dr. F.C.S. Ramaekers

\section{Beoordelingscommissie:}

Prof. dr. A. zur Hausen (voorzitter)

Prof. dr. M. W. M. van den Brekel (Nederlands Kanker Instituut-Antoni van Leeuwenhoekziekenhuis)

Prof. dr. J.L.N. Roodenburg (Universitair Medisch Centrum Groningen) Prof. dr. V.C.G. Tjan-Heijnen

Dit proefschrift is mede tot stand gekomen door financiële ondersteuning van het Koningin Wilhelmina Fonds, grant 2007-3935 en het Kankeronderzoeksfonds Limburg 


\section{Contents}

Chapter 1 General introduction and outline of the thesis 7

Chapter 2 Interobserver variability of laryngeal mucosal premalignant 27 lesions: a histopathological evaluation Modern Pathology 2011;24(7):892-898

Chapter 3 Chromosome instability predicts progression of 43 premalignant lesions of the larynx Pathology 2014;46(3):216-224

Chapter 4 Chromosome instability predicts the progression of 63 premalignant oral lesions Oral Oncology 2013;49(12):1121-8

Chapter 5 Chromosome instability in resection margins predicts 83 recurrence of oral squamous cell carcinoma Journal of Pathology 2008;215(3):347-348

Chapter 6 Objective evaluation criteria for chromosome instability 89 detection by FISH to predict malignant progression in premalignant glottic laryngeal lesions Submitted for publication

Chapter 7 General discussion and conclusion

Summary 123

Samenvatting 129

Valorisation Addendum

List of publications

Dankwoord

Curriculum Vitae 

Chapter

GENERAL INTRODUCTION 


\section{Head and neck cancer}

\section{Epidemiology}

The mucosa of the head and neck region may undergo malignant transformation which will lead to head and neck squamous cell carcinoma (HNSCC). Most cancers that develop from the head and neck mucosa are squamous cell carcinomas (SCC), which account for $90 \%$ of all head and neck malignancies. Other encountered types of cancer include adenocarcinomas, sarcomas, malignant lymphomas, salivary gland tumors and bony and cartilaginous tumors. In this thesis the focus will be on HNSCC that may evolve from premalignant precursor lesions, detectable on the vocal cords and oral cavity because of early symptoms (e.g. hoarseness and macroscopically detectable mucosal patches such as leukoplakia).

HNSCC is the sixth most common cancer type worldwide, with approximately 686.000 new cases and 376.000 cancer deaths annually. ${ }^{1,2}$ A subdivision is made according to the anatomical site of the tumor, and includes amongst others the larynx, pharynx and oral cavity, including lip-tumors. Most frequently encountered is cancer of the oral cavity and lip with an estimated 300,000 new cases worldwide, followed by laryngeal cancer (157,000 new cases) and pharyngeal cancer (nasopharynx excluded, 142,000 new cases) in 2012. ${ }^{2}$ HNSCC is encountered predominantly in men. Established risk-factors include tobacco use and alcohol consumption, which show a synergistic carcinogenic effect. Another risk factor is infection with oncogenic viruses, such as Human Papilloma Viruses (HPV) predominantly in oropharyngeal cancer and Epstein Barr Virus (EBV) in nasopharyngeal carcinoma. ${ }^{3,4}$ HPV positive HNSCC show in general a favorable survival compared to HPV negative tumors and should be considered as a separate biological entity of HNSCC. ${ }^{5,6}$ Also inherited mutations may lead to the development of HNSCC, such as those in the genes FANC, CDKN2A and p53 related to Fanconi anemia and Li Fraumeni. ${ }^{7-9}$ Finally, an association between periodontal disease and HNSCC has been reported. ${ }^{10}$

\section{Anatomy of the head and neck}

The head and neck mucosa consists of squamous cell epithelium. It is part of the aero-digestive tract and is divided in different anatomical regions consisting of the larynx (including the vocal cords), the naso-, oro- and hypopharynx, oral cavity and nose and paranasal sinuses, which can be further divided in anatomical subregions.

The larynx consists of three anatomical sub-regions: 1) the glottis containing the vocal cords and comprising the area up to $1 \mathrm{~cm}$ under the level of the free 
edge of the vocal cords, 2) the supraglottis, including the valse vocal cords and the sinus of Morgagni, and 3 ) the subglottis existing of the region downwards of the cauda; border of the glottis to the level of the lower border of the cricoid cartilage, Figure 1.1A.

The oral cavity comprises the lips, oral vestibule, alveolar processes, the teeth, cheeks, tongue, floor of the mouth, soft and hard palate and is dorsally bordered by oropharyngeal isthmus, Figure 1.1B.

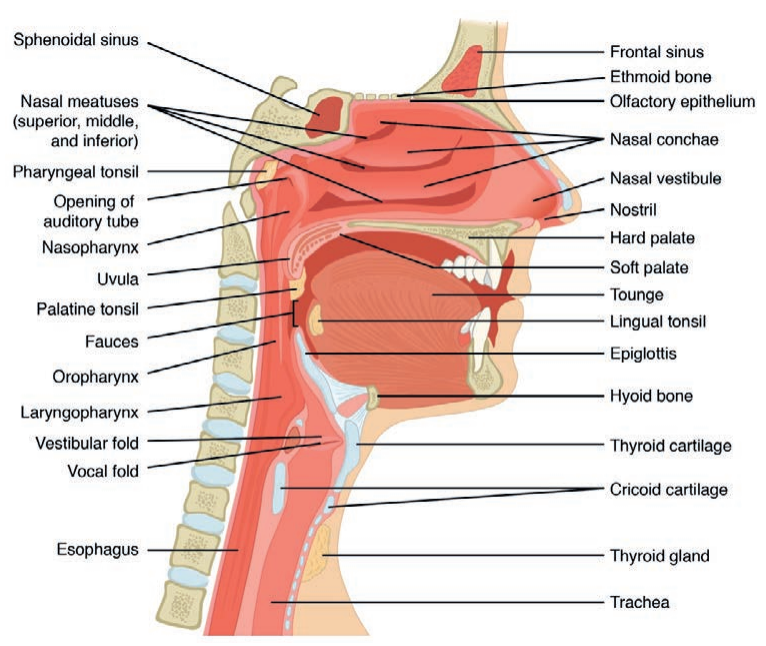

Figure 1.1A Sagittal section of the neck with the main anatomical structures and subregions displayed.

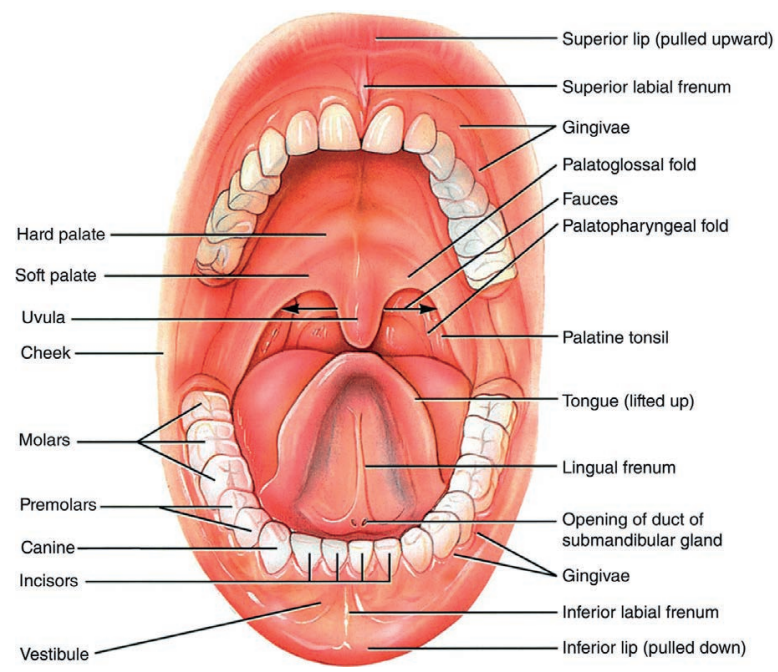

Figure 1.1B The anatomical structures of the oral cavity and oropharynx. 
The head and neck region is characterized by different functionalities including breathing, chewing, swallowing, speaking and humidification and clearance of respired air, tasting and hearing. Based on the lymphogenic drainage of the head and neck different regions ranging from I to $\mathrm{VI}$ are defined, which reflect the lymph node metastasis pattern of malignancies per mucosal region, Figure 1.2 .

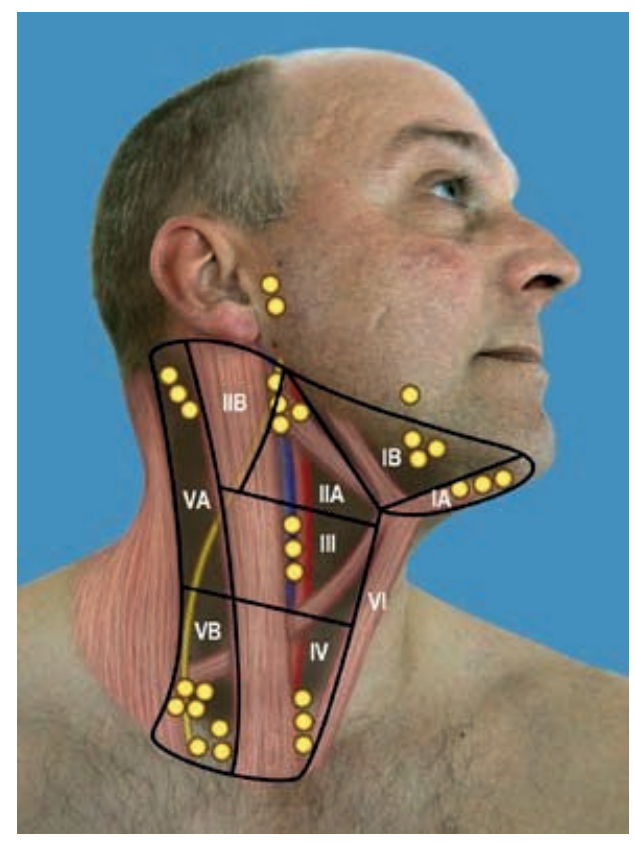

Figure 1.2 Division of the neck in anatomical subregions I-VI, which is relevant for the metastasis pattern and the surgical treatment of locoregional neck metastases.

Source: Roodenburg JLN, Witjes MJH, Schepman KP. Oncologie. In: MKA Chirurgie. Ed. Stegenga et al. Van Gorcum, Assen, 2013

\section{Clinical presentation and prognosis}

Patients with HNSCC may present with a visible alteration of the mucosa, dysphagia, referred pain to the ear, a sore throat and hoarseness. Tumor spread in HNSCC generally occurs through lymphogenic metastasis to the adjacent neck lymph nodes, resulting in a mass in the neck of the patient, which may also be the first and only symptom of the disease. Lymph node metastasis may occur more easily if the tumor is localized in a region of the head and neck mucosa with an extensive lymphatic drainage, such as the (hypo)pharynx and supraglottic larynx (Figure 1.2). The prognosis of HNSCC patients depends largely on tumor localization and spread and the presence of 
locoregional lymph node or distant metastasis, which is defined by the TNM classification and staging of the disease. Early stage HNSCC patients have in general a $60-95 \%$ overall survival rate in contrast with patients with stage III and IV disease which have a much worse survival rate of $25-30 \% .{ }^{11-13}$ Recently, it has been shown that HPV positive (oropharyngeal) tumors in general have a more favorable prognosis than HPV negative tumors with a comparable TNM classification, which implicates that the traditional TNM classification might not always provide adequate prognostic information in this HPV positive subgroup of patients. ${ }^{14}$

\section{Treatment options and factors influencing prognosis}

Treatment modalities for HNSCC include surgery, radiation therapy, chemotherapy, and targeted therapy, or a combination of these. ${ }^{5,6}$ In the last decades treatment morbidity of HNSCC could be reduced significantly because of medical progress, however, the 5-year survival rate of HNSCC could not be improved and still remains approximately $50 \% .{ }^{1,15}$ Once a tumor has developed treatment results are rather disappointing. This might be explained by 1) late presentation of patients due to a late onset of complaints, which results in the majority of patients presenting with stage III or IV disease and locoregional metastasis at primary presentation, ${ }^{16}$ 2) locoregional tumor recurrence after surgery or radiation therapy in up to $30 \%$, due to minimal residual disease in tumor resection margins and/or the presence of premalignant lesions as a result of field cancerization, ${ }^{17,18} 3$ ) limitations of surgical resection and radiation therapy, taking into account functional organ preservation and individual patient factors and 4) disappointing results using the targeted therapeutic anti-EGFR agent cetuximab. Furthermore, approximately $15 \%$ of patients with HNSCC will develop a second or third primary tumor in the aero-digestive tract due to carcinogenic exposition by tobacco and alcohol consumption and field cancerization. ${ }^{19-22}$ Therefore recent health policies focus on primary prevention of HNSCC by an improvement of the awareness of the carcinogenic effect of especially tobacco and alcohol, which led to a decrease of non-HPV induced HNSCC in the USA. However, an increase of HPV-positive HNSCC is observed in the USA and Western Europe. ${ }^{23}$ Furthermore, effects of primary prevention need decennia to occur and only a part of all cancers can be prevented.

Therefore, secondary prevention will always be of utmost importance. It consists of the prevention of malignant outgrowth of symptomatic premalignant head and neck lesions by their early detection and if necessary treatment. However, although many morphological alterations of the mucosa are macroscopically detectable, it is difficult to predict their risk of malignant transformation on the basis of histology. 
Tertiary prevention should prevent the development of tumor recurrences after treatment of the primary tumor. Markers and methods to reliably differentiate between normal or non-progressive lesions and lesions at risk for malignant

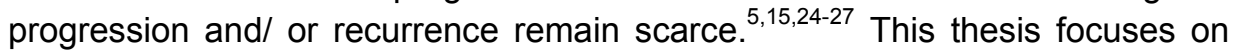
secondary prevention which is particularly useful in head and neck lesions because of the characteristics of head and neck carcinogenesis which will be described in the following section.

\section{Head and neck carcinogenesis- clinical and histopathological aspects}

It is assumed that HNSCC, in general, develop out of pre-existing precursor lesions, which can be present for many years before malignant transformation takes place. Precancerous lesions may clinically present as leukoplakia ("white patches") or erythroplakia ("red patches"), of which the former are encountered much more frequently than the latter. ${ }^{28,29}$ Furthermore, oral submucous fibrosis may be distinguished as a precursor lesion. ${ }^{27}$ These clinical descriptions of lesions, have no direct correlation to histopathological features. Erythroplakias are most at risk for malignant transformation with risk-rates up to $90 \%{ }^{28-30}$ compared to $5-30 \%$ in leukoplakias. ${ }^{31-33}$ Nevertheless, the clinical impact of leukoplakia is larger because it is encountered far more often than erythroplakia.

The gold standard for the classification of premalignant head and neck lesions is histopathological assessment of hematoxylin \& eosin-stained tissue sections by light microscopic examination. Changes in the cell morphology and tissue architecture are generally referred to as dysplasia, which can be subdivided in different degrees according to the classification system used. The three most commonly used histopathological classification systems for head and neck precursor lesions are the WHO, SIN and Ljubljana system.

\section{WHO classification system}

The WHO classification system is worldwide the most applied classification system for (pre)malignant head and neck lesions. It comprises the morphological identification of hyperplasia, mild, moderate and severe dysplasia and carcinoma in situ (CIS) (Figure 1.3A-C). Reported malignant transformation risk for hyperplasia range from 0-3\%, for mild dysplasia $0-30 \%$, for moderate dysplasia $0-44 \%$, for severe dysplasia $20-57 \%$ and CIS $0-80 \%$ for laryngeal lesions. ${ }^{34,35}$ For oral lesions a meta-analysis showed an estimated transformation rate of $10.3 \%$ for mild and moderate dysplasia and $24.1 \%$ for severe dysplasia and CIS, with a broad range of rates reported in the studies which were included. ${ }^{36}$ 


\section{Squamous Intraepithelial Neoplasia (SIN) classification}

The SIN classification is mainly used for laryngeal lesions. It consists of three classes, i.e. SIN 1, 2 and 3, in which SIN 1 and 2 are comparable to, respectively, mild and moderate dysplasia of the WHO classification system and SIN 3 to both severe dysplasia and CIS (Figure 1.3A-C). A similar classification system is also used for uterine cervical intraepithelial lesions. ${ }^{34,37}$ The reported malignant progression risk for laryngeal lesions varies from $5 \%$ (SIN 1 ) to $25 \%$ (SIN 2) and $11-25 \%$ (SIN 3). ${ }^{34,38}$

\section{Ljubljana Classification of Squamous Intraepithelial Lesions (SIL)}

This classification system is also mainly applied for laryngeal lesions and consists of 1) "simple" squamous cell hyperplasia without atypical cytologic changes, 2) "abnormal" basal/ parabasal cell hyperplasia, 3) "atypical" hyperplasia and 4) CIS, which requires treatment. ${ }^{34,39}$ The reported malignant transformation risk in laryngeal lesions varies from respectively $1.1 \%$ for basal/ parabasal cell hyperplasia to $9.5 \%$ for atypical hyperplasia. ${ }^{39}$ In oral lesions $0 \%$ is reported for simple or abnormal hyperplasia and $18.2 \%$ for atypical hyperplasia. ${ }^{40}$ Recently a modified Ljubljana 3-grade classification system for laryngeal lesions has been proposed. ${ }^{41}$

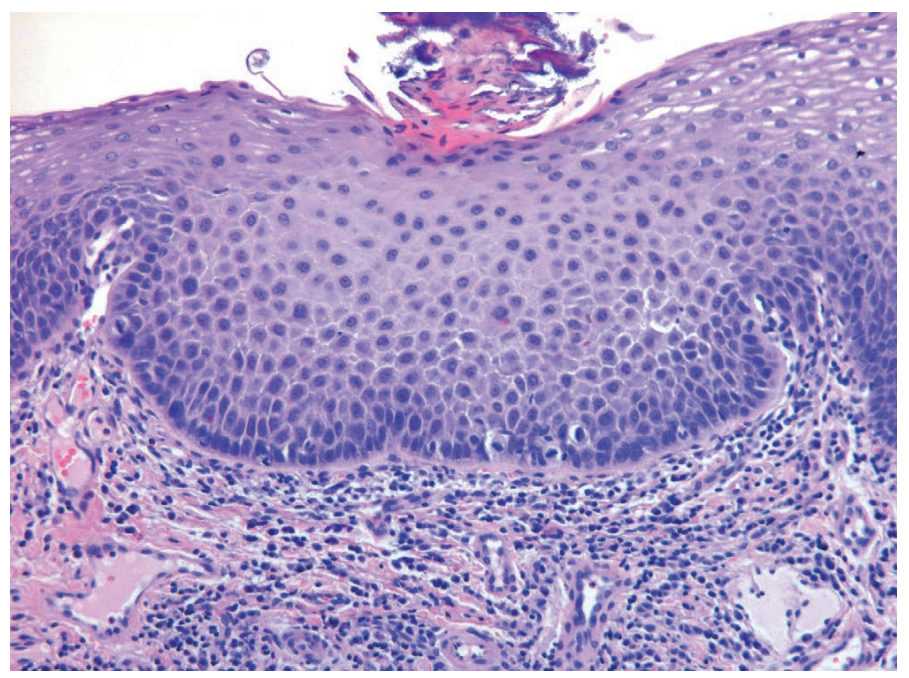

Figure 1.3A Mild dysplasia (WHO classification) or parabasal hyperplasia (Ljubljana classification), characterized by an increased thickness of the epithelium and hyperkeratosis (Fleskens et al. Head Neck Oncol 2009 May 11;1:11). 


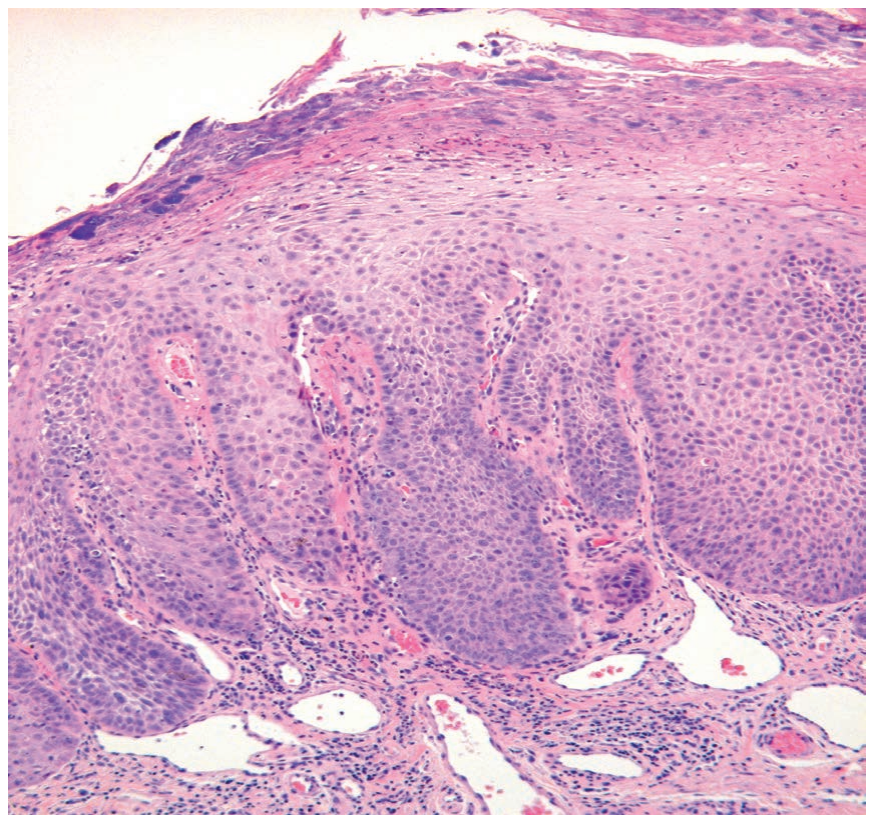

Figure 1.3B Moderate dysplasia (WHO classification) or atypical hyperplasia (Ljubljana classification), characterized by blunt and elongated epithelial ridges and nuclear atypia confined to the lower epithelial half (Fleskens et al. Head Neck Oncol 2009 May 11;1:11).

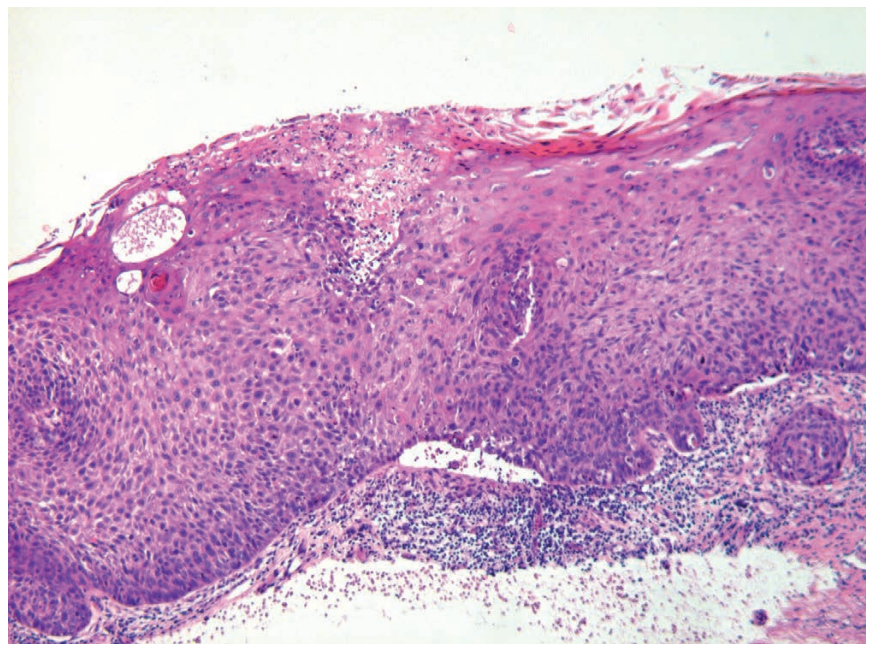

Figure 1.3C Severe dysplasia (WHO classification) or atypical hyperplasia (Ljubljana classification), characterized by morphological alterations involving the entire epithelial layer (Fleskens et al. Head Neck Oncol 2009 May 11;1:11). 


\section{Inter and intraobserver variability of histopathological assessment}

Existing classification systems do not allow for a reliable risk estimation of malignant progression and thus for an evidence based indication for treatment. Depending on classification system used a very broad range of malignant transformation risks for the different grades of dysplasia is found in literature. Furthermore, the comparison between studies remains difficult due to different study designs and inclusion criteria. Based on available data in the literature Fleskens et al. ${ }^{34}$ reported high interobserver variabilities, i.e. an overall kappa value of 0.32 for the reproducibility of the WHO classification in laryngeal lesions and kappa-values varying from $0.15-0.59$ for lesions of the oral cavity and oropharynx. For the modified Ljubljana classification applied on premalignant laryngeal lesions Gale and colleagues (9 pathologists) reported kappa-values, varying from $0.68-0.81$. Thus far, no kappa values are available for the SIN classification.

A study performed on oral dysplastic lesions using the WHO classification criteria reported very poor kappa-values for intraobserver variability, ranging from $0.15-0.40$ for exact agreement on the subclassification of dysplasia. ${ }^{42}$

No studies on intraobserver variability in the histopathological assessment of laryngeal lesions are reported in literature.

Thus, independent of the classification system used, the prediction of the malignant transformation risk of premalignant head and neck lesions on the basis of histopathological diagnosis alone remains a major challenge. Therefore, new indicators to reliably predict malignant progression are urgently needed. A better knowledge of the molecular mechanisms underlying the tumorigenesis of the head and neck mucosa is required to identify putative molecular biomarkers for this purpose. This will be described in the following section.

\section{Head and neck carcinogenesis - molecular biology}

Carcinogenesis is a complex process in which exposure to environmental carcinogens promotes the accumulation of changes on the gene and protein level of cells, generally leading to loss of cell cycle control (and induction of unlimited proliferation), loss of the capability to induce programmed cell death (apoptosis) and immortalization. In addition, processes such as angiogenesis, tumor invasion and metastasis may be induced. Underlying these tumor characteristics is the development of multiple molecular alterations that frequently lead to aneuploidy or chromosome instability, which is an increasing rate of losing or gaining whole (or large parts of) chromosomes during cell division. 
Acquired molecular alterations, however, may not always lead to histomorphological changes and thus can remain unnoticed by histopathological assessment, ${ }^{43}$ while histomorphological changes may occur without molecular alterations. Additional hallmarks of cancer include the reprogramming of energy metabolism, evasion for immune mediated destruction and the participation of the tumor microenvironment including e.g. inflammatory cells.

Many molecular genetic and gene expression studies have analyzed (pre)malignant lesions of the head and neck mucosa in order to identify molecular alterations underlying HNSCC pathogenesis and correlate them with clinical data, treatment outcome and patient survival. ${ }^{2,3,5,15,27,44-48}$ Although the exact sequence of molecular changes during carcinogenesis may vary in individual lesions, several recurrent molecular changes in (pre)malignant head and neck lesions have been identified. Figure 1.4 summarizes these molecular alterations underlying multistep tumor development and progression. ${ }^{15,49,50}$

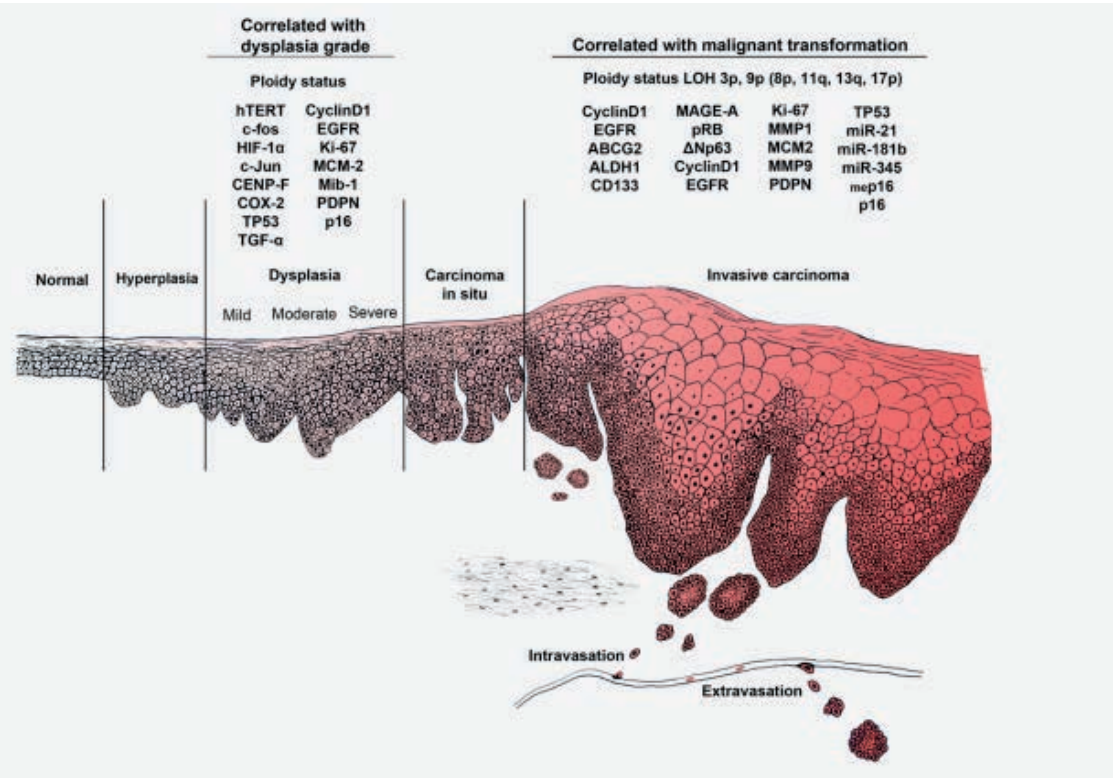

Figure 1.4 Summary of the genetic alterations that are observed at the different histopathological stages of head and neck carcinogenesis. (Dionne et al. Int J Cancer 2015 Feb 1;136(3):503-15, with permission).

Tobacco smoking and alcohol related HNSCC demonstrate near universal loss-of-function TP53 mutations and CDKN2A inactivation accompanied by frequent chromosome instability, including $3 p$ and $9 p$ loss and amplification of $11 q 13$ and $3 q .^{47}$ In contrast, HNSCC infected with High-Risk HPV (HR-HPV, 
predominantly HPV 16) are considered as a separate biological entity with a better overall prognosis and a different genetic profile compared to HPV negative tumors. ${ }^{14,51}$ These tumors inactivate $\mathrm{p} 53$ and $\mathrm{pRb}$ by expressing the viral oncoproteins $E 6$ and $E 7$, respectively, and show recurrent PIK3CA mutations, loss of TRAF3 and amplification of the cell cycle gene E2F1. ${ }^{47}$ Because the emphasis of this thesis is particularly on the carcinogenesis of the larynx and oral cavity, in which HR-HPV does not play a prominent role, ${ }^{52,53}$ a summary is given below of the most frequently used detection methods and reported recurrent molecular changes in HNSCC tumorigenesis induced by smoking and alcohol consumption.

\section{Recurrent molecular changes in premalignant head and neck lesions}

\section{Microsatellite analysis of chromosome loci}

With the use of microsatellite analysis, clonal changes (loss of heterozygosity (LOH), allelic imbalance, microsatellite instability) can be detected in extracted genomic DNA from (pre)malignant cells. LOH for alleles at chromosome $3 p$ and $9 p 21$ are the most early and frequent events in head and neck lesions, and have already been detected in hyperplasia, mild dysplasia and even in normalappearing epithelial cells. ${ }^{54}$ These regions harbor well-known tumor suppressor genes, such as FHIT at 3p14, RASSF1A at $3 p 21$ and $p 16^{\text {INK4A }}$ and $p 14^{\text {INK4B }}$ at $9 p 21$, indicating involvement of these genes in malignant transformation of cells. Indeed, precursor lesions with LOH at one of both loci showed cancer development in half of the cases in a retrospective study and, together with $\mathrm{LOH}$ at additional loci found to be involved in HNSCC development (at $4 \mathrm{q}, 8 \mathrm{p}$, $11 q, 13 q, 14 q$ and/or 17p), these lesions showed 33-fold increases in relative cancer risk. ${ }^{49}$ These results were confirmed in a subsequent prospective study by Rosin et al. (2012). ${ }^{50}$

\section{Whole genome array CGH}

Genomic DNA from oral (pre)malignant lesions has also been used for DNA profiling by means of array comparative genomic hybridization (CGH). Garnis et al. ${ }^{55}$ analyzed 86 oral (pre)malignant lesions and found a clear difference in the number of genetic alterations between low grade dysplasias that progressed into invasive disease and those that did not. Progressive low grade dysplasias showed complex patterns of genome alterations, including whole chromosome (arm) gains/amplifications and deletions as well as intrachromosomal segmental gains and losses, as was also observed in the higher grade dysplastic lesions. This study confirms the conclusions of earlier studies, that there are multiple genetic mechanisms involved in progression to invasive 
oral cancer, ${ }^{26,46,50,56}$ and that markers for aneuploidy/chromosome instability should be effective to identify progressive head and neck precursor lesions.

DNA cytometry - quantitative DNA analysis

An alternative for using genomic DNA analysis for the assessment of aneuploidy/chromosome instability is the application of image-or flow cytometry to measure DNA content in cells of oral leukoplakia. These studies have also shown that DNA cytometry may be of value to detect aneuploidy as a risk marker for malignant progression. ${ }^{57-60}$

\section{Limitations of above mentioned techniques}

The use of microsatellite ( $\mathrm{LOH}$ ) analysis, array $\mathrm{CGH}$ and DNA cytometry, however, has limitations, e.g. failure to recognize cells at risk in DNA diploid lesions, in tissues with a high number of infiltrating lymphocytes or in tissues heterogeneous for aneuploid cells. Furthermore, the relatively large amount of cells (and tissue material) required for reliable detection of aneuploidy/chromosome instability can be a limiting factor in small formalinfixed, paraffin-embedded tissue samples. Therefore, alternative approaches have been utilized to study molecular alterations directly in morphologically preserved tissue.

\section{FISH analysis of chromosome copy numbers}

We and others have shown that numerical chromosomal aberrations as detected by Fluorescence In Situ Hybridization (FISH) in head and neck precursor lesions may have a predictive value for progression to carcinoma. ${ }^{61-}$ ${ }^{64}$ Numerical aberrations for chromosomes 1 and 7 are often detected in dysplasia and carcinoma in situ (CIS), whereas histologically normal mucosa and the majority of hyperplastic lesions do not contain these alterations. ${ }^{61} \mathrm{~A}$ ten-year translational study showed that besides $\mathrm{LOH}$ for $3 p$ and $9 p$ loci, as well as overexpression of the p53 protein, also polysomy for chromosomes 9 and 17 strongly predicted cancer development. ${ }^{65}$ Poh et al. ${ }^{66}$ confirmed the reported value of chromosome 7 alterations for this purpose, and also showed that polysomy for chromosome 9 was less suitable due to the loss of chromosome 9 sequences in many of these lesions.

\section{Immunostaining of p53}

The most frequent mutations that promote the development of chromosome instability in HNSCC are those in the TP53 tumor suppressor gene. ${ }^{67,68}$ P53 gene mutations are present in up to $70 \%$ of $\mathrm{HNSCC}^{45,46,57}$ and can already be detected as an early genetic event in precursor lesions. ${ }^{22,69,70}$ P53 protein 
overexpression in cell nuclei, as detected by immunohistochemistry $(\mathrm{IHC})$, is frequently used as a biomarker predicting the presence of a TP53 gene mutation in the tissue. The presence of TP53 mutations and p53 overexpression have also been proposed as markers to predict the risk of local relapse in head and neck precursor lesions as well as local recurrence in tumor adjacent mucosa. ${ }^{25,71,72}$ However, discrepancies have been reported concerning the value of p53 dysregulation in the detection of precursor lesions at risk for progression, because p53 accumulation may also be the result of cellular stress due to for example DNA damage or viral infection.,56,69 Furthermore, p53-negative lesions may exhibit undetectable truncated TP53 or p53-independent mechanisms leading to chromosome instability. ${ }^{67,70}$ Thus, the reliability of p53 overexpression as a single marker to identify a progressive premalignant lesion remains unclear as is the time a p53 mutation occurs within the sequence of genetic changes in head and neck carcinogenesis. $^{15,22,26,69,73}$

\section{Other recurrent alterations}

Other proposed markers of malignant progression include 11q13 amplification, corresponding with the cell cycle regulation protein cyclin D1 (CCND1 $)^{74,75}$ and Fas-associated Death Domain (FADD), an adaptor protein for the cell death receptor, ${ }^{76,77} 7 \mathrm{p}$ gain and amplification related to overexpression of Epidermal Growth Factor Receptor (EGFR), ${ }^{5,78}$ which plays an extensive role in cell signaling and growth ${ }^{79}$ and $18 \mathrm{q} 21$ loss associated with the tumor suppressor gene SMAD4. ${ }^{56}$

Finally, during tumorigenesis telomerase is reactivated prolonging survival of cells, and is centrosome amplification observed in cells with aneuploidy/ $/ \mathrm{Cl}$ with genetic abnormalities and making accumulation of multiple genetic alterations possible. ${ }^{80,81}$

In this thesis, the emphasis will be on analysis by FISH, which is ideal for small tissue sections such as laryngeal biopsies and does not influence the histomorphological appearance of the tissue and facilitates histopathological assessment. Other approaches, such as CGH and DNA ploidy analysis, which require larger tissue amounts are less suitable for laryngeal lesions. 


\section{Scope of this thesis}

Based on the previous overview on the currently available knowledge on histopathological and molecular changes found in premalignant head and neck lesions, the main aim of the studies of this thesis was to identify molecular markers in combination with routine histopathological assessment as potential prognosticators in the risk-counseling of premalignant head and neck lesions. Above all, the applicability in the clinical setting was taken into account. First, we applied a double target FISH approach using centromere probes for chromosomes 1 and 7 in order to detect numerical aberrations of one or both chromosomes. This technique gives a quick impression on the presence of chromosome instability and leaves the tissue morphology unchanged. Furthermore, it does not require large tissue samples. Second, DNA ploidy analysis using image cytometry was applied on oral lesions in order to assess the general ploidy status of a lesion and to compare the results with the results of our FISH analysis. Third, we applied IHC for the detection of different protein markers in premalignant laryngeal and oral lesions as well as in resection margins of Oral Squamous Cell Carcinomas (OSCC) in order to evaluate the association of overexpression with malignant progression as well as tumor relapse. The role of the gold standard of histopathological assessment of lesions was outlined and a suggestion for a progression model was posed.

The following questions were addressed:

1. Which histopathological classification method for premalignant laryngeal lesions gives the most uniform diagnosis, and which level of uniformity can be reached (interobserver variability)?

Three worldwide applied histopathological classification systems for premalignant head and neck lesions were compared with each other in terms of interobserver variability. Clinical consequences related to a different diagnosis of a lesion were high-lighted.

2. Which biomarker(s) can reliably predict malignant progression in premalignant laryngeal lesions?

Chromosome 1 and 7 copy number analysis by FISH was compared with immunohistochemical analysis of p53, FADD, pFADD and CyclinD1 expression.

3. Which biomarker(s) can reliably predict malignant progression in premalignant oral lesions?

Chromosome 1 and 7 copy number analysis by FISH was compared with DNA ploidy detection using image cytometry.

4. Can $\mathrm{Cl}$ detection predict tumor recurrence in histopathologically tumor-free resection margins in oral squamous cell carcinoma (OSCC)? 
$\mathrm{Cl}$ detection by FISH (copy number analysis of chromosomes 1 and 7 ) was compared with p53 immunostaining on resection margins of histopathologically radically resected OSCC and related to clinical outcome.

5. Which evaluation method for $\mathrm{Cl}$ detection by FISH is preferred to predict malignant progression of premalignant laryngeal lesions?

Two evaluation methods for $\mathrm{Cl}$ detection by FISH (copy number analysis of chromosomes 1 and 7) were compared with each other and with histopathological classification to predict the progression of laryngeal precursor lesions to $\mathrm{CIS} /$ cancer. 


\section{References}

1. Ferlay $\mathrm{J}$, et al. Cancer incidence and mortality worldwide: sources, methods and major patterns in GLOBOCAN 2012. Int J Cancer 2015;136(5):E359-86.

2. Ernani V, Saba NF. Oral Cavity Cancer: Risk Factors, Pathology, and Management. Oncology 2015;89:187-95.

3. Pezzuto F, et al. Update on Head and Neck Cancer: Current Knowledge on Epidemiology, Risk Factors, Molecular Features and Novel Therapies. Oncology 2015;89:125-36.

4. Ndiaye C, et al. HPV DNA, E6/E7 mRNA, and p16INK4a detection in head and neck cancers: a systematic review and meta-analysis. Lancet Oncol 2014;15: 1319-31.

5. Leemans CR, Braakhuis BJ, Brakenhoff RH. The molecular biology of head and neck cancer. Nat Rev Cancer 2011;11:9-22.

6. Olthof NC, et al. Next-generation treatment strategies for human papillomavirusrelated head and neck squamous cell carcinoma: where do we go? Rev Med Virol 2012;22:88-105.

7. Kutler DI, et al. High incidence of head and neck squamous cell carcinoma in patients with Fanconi anemia. Arch Otolaryngol Head Neck Surg 2003;129:106-12.

8. Cloos J, et al. Genetic susceptibility to head and neck squamous cell carcinoma. J Natl Cancer Inst 1996;88:530-5.

9. Agarwal R, et al. Targeted therapy for hereditary cancer syndromes: hereditary breast and ovarian cancer syndrome, Lynch syndrome, familial adenomatous polyposis, and Li-Fraumeni syndrome. Discov Med 2014;18:331-9.

10. Eliot MN, et al. Periodontal disease and mouthwash use are risk factors for head and neck squamous cell carcinoma. Cancer Causes Control 2013;24:1315-22.

11. Xing $Y$, et al. Relation between the level of lymph node metastasis and survival in locally advanced head and neck squamous cell carcinoma. Cancer 2016;122: 534-45.

12. O'Sullivan B, Shah J. New TNM staging criteria for head and neck tumors. Semin Surg Oncol 2003;21:30-42.

13. Worsham MJ. Identifying the risk factors for late-stage head and neck cancer. Expert Rev Anticancer Ther 2011;11:1321-5.

14. Straetmans JM, et al. Human papillomavirus reduces the prognostic value of nodal involvement in tonsillar squamous cell carcinomas. Laryngoscope 2009;119: 1951-7.

15. Mao L, Hong WK, Papadimitrakopoulou VA. Focus on head and neck cancer. Cancer Cell 2004;5:311-6.

16. Vernham GA, Crowther JA. Head and neck carcinoma--stage at presentation. Clin Otolaryngol Allied Sci 1994;19:120-4.

17. van der Toorn PP, et al. Mapping of resection margins of oral cancer for p53 overexpression and chromosome instability to detect residual (pre)malignant cells. J Pathol 2001;193:66-72.

18. Gath HJ, Brakenhoff $\mathrm{RH}$. Minimal residual disease in head and neck cancer. Cancer Metastasis Rev 1999;18:109-26.

19. Gleber-Netto FO, et al. Molecular events in relapsed oral squamous cell carcinoma: Recurrence vs secondary primary tumor. Oral Oncol 2015;51:738-44.

20. Patrucco MS, Aramendi MV. Prognostic impact of second primary tumors in head and neck cancer. Eur Arch Otorhinolaryngol 2016;273:1871-7. 
21. Slaughter DP, Southwick HW, Smejkal W. Field cancerization in oral stratified squamous epithelium; clinical implications of multicentric origin. Cancer 1953;6:963-8.

22. Braakhuis BJ, et al. A genetic explanation of Slaughter's concept of field cancerization: evidence and clinical implications. Cancer Res 2003;63:1727-30.

23. Kim L, King T, Agulnik M. Head and neck cancer: changing epidemiology and public health implications. Oncology (Williston Park) 2010;24:915-9, 924.

24. van Houten VM, et al. Molecular diagnosis of head and neck cancer. Recent Results Cancer Res 2000;157:90-106.

25. van Houten VM, et al. Molecular diagnosis of surgical margins and local recurrence in head and neck cancer patients: a prospective study. Clin Cancer Res 2004;10:3614-20.

26. Califano J, et al. Genetic progression model for head and neck cancer: implications for field cancerization. Cancer Res 1996;56:2488-92.

27. Dionne KR, et al. Potentially malignant disorders of the oral cavity: current practice and future directions in the clinic and laboratory. Int J Cancer 2015;136:503-15.

28. Vokes EE, et al. Head and neck cancer. N Engl J Med 1993;328:184-94.

29. Mashberg A. Erythroplasia vs. leukoplasia in the diagnosis of early asymptomatic oral squamous carcinoma. N Engl J Med 1977;297:109-10.

30. Shafer WG, Waldron CA. Erythroplakia of the oral cavity. Cancer 1975;36:1021-8.

31. van der Waal I. Potentially malignant disorders of the oral and oropharyngeal mucosa; terminology, classification and present concepts of management. Oral Oncol 2009;45:317-23.

32. Lind PO. Malignant transformation in oral leukoplakia. Scand J Dent Res 1987;95: 449-55.

33. Hogewind WF, et al. The association of white lesions with oral squamous cell carcinoma. A retrospective study of 212 patients. Int J Oral Maxillofac Surg 1989; 18:163-4.

34. Fleskens S, Slootweg P. Grading systems in head and neck dysplasia: their prognostic value, weaknesses and utility. Head Neck Oncol 2009;1:11.

35. McLaren KM, et al. Consistency of histopathological reporting of laryngeal dysplasia. The Scottish Pathology Consistency Group. Histopathology 2000;37: 460-3.

36. Mehanna HM, et al. Treatment and follow-up of oral dysplasia - a systematic review and meta-analysis. Head Neck 2009;31:1600-9.

37. Eversole LR. Dysplasia of the upper aerodigestive tract squamous epithelium. Head Neck Pathol 2009;3:63-8.

38. Hellquist $H$, Lundgren J, Olofsson J. Hyperplasia, keratosis, dysplasia and carcinoma in situ of the vocal cords--a follow-up study. Clin Otolaryngol Allied Sci 1982;7:11-27.

39. Gale N, et al. Current review on squamous intraepithelial lesions of the larynx. Histopathology 2009; 54:639-56.

40. Zerdoner D. The Ljubljana classification - its application to grading oral epithelial hyperplasia. J Craniomaxillofac Surg 2003;31:75-9.

41. Gale $\mathrm{N}$, et al. Evaluation of a new grading system for laryngeal squamous intraepithelial lesions - a proposed unified classification. Histopathology 2014; 65:456-64. 
42. Abbey LM, et al. Intraexaminer and interexaminer reliability in the diagnosis of oral epithelial dysplasia. Oral Surg Oral Med Oral Pathol Oral Radiol Endod 1995;80: 188-91.

43. Hanahan D, Weinberg RA. Hallmarks of cancer: the next generation. Cell 2011;144:646-74.

44. Forastiere A, et al. Head and neck cancer. N Engl J Med 2001;345(26):1890-900.

45. Hittelman $W N$, et al. Early genetic changes during upper aerodigestive tract tumorigenesis. J Cell Biochem Suppl 1993;17F:233-6.

46. Haddad RI, Shin DM. Recent advances in head and neck cancer. N Engl J Med 2008;359:1143-54.

47. Cancer Genome Atlas N. Comprehensive genomic characterization of head and neck squamous cell carcinomas. Nature 2015;517:576-82.

48. Agrawal $\mathrm{N}$, et al. Exome sequencing of head and neck squamous cell carcinoma reveals inactivating mutations in NOTCH1. Science 2011;333:1154-7.

49. Rosin MP, et al. Use of allelic loss to predict malignant risk for low-grade oral epithelial dysplasia. Clin Cancer Res 2000;6:357-62.

50. Zhang $\mathrm{L}$, et al. Loss of heterozygosity $(\mathrm{LOH})$ profiles--validated risk predictors for progression to oral cancer. Cancer Prev Res (Phila) 2012;5:1081-9.

51. Syrjanen S. Human papillomavirus (HPV) in head and neck cancer. J Clin Virol 2005;32 Suppl 1:S59-66.

52. Young RJ, et al. Frequency and prognostic significance of p16(INK4A) protein overexpression and transcriptionally active human papillomavirus infection in laryngeal squamous cell carcinoma. Br J Cancer 2015;112:1098-104.

53. Chernock RD, et al. Detection and significance of human papillomavirus, CDKN2A(p16) and $\operatorname{CDKN1A}(p 21)$ expression in squamous cell carcinoma of the larynx. Mod Pathol 2013;26:223-31.

54. Mao L, et al. Frequent microsatellite alterations at chromosomes 9p21 and 3p14 in oral premalignant lesions and their value in cancer risk assessment. Nat Med 1996; 2:682-5.

55. Garnis C, et al. Genomic imbalances in precancerous tissues signal oral cancer risk. Mol Cancer 2009; 8:50.

56. Veltman JA, et al. Specific steps in aneuploidization correlate with loss of heterozygosity of $9 \mathrm{p} 21,17 \mathrm{p} 13$ and $18 \mathrm{q} 21$ in the progression of pre-malignant laryngeal lesions. Int J Cancer 2001;91:193-9.

57. Hogmo A, et al. Nuclear DNA content and p53 immunostaining in metachronous preneoplastic lesions and subsequent carcinomas of the oral cavity. Head Neck 1996;18:433-40.

58. Seoane, J., et al., Flow cytometric analysis of nuclear DNA content in oral leukoplakia. Clin Otolaryngol Allied Sci 1998;23:136-40.

59. Torres-Rendon A, et al. DNA ploidy analysis by image cytometry helps to identify oral epithelial dysplasias with a high risk of malignant progression. Oral Oncol 2009;45:468-73.

60. Bradley G, et al. Abnormal DNA content in oral epithelial dysplasia is associated with increased risk of progression to carcinoma. Br J Cancer 2010;103:1432-42.

61. Veltman JA, et al. Chromosome instability as an indicator of malignant progression in laryngeal mucosa. J Clin Oncol 2000;18:1644-51.

62. Voravud N, et al. Increased polysomies of chromosomes 7 and 17 during head and neck multistage tumorigenesis. Cancer Res 1993;53:2874-83. 
63. $\mathrm{Ai} \mathrm{H}$, et al. Chromosomal aneuploidy precedes morphological changes and supports multifocality in head and neck lesions. Laryngoscope 2001;111:1853-8.

64. Hittelman WN. Genetic instability in epithelial tissues at risk for cancer. Ann N Y Acad Sci 2001;952:1-12.

65. Lee JJ, et al. Predicting cancer development in oral leukoplakia: ten years of translational research. Clin Cancer Res 2000;6:1702-10.

66. Poh CFY, et al. Unique FISH patterns associated with biological aggressiveness of potentially malignant oral lesions. Proc AACR 2006;47:212 (abstract 900).

67. Shin DM, et al. p53 protein accumulation and genomic instability in head and neck multistep tumorigenesis. Cancer Epidemiol Biomarkers Prev 2001;10:603-9.

68. Gasco M, Crook T. The p53 network in head and neck cancer. Oral Oncol 2003;39:222-31.

69. Shahnavaz SA, et al. p53 gene mutations in sequential oral epithelial dysplasias and squamous cell carcinomas. J Pathol 2000;190:417-22.

70. van Oijen MG, van de Craats JG, Slootweg PJ. p53 overexpression in oral mucosa in relation to smoking. J Pathol 1999;187:469-74.

71. Lane DP. Exploiting the p53 pathway for the diagnosis and therapy of human cancer. Cold Spring Harb Symp Quant Biol 2005;70:489-97.

72. Hafkamp $\mathrm{HC}$, et al. A subset of head and neck squamous cell carcinomas exhibits integration of HPV 16/18 DNA and overexpression of p16INK4A and p53 in the absence of mutations in p53 exons 5-8. Int J Cancer 2003;107:394-400.

73. Cruz IB, et al. p53 expression above the basal cell layer in oral mucosa is an early event of malignant transformation and has predictive value for developing oral squamous cell carcinoma. J Pathol 1998;184:360-8.

74. Izzo JG, et al. Dysregulated cyclin D1 expression early in head and neck tumorigenesis: in vivo evidence for an association with subsequent gene amplification. Oncogene 1998;17:2313-22.

75. Papadimitrakopoulou V, et al. Cyclin D1 and cancer development in laryngeal premalignancy patients. Cancer Prev Res (Phila Pa) 2009;2:14-21.

76. Inoue N, et al. Molecular characteristics of porcine Fas-associated death domain (FADD) and procaspase-8. J Reprod Dev 2007;53:427-36.

77. Gibcus $\mathrm{JH}$, et al. Amplicon mapping and expression profiling identify the Fasassociated death domain gene as a new driver in the 11q13.3 amplicon in laryngeal/pharyngeal cancer. Clin Cancer Res 2007;13:6257-66.

78. Morrison LE, et al. Aberrant EGFR and chromosome 7 associate with outcome in laryngeal cancer. Laryngoscope 2005;115:1212-8.

79. Grandis JR, Tweardy DJ. TGF-alpha and EGFR in head and neck cancer. J Cell Biochem Suppl 1993;17F:188-91.

80. Mao L, et al. Telomerase activity in head and neck squamous cell carcinoma and adjacent tissues. Cancer Res 1996;56:5600-4.

81. Mutirangura A, et al. Telomerase activity in oral leukoplakia and head and neck squamous cell carcinoma. Cancer Res 1996;56:3530-3. 


\title{
Chapter
}

\section{INTEROBSERVER VARIABILITY OF}

\author{
LARYNGEAL MUCOSAL \\ PREMALIGNANT LESIONS: \\ A HISTOPATHOLOGICAL \\ EVALUATION
}

Stijn A.J.H.M. Fleskens*, Verona E. Bergshoeff*, Adri C. Voogd, Marie-Louise F. van Velthuysen, Frederik J. Bot, Ernst-Jan M. Speel, Bernd Kremer, Robert Takes, Piet Slootweg

* These authors contributed equally to this study Modern Pathology 2011;24:892-898 


\section{Abstract}

The objective of this study is to measure interobserver variability in the classification of laryngeal mucosal premalignant lesions by reassessing the histopathology of previously diagnosed cases and to determine the possible therapeutic consequences of disagreement among observers. Histopathological assessment of 110 laryngeal mucosal premalignant lesions was done by three pathologists. Each slide had to be classified according to the World Health Organization, Squamous Intraepithelial Neoplasia, and the Ljubljana Squamous Intraepithelial Lesions systems. After the independent assessment, a joint meeting took place. To assess the relation between histopathological grading and subsequent clinical management, we created a two- and a three-grade system besides one comprising all options. For all analyses, the SAS/STAT statistical software was used. The highest unweighted k-values concerning the all-options system are observed for the Squamous Intraepithelial Neoplasia classification $(0.28,95 \%$ confidence interval $0.23-0.33)$, followed by the World Health Organization and Ljubljana classifications. For the two-grade system the Ljubljana classification shows the highest unweighted k-values $(0.50,95 \%, 0.39-0.61)$, followed by the World Health Organization and Squamous Intraepithelial Neoplasia classifications. For the three-grade system, the unweighted j-values are similar. The implementation of weighted $\mathrm{K}$-values led to higher scores within all three classification systems, although these did not exceed 0.55 (moderate agreement). Given the high level of consensus, simultaneous pathological assessment may be said to provide added value in comparison with independent assessment. In the current study, no clear tendency is observed in favor of any one classification system. The proposed threegrade system could be an improved histopathological tool because it is easier to correlate with clinical decision making and because it yields better unweighted $\mathrm{k}$-values and proportions of concordance than the all options system. Furthermore, clinical management could benefit from assessment by more than one pathologist in suspected cases of dysplasia or carcinoma. 


\section{Introduction}

Laryngeal mucosal premalignant lesions are seen frequently in clinical practice. They are defined as an altered epithelium with an increased likelihood of progression to laryngeal squamous cell carcinoma. The altered epithelium shows a variety of cytological and architectural changes that have traditionally been brought under the common denominator of dysplasia. ${ }^{1,2}$ Grading of dysplasia, including that of laryngeal lesions, continues to be a topic of debate. It is subjective and has been shown to lack intra- and inter-observer reproducibility, which may have significant therapeutic implications. ${ }^{3-7}$ To minimize both morbidity and mortality, it is highly important to detect the lesions at risk for malignancy in its earliest stage. ${ }^{8-10}$ Unfortunately, there is no universally accepted histopathological classification system. Moreover, there is no consensus on the diagnostic criteria for the various entities, particularly on criteria to differentiate severe dysplasia from carcinoma in situ. This is illustrated by the fact that during the last decades, more than 20 classification systems have been described for laryngeal mucosal premalignant lesions. ${ }^{3,11-15}$ In the current literature and clinical practice, the 2005 World Health Organization, Squamous Intraepithelial Neoplasia, and the Ljubljana Classification of Squamous Intraepithelial Lesions systems are the most widely used and are considered the most relevant. So far, the reproducibility of one of these systems, the World Health Organization classification, has been evaluated for laryngeal lesions in just one published study. ${ }^{6}$ Thus, for the Squamous Intraepithelial Neoplasia and Ljubljana systems, no data are available on reproducibility for laryngeal lesions.

The objective of the present study is to reassess the histopathology of previously diagnosed laryngeal mucosal premalignant lesions in order to measure the interobserver variability of the World Health Organization, Squamous Intraepithelial Neoplasia, and Ljubljana classification systems and to determine the possible therapeutic consequences of disagreement among observers. Moreover, a proposal to compensate for this variability is made to facilitate the use for clinical purposes.

\section{Materials and methods}

To set up an interobserver study on the histopathological assessment of laryngeal mucosal premalignant lesions, three pathologists with head and neck pathology as a field of interest (Marie-Louise van Velthuysen, Freek Bot, and Piet Slootweg) reviewed laryngeal mucosal premalignant lesions cases. Sections stained with hematoxylin and eosin (H\&E) were obtained from the files of the Departments of Pathology at the Radboud University Nijmegen 
Medical Center $(n=60)$ and the Maastricht University Medical Center $(n=50)$. The sections represented a range of diagnoses along the spectrum of laryngeal mucosal premalignant lesions. Table 2.1 gives an overview of the original histopathological diagnoses made according to the World Health Organization classification system. ${ }^{1}$ The 110 slides were selected by two investigators (Stijn Fleskens and Ewa Bergshoeff) who did not participate as one of the reviewing pathologists. Each pathologist independently reviewed the anonymized 110 microscopic slides without any previous discussion and was completely blinded to the initial diagnosis and grade. No clinical information was provided with the cases. Each slide had to be classified according to the 2005 World Health Organization classification, the Squamous Intraepithelial Neoplasia classification, and the Ljubljana classification. The criteria they used were derived from the WHO-IARC blue book. ${ }^{1}$

Table 2.1 An overview of the cases according to the original histopathological diagnosis.

\begin{tabular}{lc}
\hline Original histopathological diagnosis & $\begin{array}{c}\text { Study population } \\
\text { Number of cases }\end{array}$ \\
\hline Hyperkeratosis & 3 \\
Inflammation & 6 \\
Squamous cell hyperplasia & 17 \\
Mild dysplasia & 23 \\
Moderate dysplasia & 32 \\
Severe dysplasia & 16 \\
Carcinoma in situ & 13 \\
Total & 110 \\
\hline
\end{tabular}

The World Health Organization classification provides the following options: normal histopathology (hyperkeratosis); inflammation; hyperplasia; mild dysplasia; moderate dysplasia; severe dysplasia; carcinoma in situ; and squamous cell carcinoma. The Squamous Intraepithelial Neoplasia classification is slightly different: normal histopathology (hyperkeratosis); inflammation; SIN 1; SIN 2; SIN 3; and squamous cell carcinoma. The options in the Ljubljana classification are different again: normal histopathology; inflammation; squamous cell (simple) hyperplasia; basal/parabasal cell hyperplasia; atypical hyperplasia; carcinoma in situ; and squamous cell carcinoma.

To calibrate the categories across the three systems and thus be able to compare the classification systems (Table 2.2), we used the proposal made in the WHO-IARC blue book and by Gale et al. ${ }^{1,16}$ All three pathologists were familiar with the different classification systems. The microscopic slides examined by the reviewers were those on which the initial diagnoses had been made. After the independent assessment, cases with different independent 
diagnoses were randomly selected on the basis of the all-options system. At a joint meeting, this random selection was assessed by the three pathologists together in order to determine the degree of consensus, which serves as an indicator of the implications of having lesions reviewed by more than one pathologist simultaneously.

Besides comparing all separate options of each system, we designed a twoand a three-grade system (see Table 2.2) to include clinical management in the histopathological grading. ${ }^{1,17}$ The two- and three-grade systems are based on the risk of malignant progression and its consequences for clinical practice: a 'low-risk' group, not needing treatment based on grading, and a 'high-risk' group, requiring treatment, usually consisting of (laser) surgery or radiotherapy. ${ }^{4,18,19}$ In the 'high-risk' group, the three-grade system additionally distinguishes mild and moderate dysplasia from severe dysplasia, carcinoma in situ, and squamous cell carcinoma (World Health Organization); it also distinguishes SIN 1 and 2 from SIN 3 and squamous cell carcinoma (Squamous Intraepithelial Neoplasia), and it differentiates (atypical hyperplasia) dysplasia from carcinoma in situ and squamous cell carcinoma (Ljubljana). This further differentiation was made because in daily practice normal histology, inflammation, and hyperplasia (green segment in Table 2.2) are generally considered to require no periodic observation. In contrast, the other histopathological diagnoses do require at least periodic observation (yellow segment in Table 2.2) and treatment (pink segment in Table 2.2), respectively.

Table 2.2 Overview of the scoring form and definition of a two- and three-grade system.

\begin{tabular}{lll}
\hline WHO & SIN & SIL \\
\hline $\begin{array}{l}\text { normal } \\
\text { inflammation }\end{array}$ & $\begin{array}{l}\text { normal } \\
\text { inflammation }\end{array}$ & $\begin{array}{l}\text { normal } \\
\text { inflammation } \\
\text { hyperplasia }\end{array}$ \\
$\begin{array}{l}\text { mild dysplasia } \\
\text { moderate dysplasia }\end{array}$ & SIN 1 2 & $\begin{array}{l}\text { squamous cell (simple) hyperplasia } \\
\text { basal/parabasal cell hyperplasia }\end{array}$ \\
$\begin{array}{l}\text { severe dysplasia } \\
\text { carcinoma in situ } \\
\text { squamous cell carcinoma }\end{array}$ & SIN 3 & atypical hyperplasia (dysplasia) \\
\hline
\end{tabular}

Two-grade system: 1) green 2) yellow + pink

\section{Statistical analysis}

The K-statistics were calculated to assess the degree of interobserver agreement in the reporting of all options for each of the three classification systems and the derived two- and three-grade systems. The statistics describe the extent to which observers concur on a diagnosis, adjusted for levels of 
agreement that are expected to occur by chance alone. The interpretation of $\mathrm{K}$ values could not rely on any absolute definitions. According to Altman (slightly adapted from Landis and $\mathrm{Koch}^{20,21}$ ), $\mathrm{K}$-values $<0.20$ indicate poor agreement; 0.21-0.4 fair agreement; 0.41-0.6 moderate agreement; 0.61-0.8 good agreement; and values $0.81-1.00$ very good agreement. Standard weighted and unweighted $\mathrm{k}$-values and their $95 \%$ confidence intervals were calculated for each pair-wise comparison of the three pathologists. Weighted K-values take into account the amount of disagreement between two raters when a scoring system has three or more categories, which means that more weight is given to a difference of more than one category than to a difference between raters of only one category. ${ }^{22}$

All analyses were performed with SAS/STAT statistical software (SAS system 8.2, SAS Institute, Cary, NC, USA). Generalized, unweighted k-values for the three raters and their $95 \%$ confidence intervals were calculated using the SAS macro MAGREE. Finally, the proportion of total concordance among the three raters was calculated for each of the three scoring systems and the derived two and three-grade systems.

\section{Results}

Two cases were excluded from analysis because of insufficient quality of the H\&E-stained sections. Two other cases were excluded because of insufficient laryngeal tissue in the H\&E-stained sections.

\section{Unweighted and Weighted $\mathrm{k}-$ Values}

Table 2.3 gives an overview of the unweighted and weighted $\mathrm{k}$-values with $95 \%$ confidence intervals. * Only unweighted K-values are applicable for the twograde system.

\section{All options}

Comparison of the results using all grading options of the World Health Organization, Squamous Intraepithelial Neoplasia, and Ljubljana classification systems yielded the following overall unweighted K-values: $0.21(95 \%$ confidence interval $0.17-0.26) ; 0.28$ (95\% confidence interval 0.23-0.33); and 0.19 (95\% confidence interval $0.14-0.24)$, respectively. Weighted and unweighted $\mathrm{k}$-values for the pair-wise comparisons of the three are presented in Table 2.3. 
Two-grade system

Comparison of the results for the two-grade system for the World Health Organization, Squamous Intraepithelial Neoplasia, and Ljubljana classification systems gave the following overall unweighted k-values: 0.44 (95\% confidence interval 0.33-0. 55); 0.43 (95\% confidence interval 0.32-0.54); and 0.50 (95\% confidence interval $0.39-0.61$ ), respectively. Weighted $\mathrm{K}$-values for the pairwise comparisons of the three observers are presented in Table 2.3.

Table 2.3 Overview of the unweighted and weighted $\mathrm{k}$-values with $95 \%$ confidence intervals.

\begin{tabular}{|c|c|c|c|c|c|}
\hline & $\begin{array}{l}\text { All options } \\
\text { unweighted }\end{array}$ & $\begin{array}{c}\text { All options } \\
\text { weighted }\end{array}$ & $\begin{array}{l}\text { Two-grade* } \\
\text { unweighted }\end{array}$ & $\begin{array}{l}\text { Three-grade } \\
\text { unweighted }\end{array}$ & $\begin{array}{c}\text { Three-grade } \\
\text { weighted }\end{array}$ \\
\hline \multicolumn{6}{|l|}{ WHO } \\
\hline Observer 1 vs. 2 & $\begin{array}{c}0.25 \\
(0.14-0.36)\end{array}$ & $\begin{array}{c}0.50 \\
(0.39-0.60)\end{array}$ & $\begin{array}{c}0.47 \\
(0.29-0.64)\end{array}$ & $\begin{array}{c}0.37 \\
(0.22-0.51)\end{array}$ & $\begin{array}{c}0.50 \\
(0.37-0.62)\end{array}$ \\
\hline Observer 1 vs. 3 & $\begin{array}{c}0.20 \\
(0.10-0.30)\end{array}$ & $\begin{array}{c}0.49 \\
(0.39-0.59)\end{array}$ & $\begin{array}{c}0.40 \\
(0.23-0.58)\end{array}$ & $\begin{array}{c}0.38 \\
(0.23-0.52)\end{array}$ & $\begin{array}{c}0.47 \\
(0.33-0.60)\end{array}$ \\
\hline Observer 2 vs. 3 & $\begin{array}{c}0.21 \\
(0.11-0.31)\end{array}$ & $\begin{array}{c}0.48 \\
(0.37-0.58)\end{array}$ & $\begin{array}{c}0.45 \\
(0.28-0.63)\end{array}$ & $\begin{array}{c}0.42 \\
(0.28-0.57)\end{array}$ & $\begin{array}{c}0.53 \\
(0.40-0.66)\end{array}$ \\
\hline Overall & $\begin{array}{c}0.21 \\
(0.17-0.26)\end{array}$ & & $\begin{array}{c}0.44 \\
(0.33-0.55)\end{array}$ & $\begin{array}{c}0.39 \\
(0.31-0.47)\end{array}$ & \\
\hline \multicolumn{6}{|l|}{ SIN } \\
\hline Observer 1 vs. 2 & $\begin{array}{c}0.24 \\
(0.13-0.35)\end{array}$ & $\begin{array}{c}0.45 \\
(0.34-0.57)\end{array}$ & $\begin{array}{c}0.41 \\
(0.23-0.59)\end{array}$ & $\begin{array}{c}0.35 \\
(0.20-0.50)\end{array}$ & $\begin{array}{c}0.48 \\
(0.35-0.61)\end{array}$ \\
\hline Observer 1 vs. 3 & $\begin{array}{c}0.29 \\
(0.17-0.40)\end{array}$ & $\begin{array}{c}0.51 \\
(0.40-0.62)\end{array}$ & $\begin{array}{c}0.42 \\
(0.24-0.59)\end{array}$ & $\begin{array}{c}0.39 \\
(0.24-0.54)\end{array}$ & $\begin{array}{c}0.48 \\
(0.34-0.61)\end{array}$ \\
\hline Observer 2 vs. 3 & $\begin{array}{c}0.33 \\
(0.21-0.44)\end{array}$ & $\begin{array}{c}0.52 \\
(0.41-0.63)\end{array}$ & $\begin{array}{c}0.46 \\
(0.29-0.63)\end{array}$ & $\begin{array}{c}0.45 \\
(0.31-0.59)\end{array}$ & $\begin{array}{c}0.55 \\
(0.42-0.68)\end{array}$ \\
\hline Overall & $\begin{array}{c}0.28 \\
(0.23-0.33)\end{array}$ & & $\begin{array}{c}0.43 \\
(0.32-0.54)\end{array}$ & $\begin{array}{c}0.40 \\
(0.32-0.48)\end{array}$ & \\
\hline \multicolumn{6}{|l|}{ Ljubljana } \\
\hline Observer 1 vs. 2 & $\begin{array}{c}0.19 \\
(0.07-0.30)\end{array}$ & $\begin{array}{c}0.41 \\
(0.29-0.52)\end{array}$ & $\begin{array}{c}0.43 \\
(0.26-0.61)\end{array}$ & $\begin{array}{c}0.32 \\
(0.17-0.47)\end{array}$ & $\begin{array}{c}0.43 \\
(0.29-0.57)\end{array}$ \\
\hline Observer 1 vs. 3 & $\begin{array}{c}0.23 \\
(0.12-0.34)\end{array}$ & $\begin{array}{c}0.43 \\
(0.32-0.55)\end{array}$ & $\begin{array}{c}0.49 \\
(0.32-0.66)\end{array}$ & $\begin{array}{c}0.46 \\
(0.32-0.61)\end{array}$ & $\begin{array}{c}0.54 \\
(0.40-0.68)\end{array}$ \\
\hline Observer 2 vs. 3 & $\begin{array}{c}0.18 \\
(0.08-0.28)\end{array}$ & $\begin{array}{c}0.40 \\
(0.30-0.50)\end{array}$ & $\begin{array}{c}0.56 \\
(0.41-0.72)\end{array}$ & $\begin{array}{c}0.40 \\
(0.26-0.54)\end{array}$ & $\begin{array}{c}0.50 \\
(0.37-0.63)\end{array}$ \\
\hline Overall & $\begin{array}{c}0.19 \\
(0.14-0.24)\end{array}$ & & $\begin{array}{c}0.50 \\
(0.39-0.61)\end{array}$ & $\begin{array}{c}0.39 \\
(0.31-0.47)\end{array}$ & \\
\hline
\end{tabular}

* Only unweighted $\mathrm{k}$-values are applicable for the two-grade system.

\section{Three-grade system}

Comparison of the results using the three-grade system for the World Health Organization, Squamous Intraepithelial Neoplasia, and Ljubljana classification systems gave overall unweighted $\mathrm{k}$-values of: 0.39 (95\% confidence interval $0.31-0.47) ; 0.40$ (95\% confidence interval $0.32-0.48)$; and 0.39 (95\% confidence interval $0.31-0.47)$, respectively. Weighted and unweighted 
$\mathrm{K}$-values of the pair-wise comparisons of the three observers are presented in Table 2.3.

\section{Proportion of Concordance}

Table 2.4 shows the proportion of concordance among the pathologists for the three classification systems. The proportions using all grading options of the World Health Organization, Squamous Intraepithelial Neoplasia, and Ljubljana classification systems were 13\% (95\% confidence interval 7-20), 24\% (95\% confidence interval 16-32), and $17 \%$ (95\% confidence interval 10-24), respectively. Using the two-grade version of the World Health Organization, Squamous Intraepithelial Neoplasia, and Ljubljana classification systems, the proportions of concordance were $60 \%$ (95\% confidence interval 51-70), 60\% (95\% confidence interval 51-70), and 62\% (95\% confidence interval 53-72), respectively. The proportions for the three-grade version of the World Health Organization, Squamous Intraepithelial Neoplasia, and Ljubljana classification systems were $42 \%$ (95\% confidence interval 33-52), 43\% (95\% confidence interval 34-53), and 47\% (95\% confidence interval 38-57), respectively.

Table 2.4 Proportion of concordance among the three pathologists and $95 \%$ confidence intervals.

\begin{tabular}{lccc}
\hline & All options & Two-grade & Three-grade \\
\hline WHO & $13 \%(7-20)$ & $60 \%(51-70)$ & $42 \%(33-52)$ \\
SIN & $24 \%(16-32)$ & $60 \%(51-70)$ & $43 \%(34-53)$ \\
Ljubljana & $17 \%(10-24)$ & $62 \%(53-72)$ & $47 \%(38-57)$ \\
\hline
\end{tabular}

\section{Simultaneous Pathological Assessment at the Joint Meeting}

\section{World Health Organization}

A total of 45 cases with different independent diagnoses that had been made on the basis of the all-options system were selected randomly. Consensus could be achieved in $37 / 45(82 \%)$ of the cases.

\section{Squamous Intraepithelial Neoplasia}

A total of 47 cases with different independent diagnoses based on the alloptions system were selected randomly. Consensus could be achieved in $37 / 47(79 \%)$ of the cases.

\section{Ljubljana}

A total of 40 cases with different independent diagnoses made on the basis of the all-options system were selected randomly. Consensus could be achieved in $28 / 40(70 \%)$ of the cases. Regarding the World Health Organization and 
Squamous Intraepithelial Neoplasia classifications, the clinically relevant differentiation between moderate and severe dysplasia (SIN 2 or 3 ) was the main source of disagreement. Consensus could not always be reached in these cases, as illustrated in Figure 2.1. For the Ljubljana classification, the clinically relevant differentiation between (para)basal and atypical hyperplasia turned out to be the most difficult for the raters, as illustrated in Figure 2.2.

\section{Discussion}

In this report, the histopathology of previously diagnosed laryngeal mucosal premalignant lesions was reassessed by three experienced head and neck pathologists. The purpose was to measure the interobserver variability of the three most frequently used classification systems. In this study, these systems have been assessed using all their original categories. Alternatively, a two- or three-grade system has been used, clustering the categories according to the clinical consequences each one would have. When comparing the results of the current study with the literature, we noted that the only available similar study-by McLaren et $\mathrm{al}^{6}{ }^{6}$ based on 100 laryngeal biopsies-published a $\mathrm{K}$ value of 0.32 using all grading options and 0.52 for a two-grade system using the World Health Organization classification.

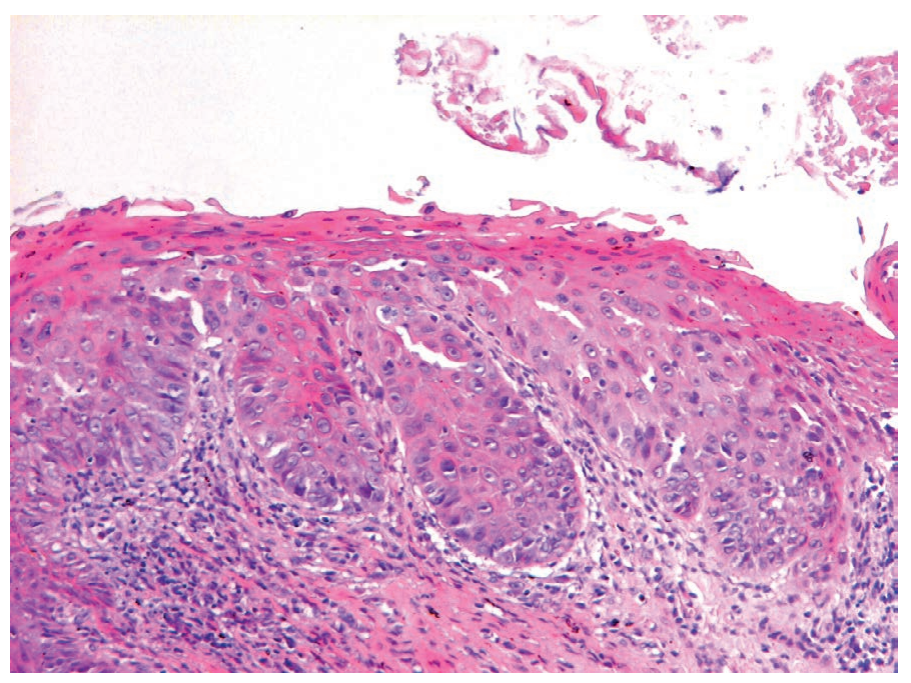

Figure 2.1 Photomicrograph showing a mucosal lesion for which no consensus could be reached, opinions differing between moderate or severe dysplasia/SIN 2 or 3 (World Health Organization and Squamous Intraepithelial Neoplasia classifications). 


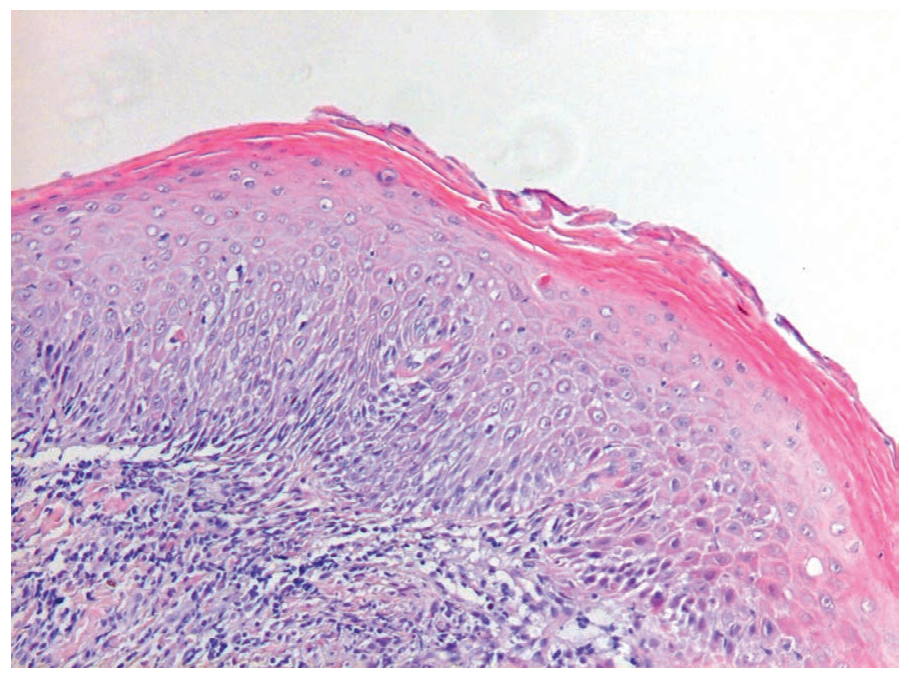

Figure 2.2 Photomicrograph showing a mucosal lesion for which no consensus could be reached, opinions differing between atypical versus basal cell hyperplasia (Ljubljana classification).

No $95 \%$ confidence intervals were given in that study. In comparison, when we used the World Health Organization classification, we found an overall unweighted $\mathrm{k}$-value for all options of 0.21 (95\% confidence interval $0.17-0.26$ ). Our weighted $\mathrm{k}$-values ranged from 0.48 (95\% confidence interval $0.37-0.58)$ to $0.50(0.39-0.60)$. Using the two- or three-grade system gave an overall $\mathrm{K}$ value of $0.44(95 \%$ confidence interval $0.33-0.55)$ and $0.39(95 \%$ confidence interval $0.31-0.47$ ), respectively. The implementation of weighted k-values led to higher values for all three classification systems. However, they did not exceed 0.55 , corresponding with moderate agreement by Altman's criteria. ${ }^{20,21}$ Concerning the proportion of concordance for the two- and three-grade system, it should be noted that in $38-40 \%$ and $53-58 \%$ of the cases, respectively, the three pathologists disagreed. The proposed two or three-grade system is based on the presumed chance of malignant progression and its implications for clinical practice: 'low risk' with mainly periodic observation in comparison with 'high risk' requiring (laser) surgery or radiotherapy. By extension, the clinical consequences would be either overtreatment (i.e., surgery or radiotherapy instead of periodic observation) or undertreatment (i.e., periodic observation instead of surgery or radiotherapy). Either way, the therapeutic implications would be significant. In that light, there is a need for additional tools to identify which lesions would and which would not become malignant if left untreated. 
In our review of the literature, we noted that other authors have also proposed or investigated a binary or two-grade system to classify head and neck mucosal premalignant lesions. ${ }^{4,6,16,23}$ Gale et al. ${ }^{16}$ concluded that the results of a long-term follow-up study of 1268 patients once again justify the proposal of the Ljubljana classification. It entails dividing the morphological criteria into two basic groups: benign (squamous hyperplasia and basal/ parabasal hyperplasia) and potentially malignant (atypical hyperplasia). It has been customary to use relatively few categories (three or two) and to assess accuracy by measuring interobserver agreement with $\mathrm{k}$-statistics. The extent of interobserver agreement is often less than anticipated when carefully controlled studies are undertaken, and there has been a tendency to recommend the use of fewer categories. ${ }^{6,23-26}$ However, according to Deolekar and Morris, ${ }^{24}$ the policy to lower the degree of inter- and intra-observer disagreement by reducing the number of subjective categories is misleading. Although acknowledging the importance of grading pathological continua, they concluded that information is lost when too few categories are used. The judgment should be cited along with a confidence interval so as not to imply a degree of accuracy that cannot be achieved. Some have argued that it would be logical to use more categories and to give the clinician a range of values within which the true value will lie (a 90,95 , or $99 \%$ confidence interval). ${ }^{24,27}$ Shannon ${ }^{28}$ measured information on a binary system. One bit of information reduces uncertainty by one-half, two bits reduce it to one-quarter of the initial level, and three bits reduce uncertainty to one-eighth.

We prefer a three-grade system because of the correlation with daily clinical practice (no periodic observation, periodic observation, and treatment ((laser) surgery or radiotherapy). We would rather avoid the use of only two categories. Furthermore, our current study shows higher unweighted K-values and proportions of concordance than found with the all-options system.

Comparison of the categories within the different systems has prompted discussion on the position of atypical hyperplasia in the Ljubljana classification. This category showed an overlap with moderate as well as severe dysplasia. Therefore, no optimal discrimination is possible between grades 2 and 3 (yellow and pink segment in Table 2.2).

In the current study, the highest k-values for the all-options system are found for the Squamous Intraepithelial Neoplasia classification, followed by the World Health Organization and Ljubljana classifications. For the two-grade system, the Ljubljana classification has the highest $\mathrm{k}$-values, followed by the World Health Organization and Squamous Intraepithelial Neoplasia classifications. The K-values are similar for the three-grade system. As the $95 \%$ confidence intervals show some overlap, as seen in Table 2.3, no statistically significant $(P<0.05)$ differences are found among the three classification systems. In the 
future, a similar study based on more cases might demonstrate statistically significant differences.

Furthermore, because of a high level of consensus, the simultaneous pathological assessment had added value in comparison with independent assessment. A consequence could be to advise assessment by more than one pathologist for suspected cases of dysplasia or carcinoma. Similar proposals are found in current guidelines for esophageal and colonic premalignant lesions. ${ }^{29-31}$

Montgomery $^{32}$ suggested that we should look beyond the problem of interobserver variability in the diagnosis of esophageal dysplasia. He thinks that sampling error on the part of endoscopists is probably more serious a problem than observer variation among the pathologists who are reviewing patient samples. However, this possibility would only make the diagnosis of premalignant lesions even less reliable and offers no excuse for the observer variation. In our opinion, the identification of patients with intermediate-level laryngeal dysplasia and high risk of malignancy is a multidisciplinary challenge for both clinician and pathologist, a claim that has been made before. ${ }^{6}$ The necessity or urgency to treat a laryngeal mucosal premalignant lesion is dependent on several factors: the (voice) complaints of the patient and the risk of progression to invasive cancer or the risk that the sample is not representative for the entire lesion. In the absence of reliable biological markers, the grade of dysplasia is still the most often used parameter to guide the treatment decision. Realizing that clinicians should be aware of the fact that sampling errors may occur and that the determination of the grade of dysplasia is variable. In case of suspicion of a sampling error, a re-biopsy or more extensive surgery should be considered.

\section{Conclusion}

In the current study, we have observed no clear tendency in favor of one particular system for classifying laryngeal mucosal premalignant lesions. The weighted $\mathrm{K}$-values did not exceed 0.55 , indicating only moderate agreement and underscoring the assertion that current clinical management is in need of additional tools to identify lesions that would or would not become malignant if left untreated. The proposed three-grade system could be useful because of its correlation with daily clinical practice (no periodic observation, periodic observation, and treatment). Another advantage is that it yields better unweighted $\mathrm{k}$-values and a higher proportion of concordance in comparison with the all-options system. Moreover, because of a high level of consensus, simultaneous pathological assessment provides added value in comparison 
Interobserver variability of laryngeal mucosal premalignant lesions

with independent assessment. Therefore, assessment by more than one pathologist might be advisable for suspected cases of dysplasia or carcinoma. 


\section{References}

1. Gale N, Pilch BZ, Sidransky D, et al. Tumours of the hypopharynx, larynx and trachea (epithelial precursor lesions). In: Barnes L, Eveson JW, Reichart, P Sidransky D (eds). World Health Organization Classification of Tumours. Pathology \& Genetics. Head and Neck Tumours. International Agency for Research on Cancer (IARC), IARC Press: Lyon, 2005:140-3.

2. Haddad RI, Shin DM. Recent advances in head and neck cancer. N Engl J Med 2008;359:1143-1154.

3. Blackwell KE, Fu YS, Calcaterra TC. Laryngeal dysplasia. A clinicopathologic study. Cancer 1995;75: 457-63.

4. Fleskens S, Slootweg P. Grading systems in head and neck dysplasia: their prognostic value, weaknesses and utility. Head Neck Oncol 2009;1:1-8.

5. Johnson FL. Management of advanced premalignant laryngeal lesions. Curr Opin Otolaryngol Head Neck Surg 2003;11:462-6.

6. McLaren KM, Burnett RA, Goodlad JR, et al. Consistency of histopathological reporting of laryngeal dysplasia. The Scottish Pathology Consistency Group. Histopathology 2000;37:460-3.

7. Bosman FT. Dysplasia classification: pathology in disgrace? J Pathol 2001;194: 143-4.

8. Dickman PW, Hakulinen $\mathrm{T}$, Luostarinen $\mathrm{T}$, et al. Survival of cancer patients in Finland 1955-1994. Acta Oncol 1999;38:1-103.

9. Sadri M, McMahon J, Parker A. Laryngeal dysplasia: aetiology and molecular biology. J Laryngol Otol 2006; 120:170-7.

10. Vokes EE, Weichselbaum RR, Lippman SM, et al. Head and neck cancer. N Engl J Med 1993;328: 184-94.

11. Gale N, Kambic V, Michaels L, et al. The Ljubljana classification: a practical strategy for the diagnosis of laryngeal precancerous lesions. Adv Anat Pathol 2000;7:240-51.

12. Kambic V, Gale N. Significance of keratosis and dyskeratosis for classifying hyperplastic aberrations of laryngeal mucosa. Am J Otolaryngol 1986;7: 323-33.

13. Kambic V. Epithelial hyperplastic lesions-a challenging topic in laryngology. Acta Otolaryngol Suppl 1997;527:7-11.

14. Sengiz S, Pabuccuoglu U, Sarioglu S. Immunohistological comparison of the World Health Organization (WHO) and Ljubljana classifications on the grading of preneoplastic lesions of the larynx. Pathol Res Pract 2004;200:181-8.

15. Vodovnik A, Gale N, Kambic V, et al. Correlation of histomorphological criteria used in different classifications of epithelial hyperplastic lesions of the larynx. Acta Otolaryngol Suppl 1997;527:116-9.

16. Gale N, Michaels L, Luzar B, et al. Current review on squamous intraepithelial lesions of the larynx. Histopathology 2009;54:639-56.

17. Dutch Cooperative Head and Neck Group (NWHHT). CBO Revision Guidelines Laryngeal Carcinoma. Van Zuiden Communications: Alphen aan de Rijn, 2009.

18. Hellquist $\mathrm{H}$, Cardesa $\mathrm{A}$, Gale $\mathrm{N}$, et al. Criteria for grading in the Ljubljana classification of epithelial hyperplastic laryngeal lesions. A study by members of the Working Group on Epithelial Hyperplastic Laryngeal Lesions of the European Society of Pathology. Histopathology 1999;34:226-33.

19. Fleskens SA, van der Laak JA, Slootweg PJ, et al. Management of laryngeal premalignant lesions in the Netherlands. Laryngoscope 2010;120:1326-35. 
20. Landis JR, Koch GG. The measurement of observer agreement for categorical data. Biometrics 1977;33: 159-74.

21. Altman DG. Inter-Rater agreement. Practical Statistics for Medical Research. Chapman \& Hall: London, 1991;403-9.

22. Cohen J. Weighted kappa: nominal scale agreement with provision for scaled disagreement or partial credit. Psychol Bull 1968;70:213-20.

23. Kujan O, Oliver RJ, Khattab A, et al. Evaluation of a new binary system of grading oral epithelial dysplasia for prediction of malignant transformation. Oral Oncol 2006;42:987-93.

24. Deolekar M, Morris JA. How accurate are subjective judgements of a continuum? Histopathology 2003;42: 227-32.

25. Lang $\mathrm{H}$, Lindner $\mathrm{V}$, de $\mathrm{FM}$, et al. Multicenter determination of optimal interobserver agreement using the Fuhrman grading system for renal cell carcinoma: assessment of 241 patients with 415-year follow-up. Cancer 2005;103:625-9.

26. Littleford SE, Baird A, Rotimi $O$, et al. Interobserver variation in the reporting of local peritoneal involvement and extramural venous invasion in colonic cancer. Histopathology 2009;55:407-13.

27. Morris JA. Information and observer disagreement in histopathology. Histopathology 1994;25:123-8.

28. Shannon CE. A mathematical theory of information. Bell System Techn J 1948;27: 379-423.

29. Haggitt RC. Barrett's esophagus, dysplasia, and adenocarcinoma. Hum Pathol 1994;25:982-93.

30. Lessells AM, Burnett RA, Goodlad JR, et al. Comment on a recent paper and editorial on the subject of dysplasia classification. J Pathol 2002;198:131-2.

31. Riddell RH. Grading of dysplasia. Eur J Cancer 1995;31A:1169-70.

32. Montgomery E. Is there a way for pathologists to decrease interobserver variability in the diagnosis of dysplasia? Arch Pathol Lab Med 2005;129:174-6. 


\section{Chapter}

\section{3 - CHROMOSOME INSTABILITY PREDICTS PROGRESSION OF PREMALIGNANT LESIONS OF THE LARYNX}

Verona E. Bergshoeff, Stijn J.A. Van der Heijden, Annick Haesevoets, Sophie G.H. Litjens,

Fredrik J. Bot, Adri C. Voogd, Michelene N. Chenault, Anton H.N. Hopman, Ed Schuuring, Jacqueline M. Van der Wal, Johannes J. Manni, Frans C.S. Ramaekers,

Bernd Kremer, Ernst-Jan M. Speel

Pathology 2014;46:216-224 


\section{Abstract}

Aims

Because the histopathology of premalignant laryngeal lesions does not provide reliable information on the risk of malignant transformation we examined new molecular markers which can easily be implemented in clinical practice.

\section{Methods}

Dual-target Fluorescence In Situ Hybridization (FISH) for chromosome 1 and 7 centromeres was performed on tissue sections of laryngeal premalignancies of 69 patients. Chromosome Instability $(\mathrm{Cl})$ was indicated by numerical imbalances and/or polysomy for chromosomes 1 and 7. Additionally, immunostainings for p53, Cyclin D1 and (p)FADD expression were evaluated. Malignant progression was recorded. Eighteen patients with carcinoma in situ (CIS) were treated after diagnosis and excluded from follow-up.

\section{Results}

$\mathrm{Cl}$ was strongly associated with a high risk of malignant transformation, especially in lower-grade lesions (hyperplasia, mild and moderate dysplasia; Odds Ratio $=8.4$, $P=0.004)$. Patients with $\mathrm{Cl}$-containing lesions showed a significantly worse 5-year progression-free survival than those with premalignancies without $\mathrm{Cl}(P=0.002)$. Neither histopathology nor the protein markers predicted progression in univariate analysis, although histopathological diagnosis, p53 and FADD contributed positively to $\mathrm{Cl}$ in multivariate analysis.

\section{Conclusions}

$\mathrm{Cl}$ is associated with malignant progression of laryngeal premalignancies, especially in lower-grade lesions. These results may contribute to better risk-counselling, provided that they can be validated in a larger patient-set. 


\section{Introduction}

Head and neck squamous cell carcinoma (HNSCC) is the sixth most common cancer in the world with an estimated 500,000 new cases annually and has a poor 5-years survival rate of approximately 50 percent. ${ }^{1}$ The predominant etiological risk factors for HNSCC are alcohol consumption and tobacco smoking. ${ }^{1-3}$ Important factors which influence prognosis are locoregional recurrence in up to $30 \%$ of patients, originating from minimal residual disease, ${ }^{4,5}$ and the development of new or progression of existing precursor lesions. ${ }^{5,6}$ Furthermore, molecularly targeted therapies are directed toward activated oncogenes and do not influence inactivated tumor suppressor genes, which are frequently found in HNSCC. ${ }^{7}$ This makes early detection of potentially malignant head and neck precursor lesions extremely important.

A diagnostic dilemma is to decide which precursor lesions are potentially malignant. However, histopathological examination is troubled by inter-observer variability. ${ }^{8-10}$ Therefore, we need more reliable, sensitive, fast, and easily to interpret molecularly based detection-methods to identify potentially malignant precursor lesions, which can be easily implemented in clinical diagnostics.

The histomorphological transition from normal mucosa to cancer is driven by the accumulation of genetic changes, resulting in chromosome instability $(\mathrm{Cl}),{ }^{1,5,11}$ which can already be detected in premalignant lesions using different molecular biological approaches. The relationship of $\mathrm{Cl}$ with cancer development has been extensively studied in oral lesions. First, loss of heterozygosity (LOH) on chromosome 9p21 (p16INK4A and p14 ARF locus) and possibly also $3 p$ correlates with cancer development in half of the cases, and is associated with a 11 to 52 -fold increase in relative cancer risk if detected together with $\mathrm{LOH}$ at $4 \mathrm{q}, 8 \mathrm{p}, 11 \mathrm{q}, 13 \mathrm{q}, 14 \mathrm{q}$ and/or $17 \mathrm{p} .^{12-15}$ Second, DNA flowand image cytometry demonstrated an association between aneuploidy and malignant outgrowth of oral premalignant lesions. ${ }^{16,17}$ Third, array CGH also showed accumulation of chromosomal alterations in association with disease progression. ${ }^{18}$ Fourth, in situ hybridization (ISH) analyses revealed that numerical chromosomal aberrations can predict progression. ${ }^{4,19,20}$ Numerical aberrations for chromosomes 1 and 7 were detected in dysplasia and carcinoma in situ (CIS) and not in histologically normal mucosa and the majority of hyperplastic lesions. ${ }^{21} \mathrm{~A}$ ten-year translational study showed that $\mathrm{LOH}$ for $3 p$ and $9 p$, p53 protein overexpression and polysomy for chromosomes 9 and 17 strongly predicted cancer development in oral leukoplakia. $^{12}$ The use of chromosome 7 alterations to assess the aggressiveness of potentially malignant oral lesions has been demonstrated by Poh et al... ${ }^{22}$ This study also showed that polysomy for chromosome 9 seems less suitable for this purpose due to loss of chromosome 9 sequences. 
Relatively few studies have assessed the clinical value of $\mathrm{Cl}$ to predict malignant development of laryngeal precursor lesions. DNA ploidy analysis showed that $77 \%$ of the lesions which preceded carcinoma (in situ) showed aberrant DNA ploidy results. ${ }^{23}$ Furthermore, microsatellite and single-target brightfield ISH-analysis showed that LOH at 9p21, 17p13 and 18q23 correlated with numerical abnormalities for chromosomes 1, 7, 9, 17 and 18 in high risk premalignant lesions. ${ }^{24}$ Because of the limited size of laryngeal biopsies, variations in the number of (pre)malignant cells and loss of tissue architecture during processing, microsatellite-, array $\mathrm{CGH}$ - and DNA content analyses are not ideal. Therefore, we applied ISH in an earlier retrospective study on $\mathrm{Cl}$ detection (indicated by the presence of imbalances in chromosome 1 and 7 centromere copy numbers and/or polyploidization). This study showed that $\mathrm{Cl}$ predicted malignant progression in premalignant laryngeal lesions. ${ }^{25}$

Other potential molecular markers of progression include the cell cycle proteins p53, Cyclin D1, Fas-associated Death Domain (FADD) and its phosphorylated isoform pFADD. Multiple studies have shown that accumulation of p53 occurs more often in high-grade than in low-grade precursor lesions, although a strong association with malignant progression has not been identified. 12,26,27 Amplification of the 11q13 region, including the Cyclin D1 and FADD genes, is frequently found in HNSCC. ${ }^{28,29}$ Particularly Cyclin D1 and FADD proteins are accumulated in tumor cells which is indicative of a worse cancer free survival. $^{30,31}$ Furthermore, dysregulated Cyclin D1 expression has been associated with progression in premalignant head and neck lesions. ${ }^{29,32}$ High levels of FADD and pFADD have been associated with a poor disease-specific survival in laryngeal and pharyngeal carcinomas, and pFADD overexpression with a better response to taxol-based chemotherapy. ${ }^{30,33}$ Its value as a predictor for progression of premalignant laryngeal lesions has not as yet been investigated.

In this study we examined a new collection of premalignant laryngeal lesions for the presence of $\mathrm{Cl}$ as well as p53, Cyclin D1, FADD and pFADD and analyzed their value to predict malignant progression.

\section{Materials and methods}

\section{Patient data and tissue material}

Out of 180 patients with laryngeal dysplasia that had undergone a laryngeal biopsy during microlaryngeal surgery between 1986 and 2001 in the Maastricht University Medical Centre, we included 69 premalignant laryngeal (5 supraglottic, 64 glottic) lesions of 69 patients ( 57 male, 12 female) in this study (referred to as group 1). The other patients were excluded in case of 1) a follow-up time 
shorter than 6 months prior to malignant progression, 2) a lack of sufficient patient material 3) a radically performed biopsy e.g. vocal cord "stripping" or 4) previous inclusion in a previous study from our institute..$^{25}$ In case of multiple available biopsies the last biopsy preceding SCC or CIS was chosen, taking into account the 6-months period as a minimum. The material was treated according to the Code for Proper Secondary Use of Human Tissue (Federation of Medical Scientific Societies, The Netherlands; 2003) and the study protocol was approved by the institutional ethical committee.

The histopathological assessment of the lesions was performed using the WHO classification system and thoroughly reviewed (F.J.B). Eighteen cases diagnosed as CIS were treated by radiotherapy or (laser-assisted) microlaryngeal surgery after diagnosis and therefore excluded from follow-up and survival analyses, resulting in a follow-up group of $n=51$ (referred to as group 2). Because of the current discussion whether a distinction between severe dysplasia and $\mathrm{CIS}$ can be made, possibly resulting in the treatment of these lesions we also defined a third group (referred to as group 3): lesions with hyperplasia, mild or moderate dysplasia only, severe dysplasia excluded. Follow-up information of the 69 patients was collected from the medical records. Lesions were classified as "progressive" in case of development of carcinoma in situ (CIS) or squamous cell carcinoma (SSC) at the same localisation as the primary biopsy site.

Four- $\mu \mathrm{m}$ thick formalin-fixed, paraffin embedded tissue sections of all 69 specimens (further referred to as group 1) were subjected to dual-colour FISH analysis using centromere-specific DNA probes for chromosomes 1 and 7. A control group consisting of 10 tissue samples of normal squamous head and neck epithelium was also subjected to FISH analysis. On subsequent tissue sections of the 51 cases which were submitted to follow-up and survival analyses (group 2) immunostainings were performed for p53, Cyclin D1, FADD and pFADD in 50, 50, 48 and 48 specimens respectively. Missing cases were due to insufficient patient material.

Data concerning tobacco smoking and alcohol consumption were available in 52 of the 69 patients. Patients were divided into 1 ) non-smokers (never smoked or ceased smoking for at least 20 years) and 2) smokers (current smokers or ceased smoking for less than 20 years). Alcohol consumption was categorized as 1) non-user, i.e. $\leq 2$ Alcohol Units (AU) /day) and 2) user i.e. $>2$ AU/day).

\section{Detection of chromosome 1 and 7 alterations by FISH}

FISH was performed on $4 \mu \mathrm{m}$ thick tissue sections as described previously. ${ }^{4,34}$ Briefly, sections were deparaffinized, pretreated with $85 \%$ formic acid / $0.3 \%$ $\mathrm{H}_{2} \mathrm{O}_{2}, 1 \mathrm{M} \mathrm{NaSCN}$ and $4 \mathrm{mg} / \mathrm{ml}$ pepsin in $0.01 \mathrm{M} \mathrm{HCl}$, post-fixed in $1 \%$ formaldehyde in phosphate-buffered saline (PBS), dehydrated in an ethanol 
series and hybridized with a mixture of digoxigenin-labeled human centromere 1-specific and biotin-labeled centromere 7-specific DNA probes [1 $\mathrm{ng} / \mu \mathrm{l} 60 \%$ formamide, $2 x$ sodium-saline citrate (SSC), 10\% dextran sulphate and $50 x$ excess salmon sperm carrier DNA]. After hybridization the preparations were washed stringently in $2 \times \mathrm{SSC}$ at $42{ }^{\circ} \mathrm{C}$ (two times for $5 \mathrm{~min}$ ) and $0.1 \times \mathrm{SSC}$ at $60^{\circ} \mathrm{C}$ (two times for $5 \mathrm{~min}$ ). The probes were detected by application of (i) mouse anti-digoxin (Sigma) / avidin fluorescein (Vector Laboratories, Burlingame, CA, USA), (ii) rabbit anti-mouse rhodamin (Dako, Glostrup, Denmark) / biotinylated goat anti-avidin (Vector) and (iii) swine anti-rabbit rhodamin (Dako) / avidin fluorescein. Preparations were mounted in Vectashield (Vector Laboratories) containing 4,6-diamidino-2-phenyl indole (Sigma; $0.2 \mu \mathrm{g} / \mathrm{ml}$ ).

Microscope images were recorded with the Metasystems Image Pro System (black and white charge coupled device camera; Metasystems, Sandhausen, Germany) mounted on top of a Leica DM-RE fluorescence microscope (Leica, Wetzler, Germany) equipped with fluorescein-, rhodamine- and DAPI-specific filter sets for single-colour analysis and a double bandpass filter set (fluorescein, rhodamine) for simultaneous dual-colour analysis.

\section{Controls and evaluation of FISH results}

Hybridizations on tissue sections with proven aneusomies (monosomy, disomy, trisomy, and tetrasomy) as well as on 10 normal squamous tissue sections were used as a control group to exclude hybridization artefacts and interpretation problems. Evaluation of the FISH results was carried out by two investigators (AH and EJMS) according to our earlier described and validated protocol. ${ }^{25,34} \mathrm{FISH}$ signals were scored per colour and nucleus for the presence of aberrant copy numbers of chromosomes 1 and 7 . The highest copy number per nucleus was determined and set if $\geq 20 \%$ of the nuclei (with a minimum of 50 nuclei and a maximum of 500 nuclei, depending on the size of the lesion) showed this number of FISH signals. Based on this evaluation, the lesions were categorized as either monosomic, disomic, trisomic, tetrasomic or polysomic ( $>4$ signals per nucleus) for the respective probe targets.

After this evaluation, the lesions were divided into 1) a group of lesions without $\mathrm{Cl}$, i.e. no evidence of numerical chromosomal alterations (diploid) or an altered but balanced chromosome 1 and 7 status (trisomy or tetrasomy for both chromosomes, indicating tri- or tetraploidization), and 2) a group of lesions containing $\mathrm{Cl}$, i.e. showing chromosome $1 / 7$ copy number imbalances and/or chromosome polysomy ( $>4$ signals per nucleus). 


\section{Immunohistochemistry}

Immunohistochemical staining was performed for p53 (clone DO-7; Dako), Cyclin D1 (clone SP4; Labvision, Fremont, USA), FADD (clone A66-2; BD Biosciences, Breda, NL) and Ser ${ }^{194}$ pFADD (polyclonal; Cell Signaling, Danvers, USA) expression on 4- $\mu \mathrm{m}$ thick formaldehyde fixed, paraffinembedded tissue sections as described earlier. ${ }^{30,35}$ Evaluation was performed by VEB, SGHL, AH, and EJMS for p53 staining and ES, JW, and EJMS for Cyclin D1, FADD and pFADD.

p53: Lesions were classified as negative when no or only few cells with nuclear staining were observed, or positive when either multiple cells with nuclear staining were present above the basal cell layer or tissue areas showed $\geq 10 \%$ stained cell nuclei. ${ }^{35}$

Cyclin D1: Lesions were evaluated using a cut-off value for strong nuclear staining in $>10 \%$ of cells based on earlier reports. ${ }^{29}$

$F A D D$ and $p F A D D$ : The stainings of both proteins are morphologically different in head and neck carcinomas ${ }^{30}$ and therefore have been evaluated separately. FADD staining was mostly cytoplasmic and categorized as low (no or weak expression) or high (intermediate or strong expression). When normal epithelium was present in the tissue section, cytoplasmic staining of the suprabasal layer was used as the reference. ${ }^{30}$ pFADD expression was assessed as the percentage of cells with strong nuclear staining. For statistical analysis the cut-off value for was set at $\geq 60 \%$ positivity, based on the population mean staining percentage.

\section{Statistical analysis}

All data were analyzed using SAS (version 8.02, SAS Institute Inc., Cary, NC, USA) and SPSS 18.0. Patients with non-progressive lesions were censored at the date of last follow-up (with a minimum of 5 years of follow-up from the date of biopsy) or date of death, provided that death was not related to laryngeal malignancy. Differences in patient characteristics between subgroups in the study population were evaluated with a two-tailed T-test for continuous variables and the Chi-square test or Fisher's Exact test for categorical variables. Univariate logistic regression analysis was performed to identify potential predictive markers for malignant progression and to assess their Odds Ratios (ORs). Based on these results and taking into account the influence of possible confounders, multivariate logistic regression analysis was carried out, which resulted in a risk model based on the combination of different prognostic markers, including ROC curves. These analyses were also performed on group 3 (i.e. hyperplasia, mild and moderate dysplasia only $(n=39)$ in order to exclude a potential bias by the severe dysplastic cases. Progression-free survival analysis was calculated using the Kaplan-Meier method. A log rank test was 
performed to compare the progression-free survival of subgroups, classified according to histopathology, $\mathrm{Cl}$, and protein expression. In all analyses the $P$ value for significance was set at 0.05 .

\section{Results}

\section{$\mathrm{Cl}$ analysis}

FISH analysis performed on group 1 resulted in $42(60 \%)$ lesions with Cl. All 27 lesions without $\mathrm{Cl}$ exhibited a diploid chromosome status, except for one case of hyperplasia and one case of moderate dysplasia, which harboured a balanced tetrasomy for chromosomes 1 and 7. Representative images of FISH analyses on tissue sections of premalignant laryngeal lesions are displayed in Figure $3.1 \mathrm{~A}$ and 3.1B, and an example of a FISH 1c/7c counting in a lesion with $\mathrm{Cl}$ is shown in Figure 3.1C. The percentage of lesions with $\mathrm{Cl}$ increased with advancing histopathological stage (Figure 3.1D). The 10 cases of normal squamous epithelium showed a disomy for both chromosomes.

A significantly higher mean age at biopsy, i.e. 64 yrs (range 43-79) was found in the group of patients with $\mathrm{Cl}$ compared to the group without $\mathrm{Cl}$ (56 yrs, range 23-77; $P=0.0001$ ), which may reflect the effect of longer carcinogenic exposure. No significant differences were observed between the patients with $\mathrm{Cl}$ and without $\mathrm{Cl}$ with respect to the other potential confounders (gender and alcohol consumption/tobacco smoking). Thirty patients (58\%) of group 2 showed progression to $\mathrm{CIS}$ or SCC. Six lesions harboured $\mathrm{Cl}$, but were nonprogressive, 9 lesions did not harbour $\mathrm{Cl}$ but developed SCC in 4, and $\mathrm{CIS}$ in 5 patients. Interestingly, in these cases also the developed SCC or CIS showed no $\mathrm{Cl}$. Univariate logistic regression analysis on group 2 indicated that $\mathrm{Cl}$ is a strong individual marker of progression $(\mathrm{OR}=5.8, P=0.005)$, corresponding with a sensitivity of $70 \%$ and specificity of $71 \%$. Also in group $3 \mathrm{Cl}$ was strongly associated with malignant outcome $(\mathrm{OR}=8.4, P=0.004)$; sensitivity $75 \%$, specificity $74 \%)$.

\section{p53, Cyclin D1, FADD and pFADD expression analyses}

P53 immunostaining resulted in 23 (46\%) p53-positive cases (group 2). Representative images of a p53 positive lesion are depicted in Figure 3.1E and 3.1F. Patients with P53-positive lesions did not differ significantly from patients with P53-negative lesions with respect to age, gender and tobacco smoking and alcohol consumption or $\mathrm{Cl}$ status. P53 did not appear to be a reliable prognosticator in univariate logistic regression $(\mathrm{OR}=2.29$ Confidence Interval (0.72-7.27); Table 3.1). 
Nuclear Cyclin D1 overexpression was found in 16 (32\%) lesions (group 2). A representative case with Cyclin D1 overexpression is depicted in Fig. 1G. No significant differences were found for $\mathrm{Cl}$ status or potential confounders (age, gender, tobacco smoking and alcohol consumption) when comparing the Cyclin D1-positive and -negative patients. In univariate logistic regression analysis Cyclin D1 overexpression did not appear to be a prognosticator $(\mathrm{OR}=1.0$, Confidence Interval (0.50-6.10); Table 3.1).

Seven samples (15\%) were categorized as "high FADD". Six of these lesions displayed $\mathrm{Cl}$ and were progressive, although no statistically significant association with outcome was found. FADD showed a high OR in univariate logistic regression analysis, which however was not statistically significant (OR=5.71, Confidence Interval (0.63-51.77), Table 3.1). A nuclear pFADD staining was identified in 45 (93\%) lesions (range 10-90\% positive nuclei) and pFADD positivity was not significantly associated with progression in univariate logistic regression analysis $(\mathrm{OR}=0.94$, Confidence Interval (0.30-2.99), Table 3.1). Representative images of cases with high FADD and pFADD overexpression can be found in Figure $3.1 \mathrm{H}$ and $3.1 \mathrm{I}$ respectively.

\section{Histopathology}

Histopathological examination resulted in 4 cases of hyperplasia, 14 mild dysplasias, 21 moderate dysplasias, 12 severe dysplasias and 18 cases of $\mathrm{CIS}$. Univariate logistic regression analysis on group 2 showed that only severe dysplasia predicted progression (OR=15.0, Confidence Interval (0.98-228.90), $P=0.05$ ), (Table 3.1). Neither pooling of hyperplasia and mild dysplasia versus moderate and severe dysplasia nor severe dysplasia versus the 3 combined lower histopathological classifications improved the prognostic value of histopathology (Table 3.1).

All analyses as described above were also performed in group 3. Univariate analyses showed that also in this group, which contained only low-grade dysplasia, only $\mathrm{Cl}$ was significantly associated with malignant outcome (OR= 8.4, Confidence Interval (1.96-35.37), $(P=0.004)$; (Table 3.1). 


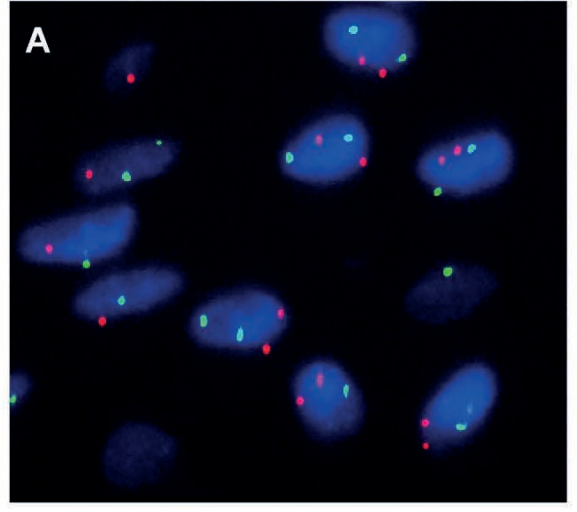

C

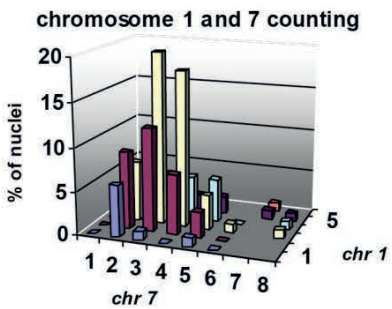

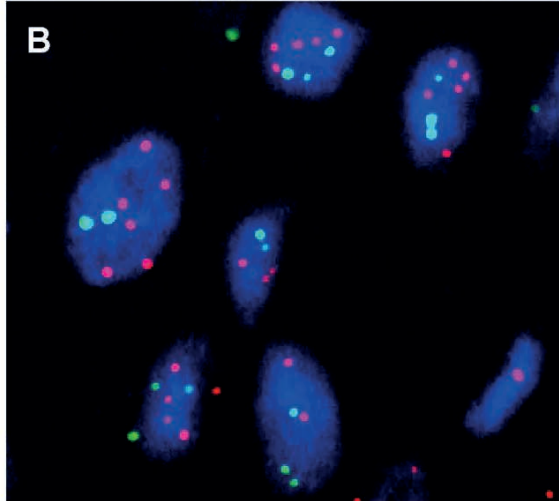

D
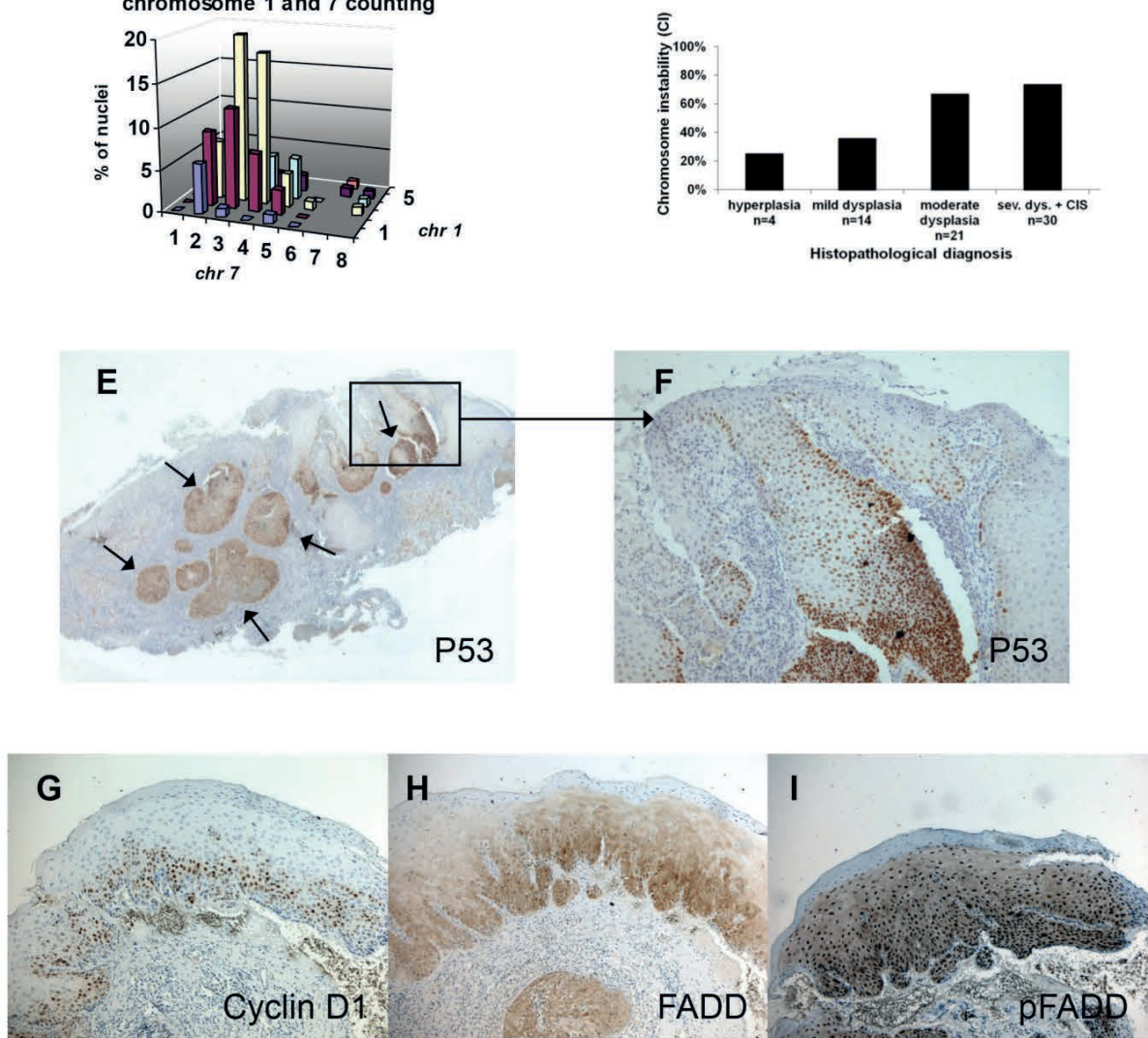

Figure 3.1 Representative images of tissue sections of premalignant laryngeal lesions, analyzed by $\mathrm{FISH}$ for $\mathrm{Cl}$ detection, and immunohistochemistry; 
A, B)FISH analyses, showing (A) disomy for chromosomes 1 (green) and 7 (red) (no $\mathrm{Cl}$ ), and (B) trisomy for chromosome 1 and polysomy for chromosome $7(\mathrm{Cl})$. C) Example of a chromosome 1 and 7 counting of 200 nuclei in a tissue section containing $\mathrm{Cl}$. Trisomy, tetrasomy and polysomy is encountered. D) Enhanced percentage of chromosome instability $(\mathrm{Cl})$ in premalignant laryngeal lesions ranging from hyperplasia, mild, moderate to severe dysplasia/CIS as determined by $\mathrm{FISH}$ 1c/7c. E, F) P53 immunostaining, showing (E) p53 overexpression, displaying nuclear staining of the (para)basal cell layer in "patches" (indicated by arrows), and (F) detail of this tissue section. G, H, I) Immunostaining images for overexpression of (G) Cyclin D1: nuclear staining $10 \%$, (H) FADD: mostly cytoplasmic staining categorized as "high", (I) pFADD: $80 \%$ nuclear staining.

Table 3.1 Odds Ratios for individual markers to predict malignant progression of premalignant lesions.

\begin{tabular}{lccc}
\hline Marker & \multicolumn{2}{c}{ OR (95\% Confidence Interval) } \\
Group 2 & Group3 & $\begin{array}{c}P \text {-value } \\
\text { Group 2/Group 3 }\end{array}$ \\
\hline Cl & $5.83(1.71-19.90)$ & $8.4(1.96-35.37)$ & $0.005^{\star} / 0.004^{*}$ \\
P53 & $2.29(0.72-7.27)$ & $2.29(0.60-8.83)$ & $0.16 / 0.228$ \\
FADD & $5.71(0.63-51.77)$ & $3.96(0.361-41.20)$ & $0.12 / 0.26$ \\
pFADD (>60\% nuclear staining) & $0.94(0.30-2.99)$ & $1.00(0.28-3.57)$ & $0.92 / 1.00$ \\
Cyclin D1 (>10\%) & $1.74(0.50-6.10)$ & $1.73(0.44-6.79)$ & $0.39 / 0.43$ \\
$\quad$ Histopathology: & & & \\
Mild dysplasia (MD) & $3.00(025-36.33)$ & $3.00(0.25-36.33)$ & $0.39 / 0.39$ \\
$\quad$ Moderate dysplasia (MDD) & $4.00(0.36-45.10)$ & $4.00(0.36-45.10)$ & $0.26 / 0.26$ \\
Severe dysplasia (SD) & $15.00(0.98-228.90)$ & & 0.05 \\
HP + MD vs. MDD+SD & $2.50(0.77-8.12)$ & & 0.13 \\
HP + MD + MDD vs. SD & $4.75(0.92-24.56)$ & & 0.06 \\
HP +MD vs. MDD & & $1.67(0.47-5.93)$ & 0.43 \\
HP vs. MD + MDD & & $1.05(0.34-37.69)$ & 0.87 \\
\hline
\end{tabular}

* significant $P$-value. OR, Odds Ratio; $\mathrm{Cl}$, Chromosome Instability; HP, hyperplasia; MD, mild dysplasia; MDD, moderate dysplasia; SD, severe dysplasia. Group 2: $n=51$. Group 3: $n=39$, cases with severe dysplasia excluded.

\section{Progression-free survival analysis}

Of the 51 patients 20 developed SCC and 10 developed CIS on the site of primary biopsy. The 5-year progression-free survival of group 2 was $45 \%$ (95\% Confidence Interval: 30.2-59.8). Survival analysis showed a significantly shortened progression-free survival time for patients with $\mathrm{Cl}$ compared with patients without $\mathrm{Cl}(P=0.0022)$, Figure 3.2A. This finding was even more pronounced in group $3(P=0.0006)$, Figure $3.2 \mathrm{~B}$. 

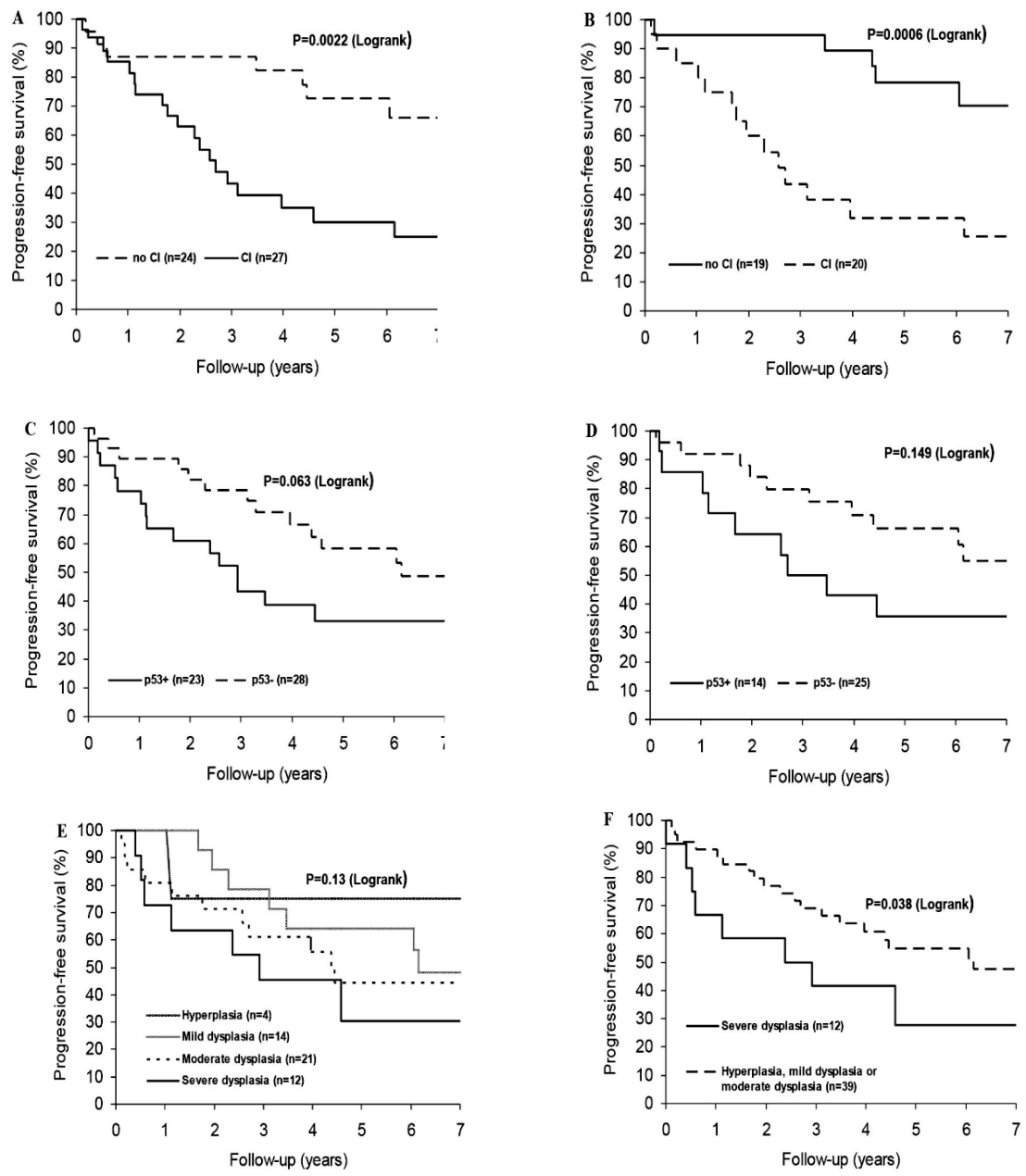

Figure 3.2 Kaplan-Meier survival analyses for histopathology and molecular markers. A) Progression-free survival, according to the presence of $\mathrm{Cl}$ (CIS excluded): lesions with $\mathrm{Cl}$ versus lesions without $\mathrm{Cl}$. Lesions with $\mathrm{Cl}$ show a significantly increased risk for malignant progression $(P=0.0022)$. B) Progression-free survival according to the presence of $\mathrm{Cl}$ (in hyperplasia, mild and moderate dysplasia only); lesions with $\mathrm{Cl}$ versus lesions without $\mathrm{Cl}$. Lesions with $\mathrm{Cl}$ are strongly at risk for malignant progression $(P=0.0006)$. C) Progression-free survival according to p53-status (CIS lesions excluded). Lesions with p53-overexpression (p53+) versus lesions without p53 overexpression (p53-). P53+ shows a tendency towards a worse progression-free survival, however non-significant $(P=0.063)$. D) Progression-free survival according to p53-status (in hyperplasia, mild and moderate dysplasia only). Lesions with p53overexpression (p53+) versus lesions without p53-overexpression (p53-), difference between groups is not significant $(P=0.149)$. E) Progression-free survival according to histopathological diagnosis (CIS excluded), non- significant difference between groups $(P=0.13)$. F) Progression-free survival for severe dysplasia versus the joined group of hyperplasia, mild and moderate dysplasia. Severe dysplasia has a significantly increased risk for malignant progression $(P=0.038)$. 
A (non-significant) trend towards a worse progression-free survival for p53positive versus p53-negative lesions was found in group $2(P=0.063$, Figure 3.2C), which was not observed in group 3 (Figure 3.2D). In group 2 the $\mathrm{Cl}$ positive patients with p53-overexpression showed a significantly shortened progression-free survival $(P=0.0344)$ compared with the p53-negative patients (results not shown).

Progression-free survival analysis according to histopathological classification revealed no significant difference between the concomitant histopathological subgroups, as shown in Figure 3.2E. However, a significantly shortened progression-free survival was found for severe dysplasia as compared to the combined group of hyperplasia, mild and moderate dysplasia $(P=0.038)$ (Figure 3.2F). In group 3 no significant association with malignant outcome was found. Cyclin D1, FADD or pFADD did not significantly influence progression-free survival (results not shown).

A summary of clinical and molecular patient data is shown in Table 3.2.

Table 3.2 Summary of clinical and molecular data of 51 patients with premalignant lesions of the larynx.

\begin{tabular}{|c|c|c|c|c|c|c|c|c|c|}
\hline $\begin{array}{l}\text { Patient- } \\
\text { number }\end{array}$ & $\begin{array}{l}\text { e at biopsy } \\
\text { (yrs) }\end{array}$ & $\begin{array}{l}\text { Follow-up } \\
\text { time (yrs) }\end{array}$ & Histopatholog & $\mathrm{yCl}$ & ${ }^{*} \mathrm{p} 53^{t}$ & $\mathrm{FADD}^{\ddagger}$ & $\begin{array}{c}\mathrm{pFADD} \\
(\%)\end{array}$ & $\begin{array}{c}\text { Cyclin D1 } \\
(\%)\end{array}$ & Outcome \\
\hline 1 & 45 & 16.3 & $\mathrm{HP}$ & - & - & - & 20 & & NED \\
\hline 2 & 66 & 14.9 & $\mathrm{HP}$ & - & - & - & 60 & 10 & NED \\
\hline 3 & 44 & 5.1 & $\mathrm{HP}$ & - & + & - & 90 & 5 & NED \\
\hline 4 & 65 & 1.1 & $\mathrm{HP}$ & + & + & - & 40 & 10 & ScC \\
\hline 5 & 47 & 20.1 & MD & - & - & - & 20 & 30 & NED \\
\hline 6 & 23 & 14 & $M D$ & - & - & - & 40 & 10 & NED \\
\hline 7 & 52 & 6.1 & MD & - & - & - & 60 & 10 & $\mathrm{SCC}$ \\
\hline 8 & 74 & 8.9 & MD & - & - & - & 70 & 30 & NED \\
\hline 9 & 35 & 3.9 & MD & - & - & - & 50 & 5 & NED \\
\hline 10 & 71 & 5.8 & MD & - & - & - & 80 & 10 & NED \\
\hline 11 & 58 & 17.1 & MD & - & + & - & 80 & 0 & NED \\
\hline 12 & 78 & 13.8 & MD & - & + & - & 60 & 10 & NED \\
\hline 13 & 65 & 3.4 & MD & - & + & - & 80 & 15 & SCC \\
\hline 14 & 61 & 17.4 & MD & + & - & - & 60 & 0 & SCC \\
\hline 15 & 50 & 3 & MD & + & - & & 80 & 20 & SCC \\
\hline 16 & 54 & 2.2 & MD & + & - & - & 70 & 5 & SCC \\
\hline 17 & 80 & 2 & MD & + & - & + & 90 & 20 & SCC \\
\hline 18 & 56 & 1.8 & MD & + & + & - & 90 & 30 & SCC \\
\hline 19 & 55 & 4.2 & MDD & - & - & - & 40 & 1 & CIS \\
\hline 20 & 76 & 5.5 & MDD & - & - & - & & 30 & NED \\
\hline 21 & 63 & 5 & MDD & - & - & - & 80 & 50 & NED \\
\hline 22 & 72 & 17.5 & MDD & - & + & - & 60 & 2 & NED \\
\hline 23 & 25 & 5.2 & MDD & - & + & - & 70 & 10 & NED \\
\hline 24 & 51 & 4.5 & MDD & - & + & - & 90 & 10 & CIS \\
\hline 25 & 75 & 1.2 & MDD & - & + & & 60 & 10 & SCC \\
\hline 26 & 79 & 0.9 & MDD & + & - & - & 35 & 20 & SCC \\
\hline 27 & 55 & 16.4 & MDD & + & - & - & 80 & 20 & SCC \\
\hline 28 & 69 & 18.8 & MDD & + & - & - & 70 & 1 & NED \\
\hline 29 & 67 & 9.7 & MDD & + & - & - & 70 & 30 & NED \\
\hline
\end{tabular}


Table 3.2 (continued)

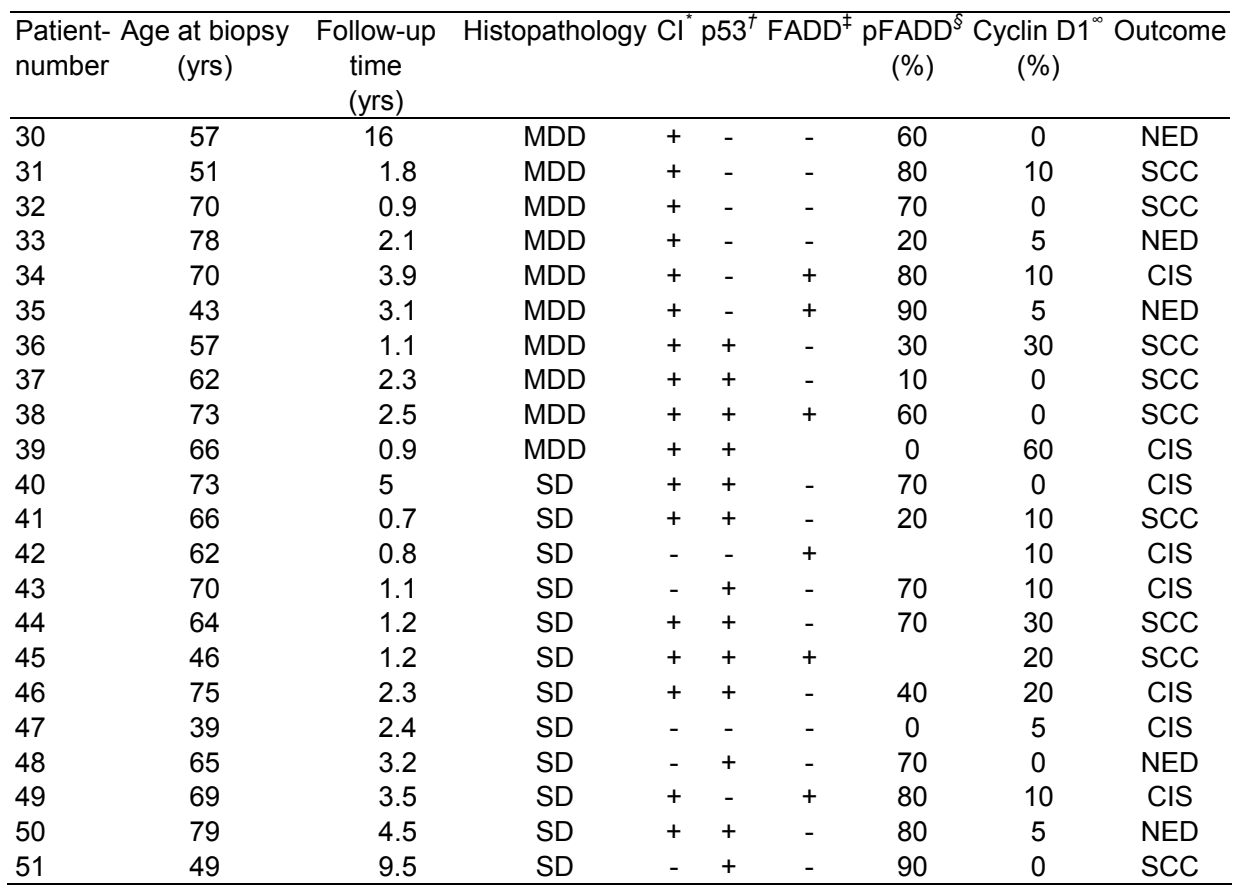

HP, hyperplasia; MD, mild dysplasia; MDD, moderate dysplasia; SD, severe dysplasia; NED, No evidence of disease; SCC, squamous cell carcinoma; CIS, carcinoma in situ. " $\mathrm{Cl}(-)$, balanced chromosome 1 and 7 copy numbers and (+), imbalances chromosome 1 and 7 copy numbers. ${ }^{+}$ $p 53(-)$, no or only few cells with nuclear staining and (+), either multiple cells with nuclear staining above the basal cell layer, or tissue areas with $\geq 10 \%$ stained cell nuclei. ${ }^{\ddagger} F A D D$ : (-) no or weak expression and $(+)$ intermediate or strong expression. ${ }^{\S} p F A D D$ : the percentage of cells with strong nuclear staining. ${ }^{\infty}$ Cyclin D1: (-) nuclear staining in $\leq 10 \%$ of cells, and (+) nuclear staining in $>10 \%$ of cells.

\section{Multivariate progression model for combined markers}

Based on the results of the univariate logistic regression analysis in group 2, multivariate model was obtained including $\mathrm{Cl}$ and other markers with predictive value i.e. p53, FADD and histopathological diagnosis. This resulted in the best prognostic tool with a sensitivity of $80 \%$ and a specificity of $71 \%$ and a Receiver Operating Characteristic (ROC) curve with an Area Under the Curve (AUC) of 0.82, which represents a good predicting model (Figure 3.3.). For group 3 , only p53 contributed positively to the model based on $\mathrm{Cl}$, resulting in a sensitivity op $90 \%$ and specificity of $74 \%$; AUC $=0.81$ (Figure 3.3 ). 


\section{Multivariate progression model for combined markers}

Based on the results of the univariate logistic regression analysis in group 2, multivariate model was obtained including $\mathrm{Cl}$ and other markers with predictive value i.e. p53, FADD and histopathological diagnosis. This resulted in the best prognostic tool with a sensitivity of $80 \%$ and a specificity of $71 \%$ and a Receiver Operating Characteristic (ROC) curve with an Area Under the Curve (AUC) of 0.82, which represents a good predicting model (Figure 3.3.). For group 3 , only p53 contributed positively to the model based on $\mathrm{Cl}$, resulting in a sensitivity op $90 \%$ and specificity of $74 \%$; AUC $=0.81$ (Figure 3.3).

\section{Confounders}

The influence of the potential confounders gender, age, tobacco smoking and alcohol consumption was also analyzed. Non-alcohol-users had a significantly better prognosis than alcohol users $(P=0.02)$, however, in multivariate analysis with $\mathrm{Cl}$ alcohol use did not contribute to outcome prediction.
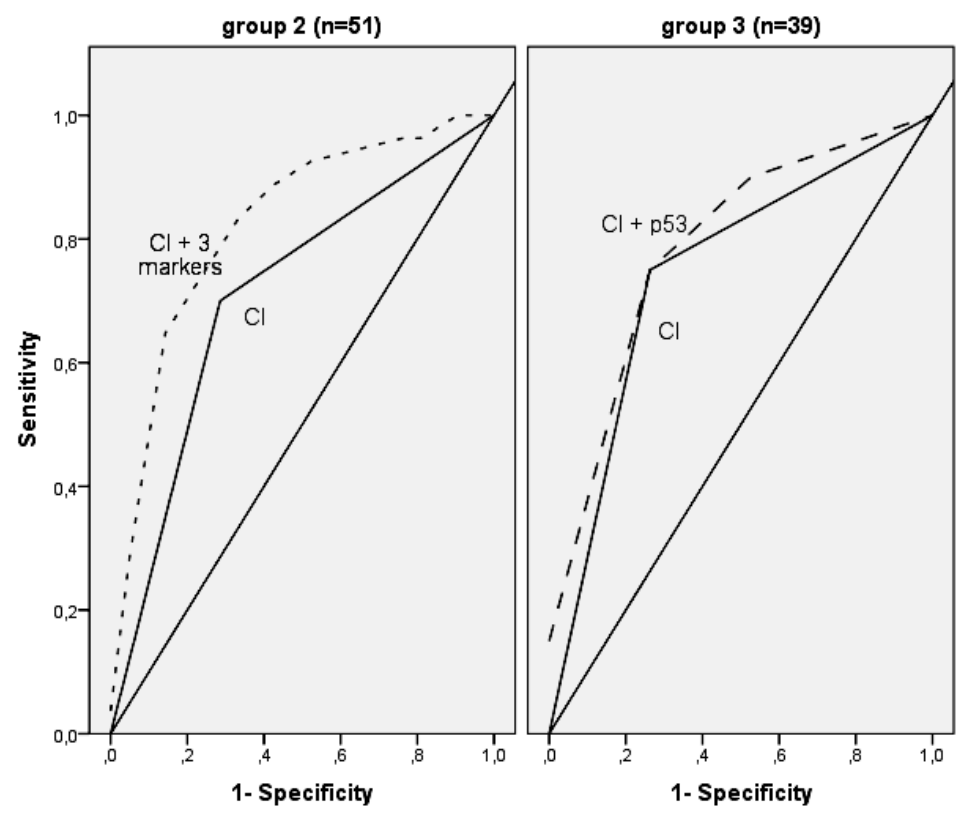

Figure 3.3 Receiver operating characteristic (ROC) curves for the progression model of $\mathrm{Cl}, \mathrm{Cl}$ with the following additional markers: histopathological assessment, p53 and FADD (Area Under the Curve $(A \cup C)=0.82)$ and also for $\mathrm{Cl}+\mathrm{p} 53$ in group $3(n=39$, severe dysplasia cases excluded); $A \cup C=0.81$ ). 


\section{Discussion}

Early detection of potentially malignant precursor lesions is a key-issue in reducing patient morbidity and mortality of HNSCC. As routine histopathological assessment does not provide reliable information on the risk of malignant outgrowth of these lesions, as is also shown in this study, there is a need for other markers to predict progression. Such a diagnostic method should not only be reliable but also easy implementable in daily clinical practice. Therefore, in this study we have investigated the value of $\mathrm{Cl}, \mathrm{p} 53$, Cyclin D1, FADD and pFADD protein overexpression as potential prognosticators in premalignant laryngeal lesions in relation to histopathological classification. We found an increasing level of $\mathrm{Cl}$ with advancing histopathological grade. This is in line with the current molecular progression models showing $\mathrm{Cl}$ development early in head and neck tumorigenesis. ${ }^{1,3,11} \mathrm{Cl}$ proved to be significantly associated with malignant progression $(\mathrm{OR}=5.8)$, and this association was even stronger in low-grade lesions including hyperplasia, mild and moderate dysplasia $(\mathrm{OR}=8.4)$. Patients with $\mathrm{Cl}$ containing lesions showed a significantly shorter progression-free survival. None of the other individually tested markers was clearly able to predict progression in univariate analysis. The best multivariate risk-model consisted of $\mathrm{Cl}$, histopathological assessment, p53 and FADD with a sensitivity of $80 \%$ and a specificity of $71 \%$. In low-grade lesions only p53 contributed positively to $\mathrm{Cl}$ in the risk-model (sensitivity $90 \%$, specificity $75 \%$ ). The fact that Cyclin D1 and pFADD immunostainings are of less importance in this model might be explained by the fact that strong cyclin D1 and pFADD expression is observed both in lesions with and without $\mathrm{Cl}$, reflecting a disruption of the balance between cell proliferation and apoptosis in tumorigenesis without association with malignant outgrowth. We found high FADD expression in only $15 \%$ of cases, 6 of which were progressive and harboured $\mathrm{Cl}$. Therefore, FADD overexpression seems not to be an early event in carcinogenesis but rather indicates later molecular changes associated with progression. Six of the Cl-containing cases did not show malignant progression, which may be explained by the radical excision of potentially malignant cells during biopsy. On the other hand, 9 of the remaining 24 lesions without $\mathrm{Cl}$ showed progression nevertheless. This interesting finding suggests that a certain group of premalignant lesions without $\mathrm{Cl}$ may progress to a diploid tumor. ${ }^{5}$ Four of the $\mathrm{Cl}$-negative and progressive lesions showed p53 overexpression and one of these was classified as high-FADD, indicating that p53 analysis could possibly contribute to a reduction of false-negative cases in this specific group of $\mathrm{Cl}$-negative lesions.

Carcinogenic mechanisms that can be involved in Cl-negative lesions include infection with high risk-HPV viruses ${ }^{35-37}$ (although this is usually confined to the oropharynx), microsatellite instability, ${ }^{38,39}$ narrow amplicons e.g. on 
chromosomes $8 \mathrm{q}$ or $11 \mathrm{q} 13,{ }^{40,41}$ or inactivation of tumor suppressor genes by promotor hypermethylation or truncation of its gene product. ${ }^{42,43}$

This study confirms and extends the results of our previous analyses ${ }^{25}$ and is in agreement with earlier reported FISH results on oral premalignant lesions and histologically tumor free resection margins, showing numerical aberrations of chromosomes 1 and 7 as indicators for malignant progression or tumor recurrence, respectively. ${ }^{4,21,22}$ This assay is easily applicable in routine molecular diagnostics, and the use of only one 4- $\mu \mathrm{m}$ paraffin tissue section for analysis of $\mathrm{Cl}$ makes the approach extremely useful for laryngeal biopsies that are often small in size.

In conclusion, this study shows that $\mathrm{Cl}$ as an individual marker can predict malignant progression in premalignant laryngeal lesions, especially in lowergrade premalignancies, in which histopathological examination does not provide reliable information on malignant potential. $\mathrm{Cl}$ analysis by $\mathrm{FISH}$ can, in contrast to other molecular diagnostic techniques, easily be incorporated in the standard clinical routine of risk-counselling of premalignant head and neck lesions, which may eventually minimize patient morbidity. Validation of our results in a larger patient population is however required. 


\section{References}

1. Haddad RI, Shin DM. Recent advances in head and neck cancer. New Engl J Med 2008;359:1143-54.

2. Neville BW, Day TA. Oral cancer and precancerous lesions. CA Cancer J Clin 2002;52:195-215.

3. Mao L, Hong WK, Papadimitrakopoulou VA. Focus on head and neck cancer. Cancer Cell 2004;5:311-6.

4. Bergshoeff VE, Hopman AH, Zwijnenberg IR, et al. Chromosome instability in resection margins predicts recurrence of oral squamous cell carcinoma. J Pathol 2008;215:347-8.

5. Leemans $\mathrm{CR}$, Braakhuis BJ, Brakenhoff RH. The molecular biology of head and neck cancer. Nature rev Cancer 2011;11:9-22.

6. Slaughter DP, Southwick HW, Smejkal W. Field cancerization in oral stratified squamous epithelium; clinical implications of multicentric origin. Cancer 1953;6:963-8.

7. Agrawal N, Frederick MJ, Pickering CR, et al. Exome sequencing of head and neck squamous cell carcinoma reveals inactivating mutations in NOTCH1. Science 2011;333:1154-7.

8. Eversole LR. Dysplasia of the upper aerodigestive tract squamous epithelium. Head Neck Pathol 2009;3:63-8.

9. Fleskens SA, Bergshoeff VE, Voogd AC, et al. Interobserver variability of laryngeal mucosal premalignant lesions: a histopathological evaluation. Mod Pathol 2011;24:892-8.

10. Gale N, Michaels L, Luzar B, et al. Current review on squamous intraepithelial lesions of the larynx. Histopathol 2009;54:639-56.

11. Califano J, van der Riet $P$, Westra W, et al. Genetic progression model for head and neck cancer: implications for field cancerization. Cancer Res 1996;56:2488-92.

12. Lee JJ, Hong WK, Hittelman WN, et al. Predicting cancer development in oral leukoplakia: ten years of translational research. Clin Cancer Res 2000;6:1702-10.

13. Partridge M, Pateromichelakis S, Phillips E, et al. Profiling clonality and progression in multiple premalignant and malignant oral lesions identifies a subgroup of cases with a distinct presentation of squamous cell carcinoma. Clin Cancer Res 2001;7:1860-6.

14. Rosin MP, Cheng X, Poh C, et al. Use of allelic loss to predict malignant risk for low-grade oral epithelial dysplasia. Clin Cancer Res 2000;6:357-62.

15. Zhang L, Poh CF, Williams M, et al. Loss of heterozygosity (LOH) profiles-validated risk predictors for progression to oral cancer. Cancer Prev Res 2012;5:1081-9.

16. Hogmo A, Munck-Wikland E, Kuylenstierna R, et al. Nuclear DNA content and p53 immunostaining in metachronous preneoplastic lesions and subsequent carcinomas of the oral cavity. Head Neck 1996; 18:433-40.

17. Abou-Elhamd KE, Habib TN. The flow cytometric analysis of premalignant and malignant lesions in head and neck squamous cell carcinoma. Oral Oncol 2007;43:366-72

18. Garnis C, Chari R, Buys TP, et al. Genomic imbalances in precancerous tissues signal oral cancer risk. Molec Cancer 2009;8:50.

19. Voravud N, Shin DM, Ro JY, et al. Increased polysomies of chromosomes 7 and 17 during head and neck multistage tumorigenesis. Cancer Res 1993;53:2874-83. 
20. Ai H, Barrera JE, Meyers AD, et al. Chromosomal aneuploidy precedes morphological changes and supports multifocality in head and neck lesions. Laryngoscope 2001;111:1853-8.

21. van der Toorn PP, Veltman JA, Bot FJ, et al. Mapping of resection margins of oral cancer for p53 overexpression and chromosome instability to detect residual (pre)malignant cells. J Pathol 2001; 193:66-72.

22. Poh CFY ZY, Sun R, Tseng I-L, Zhang L, Rosin MP Unique FISH patterns associated with biological aggressiveness of potentially malignant oral lesions. Proc AACR 2006;47:212 (abstract 900).

23. Munck-Wikland $E$, Kuylenstierna R, Lindholm J, et al. p53 immunostaining and image cytometry DNA analysis in precancerous and cancerous squamous epithelial lesions of the larynx. Head Neck 1997; 19:107-15.

24. Veltman JA, van Weert I, Aubele $M$, et al. Specific steps in aneuploidization correlate with loss of heterozygosity of $9 p 21,17 p 13$ and $18 q 21$ in the progression of pre-malignant laryngeal lesions. Int J Cancer 2001;91:193-9.

25. Veltman JA, Bot FJ, Huynen FC, et al. Chromosome instability as an indicator of malignant progression in laryngeal mucosa. J Clin Oncol 2000;18:1644-51.

26. Jeannon JP, Soames JV, Aston V, et al. Molecular markers in dysplasia of the larynx: expression of cyclin-dependent kinase inhibitors p21, p27 and p53 tumor suppressor gene in predicting cancer risk. Clinical Otolaryngol Allied Sci 2004;29:698-704.

27. Pignataro L, Capaccio $P$, Pruneri $G$, et al. The predictive value of $p 53$, MDM-2, cyclin D1 and Ki67 in the progression from low-grade dysplasia towards carcinoma of the larynx. J Laryngol Otol 1998;112: 455-9.

28. Schuuring E. The involvement of the chromosome $11 \mathrm{q} 13$ region in human malignancies: cyclin D1 and EMS1 are two new candidate oncogenes--a review. Gene 1995;159:83-96.

29. Izzo JG, Papadimitrakopoulou VA, Li XQ, et al. Dysregulated cyclin D1 expression early in head and neck tumorigenesis: in vivo evidence for an association with subsequent gene amplification. Oncogene 1998;17:2313-22.

30. Gibcus JH, Menkema L, Mastik MF, et al. Amplicon mapping and expression profiling identify the Fas-associated death domain gene as a new driver in the 11q13.3 amplicon in laryngeal/pharyngeal cancer. Clin Canc Res 2007;13: 6257-66.

31. Kaminagakura E, Werneck da Cunha I, Soares FA, et al. CCND1 amplification and protein overexpression in oral squamous cell carcinoma of young patients. Head Neck 2011;33:1413-9

32. Papadimitrakopoulou V, Izzo JG, Liu DD, et al. Cyclin D1 and cancer development in laryngeal premalignancy patients. Cancer Prev Res 2009;2:14-21.

33. Prapinjumrune $\mathrm{C}$, Morita $\mathrm{KI}$, Kuribayashi $\mathrm{Y}$, et al. DNA amplification and expression of FADD in oral squamous cell carcinoma. J Oral Pathol Med 2009;39:525-32.

34. Hopman $\mathrm{AH}$, Kamps MA, Speel EJ, et al. Identification of chromosome 9 alterations and p53 accumulation in isolated carcinoma in situ of the urinary bladder versus carcinoma in situ associated with carcinoma. Am J Pathol 2002; 161:1119-25.

35. Hafkamp HC, Mooren JJ, Claessen SM, et al. P21 Cip1/WAF1 expression is strongly associated with HPV-positive tonsillar carcinoma and a favorable prognosis. Mod Pathol 2009;22:686-98. 
36. Kreimer AR, Villa A, Nyitray AG, et al. The epidemiology of oral HPV infection among a multinational sample of healthy men. Cancer Epidemiol Biomarkers Prev 2011;20:172-82.

37. Manjarrez ME, Ocadiz R, Valle L, et al. Detection of human papillomavirus and relevant tumor suppressors and oncoproteins in laryngeal tumors. Clin Cancer Res 2006;12:6946-51.

38. Ha PK, Pilkington TA, Westra WH, et al. Progression of microsatellite instability from premalignant lesions to tumors of the head and neck. Int $\mathrm{J}$ Canc 2002; 102:615-7.

39. Sardi I, Franchi A, De Campora L, et al. Microsatellite instability as an indicator of malignant progression in laryngeal premalignancy. Head Neck 2006;28:730-9.

40. Garnis C, Coe BP, Ishkanian A, et al. Novel regions of amplification on $8 q$ distinct from the MYC locus and frequently altered in oral dysplasia and cancer. Gene Chromosom Canc 2004;39:93-8.

41. Snijders A, Bhattacharya A, Dekker N, et al. Rare narrow amplicons in oral cancers and pre-cancers. Oral Oncology- Head Neck Oncol \& Pathol- Suppl 2007;2:65.

42. Calmon MF, Rodrigues RV, Kaneto CM, et al. Epigenetic silencing of CRABP2 and MX1 in head and neck tumors. Neoplasia 2009;11:1329-39.

43. Snijders AM, Schmidt BL, Fridlyand J, et al. Rare amplicons implicate frequent deregulation of cell fate specification pathways in oral squamous cell carcinoma. Oncogene 2005;24:4232-42. 


\section{Chapter}

CHROMOSOME INSTABILITY PREDICTS THE PROGRESSION OF PREMALIGNANT ORAL LESIONS

Theodorus J.H. Siebers*, Verona E. Bergshoeff*, Irene Otte-Höller, Bernd Kremer, Ernst-Jan M. Speel,

Jeroen W.M. van der Laak, Matthijs A.W. Merkx, Piet J. Slootweg

* These authors contributed equally to this study Oral Oncology 2013;49(12):1121-8 


\section{Abstract}

\section{Objectives}

One of the main problems in reducing the incidence of oral squamous cell carcinoma (OSCC) is the inability to appropriately deal with leukoplakia. Accurately identifying lesions which will progress to malignancy is currently not possible. The present study aims to establish the value of chromosome instability $(\mathrm{Cl})$ detection by DNA image cytometry and FISH analysis for prognosis and monitoring of oral leukoplakia

\section{Materials and methods}

For this purpose, we included from our archives 102 oral leukoplakia cases, which had been diagnosed between 1991 and 2008. Patient follow-up data were collected and the histopathological diagnosis was revised. $\mathrm{Cl}$ assessment was carried out on paraffinembedded tissue sections using both DNA image cytometry (ICM) and dual target FISH for chromosomes 1 and 7 .

\section{Results}

16 of 102 patients developed carcinoma in situ or OSCC. Both detection methods were found to yield prognostic information independent of the histopathological diagnosis. $\mathrm{Cl}$ was a strong individual marker of progression, with Hazard Ratios (HR) of 7.2 and 6.8 for ICM and FISH respectively. Moreover, this approach seems suitable for monitoring lesions over time, (especially ICM). Combining histopathology and $\mathrm{Cl}$ enables subdivision of patients into three risk groups, with different probabilities of malignant progression.

\section{Conclusion}

$\mathrm{Cl}$ detection seems a reliable method for risk assessment of oral premalignancies and its application may contribute to a better risk-counselling and appropriate treatment regimen or watchful-waiting approach of patients. 


\section{Introduction}

Oral cancer is the sixth most common malignancy worldwide, with a yearly incidence of about 274.000 cases. ${ }^{1}$ Most oral tumours are squamous cell carcinomas (SCCs) with smoking and alcohol consumption as major risk factors. ${ }^{1,2}$ In contrast to cancers of the breast, colon, prostate and melanoma that are showing a significantly better prognosis due to improvements in early detection and therapy ${ }^{3}$, the survival rate of patients with oral squamous cell carcinomas (OSCC) has not increased substantially over the last decades. ${ }^{2,4}$ The oral cavity and oropharynx are easily accessible for visualization, which may facilitate early diagnosis of (pre)malignant lesions. Nevertheless, in spite of advances in surgical and other treatment modalities, the 5-year survival rate of OSCC remains only approximately $50 \%{ }^{2,3}$ This lack of progress can partially be explained by our inability to adequately recognize early developed OSCC as well as precursor lesions at risk for progression. ${ }^{3}$

Oral leukoplakia and, to a lesser degree, erythroplakia are relatively common lesions of the oral mucosa, some of which are at risk for malignant transformation. ${ }^{5}$ In particular, the borders of the tongue and the floor of the mouth have been mentioned as high-risk sites. ${ }^{6}$ Whereas oral erythroplakia show malignant transformation in almost all cases, oral leukoplakia eventually progress to malignancy in an estimated $1.1-17.5 \% .^{7}$ Therefore, especially discrimination between potentially malignant leukoplakias and non-harmful lesions is of key importance.

Unfortunately, current histopathological examination of precursor lesions (i.e. dysplastic and non-dysplastic) is insufficiently accurate to predict their malignant potential. ${ }^{8}$ In addition, histopathological classification is hampered by observer variability ${ }^{9,10}$ and sampling variability. ${ }^{11}$ Therefore, more effective methods for the assessment of the malignant potential of oral leukoplakia are urgently needed. ${ }^{12}$ It is widely believed that instability of the genome is the driving force behind the development of the majority of human epithelial cancers. ${ }^{13} \mathrm{Cl}$ may be detected by different molecular biological approaches. DNA content analysis using image cytometry (ICM) or flow cytometry (FCM) are frequently used techniques., ${ }^{414,15,16,17}$ Three recently published retrospective studies have shown that ICM is able to identify patients with dysplasias that are more likely to progress to OSCC. ${ }^{14,16,17} \mathrm{FCM}$ displays an increasing degree of aneuploidy in the spectrum of lesions ranging from healthy oral mucosa, non-dysplastic and dysplastic leukoplakia to OSCC. ${ }^{15}$ Alternatively, copy number alterations of individual chromosome loci can be studied using fluorescence in situ hybridization (FISH) analysis. ${ }^{18,19,20,21}$ Several studies on FISH for chromosomes 1 and 7 revealed that numerical 
chromosome aberrations have a predictive value in the progression of oral precursor lesions to SCC. ${ }^{18,19,22}$

The aim of the present study was to establish the value of $\mathrm{Cl}$ detection by means of both ICM and FISH in comparison with routine histopathological assessment for the risk assessment of oral precursor lesions in a series of 102 leukoplakia. In addition, we evaluated both essays for their reliability to monitor possible progression of premalignant lesions over time.

\section{Materials and methods}

\section{Patient selection}

This retrospective study included patients who were admitted to the department of Oral and Maxillofacial Surgery at the Radboud University Nijmegen Medical Centre (RUNMC), The Netherlands, between 1991 and 2008 for evaluation of suspicious lesions of the oral mucosa. The minimal follow-up time was 6 months. Patients with oral hyperplastic or dysplastic lesions were identified using the Dutch Pathology diagnosis and registration system (PALGA). Patients who had been previously treated for malignancy as well as patients with a histologically confirmed carcinoma in situ at first biopsy were excluded. Clinical data including age, etiological factors, localization, type of treatment (surgery, laser ablation or expectative policy) were obtained from the patients' medical charts. Only patients with a complete data-set were included, resulting in 102 specimens (of 102 patients). Data collection was performed in accordance with local ethical guidelines.

ICM and FISH analyses were performed on biopsy specimens obtained at the time of the first diagnosis of leukoplakia and on specimens from eventually developed carcinoma (carcinoma in situ or invasive carcinoma). The time between consecutive lesions was set at a minimum of six months in order to exclude synchronous lesions. To assess the value of ICM and FISH for the monitoring of lesions over time, subsequent premalignant lesions and recurrent malignancies were analysed.

For each case of leukoplakia and SCC first a $4 \mu \mathrm{m}$ thick slide was cut from a paraffin-embedded specimen for Haematoxylin-eosin (HE) analysis followed by three $50 \mu \mathrm{m}$ and two $4 \mu \mathrm{m}$ sections for ICM and FISH respectively and ending again with one $4 \mu \mathrm{m}$ slide for HE analysis. The first and last slides of the initial leukoplakia were haematoxylin-eosin stained and revised by an experienced pathologist (PJS). In this manner it could be assured that both ICM and FISH analysis were performed on representative areas, to enhance the accuracy of the test. 


\section{DNA ploidy measurement of isolated nuclei from tissue sections}

Two to four $50 \mu \mathrm{m}$ thick paraffin-embedded sections were used to isolate cell nuclei according to well-established procedures. ${ }^{10} \mathrm{~A}$ thickness of $50 \mu \mathrm{m}$ was shown to minimize the number of artefacts in DNA histograms. ${ }^{23}$ Sections were deparaffinised and rehydrated as follows: xylene (three times 15 minutes), $100 \%$ ethanol (twice), 96\% ethanol (twice), $70 \%$ ethanol, $40 \%$ ethanol, distilled water and phosphate-buffered saline (PBS) at least ten minutes in each solution. The tissue sections were transferred into a centrifuge tube and incubated with $0.5 \%$ pepsin (Sigma Aldrich, St Louis, MO, USA) in PBS (pH $1.50)$ at 37 degree Celsius, for 60 minutes. After enzymatic digestion, $4 \mathrm{ml}$ of ice-cold PBS was added to stop the reaction. Next the tissue suspension was filtered through a CellTrics filter with $50 \mu \mathrm{m}$ pore size to separate nuclei from tissue debris. After centrifugation (1000 rpm, $10 \mathrm{~min}$ ), $2 \mathrm{ml}$ PBS was added and the amount of nuclei was counted with a cell-counting device (Z1 Coulter Particle Counter $\circledast$, Beckman Coulter Inc., Woerden, The Netherlands). The cell suspension was diluted until the right concentration, (20 000 cells) was reached, to form a monolayer in a cytospin-centrifuge (10 minutes $700 \mathrm{rpm}$ ), air dried, and fixed in Böhm fixative for 1 hour, hence a mixture of $85 \%$ methanol absolute, $10 \%$ formaldehyde $(37 \%)$, and $5 \%$ acetic acid $(96 \%)$. Slides were air dried after twice rinsing in methanol absolute.

\section{Feulgen staining}

First the cell preparations were hydrolysed in $5 \mathrm{M} \mathrm{HCl}$ under controlled temperature at $25^{\circ} \mathrm{C}$ for one hour, after which the process was stopped using distilled water. Thereupon the isolated nuclei were stained by the Schiff method $^{10}$ (Merck ${ }^{\circledR}$, Darmstadt, Germany) for 1 hour at room temperature. Next the slides were rinsed in streaming tap water for 20 minutes, dehydrated in increasing concentrations of ethanol, xylol and mounted in Permount $₫$ (Thermo Fisher Scientific, Landsmeer, The Netherlands).

\section{Measurement of DNA content}

All measurements were performed using the Leica QPath Image Cytometry Workstation (Leica Microsystems $\mathrm{GmbH}$, Wetzlar, Germany) according to an established protocol. ${ }^{10}$ Slides of stained cell nuclei were analysed using a microscope equipped with a 550-nm green filter and a computer controlled stage. Each monolayer contained at least 1500 sampled nuclei. The QPath software measures the Feulgen integrated optical density (IOD) of individual nuclei while avoiding the measurement of overlapping, folded, or clumped cells. ICM analysis of all histological specimens was performed in a blinded fashion at the RUNMC. DNA ploidy histograms were visually classified independently 
by two experienced observers ( $\mathrm{JvdL} ; \mathrm{IOH})$. In all cases of discrepancy, a consensus classification was reached by the same two observers.

In the present study, a diploid histogram is defined by a single dominant $2 \mathrm{c}$ peak (representing $G_{0} / G_{1}$ phase cells) and possibly a $4 c$ peak ( $G_{2}$ phase cells) not exceeding 10 percent of the total number of nuclei (Figure 4.1A). If the number of nuclei with a DNA content $>5 c$ exceeded 1 percent of the total number of cells, the histogram was classified as aneuploid. Also, a histogram was classified as aneuploid if there was a clear and distinct peak outside the $2 \mathrm{c} / 4 \mathrm{c}$ regions (Figure 4.1B). A lesion was defined as tetraploid if the number of $4 \mathrm{c}$ nuclei exceeded 10 percent of the total number of epithelial cells and a $8 \mathrm{c}$ peak was observed. The measurements were performed according to previous published guidelines. ${ }^{24}$ Because in some cases the coefficient of variation (CV: standard deviation of the 2c peak divided by the mean, given in percent) slightly exceeded the advised threshold of $5 \%, C V s$ up to $6 \%$ were allowed in the present study.
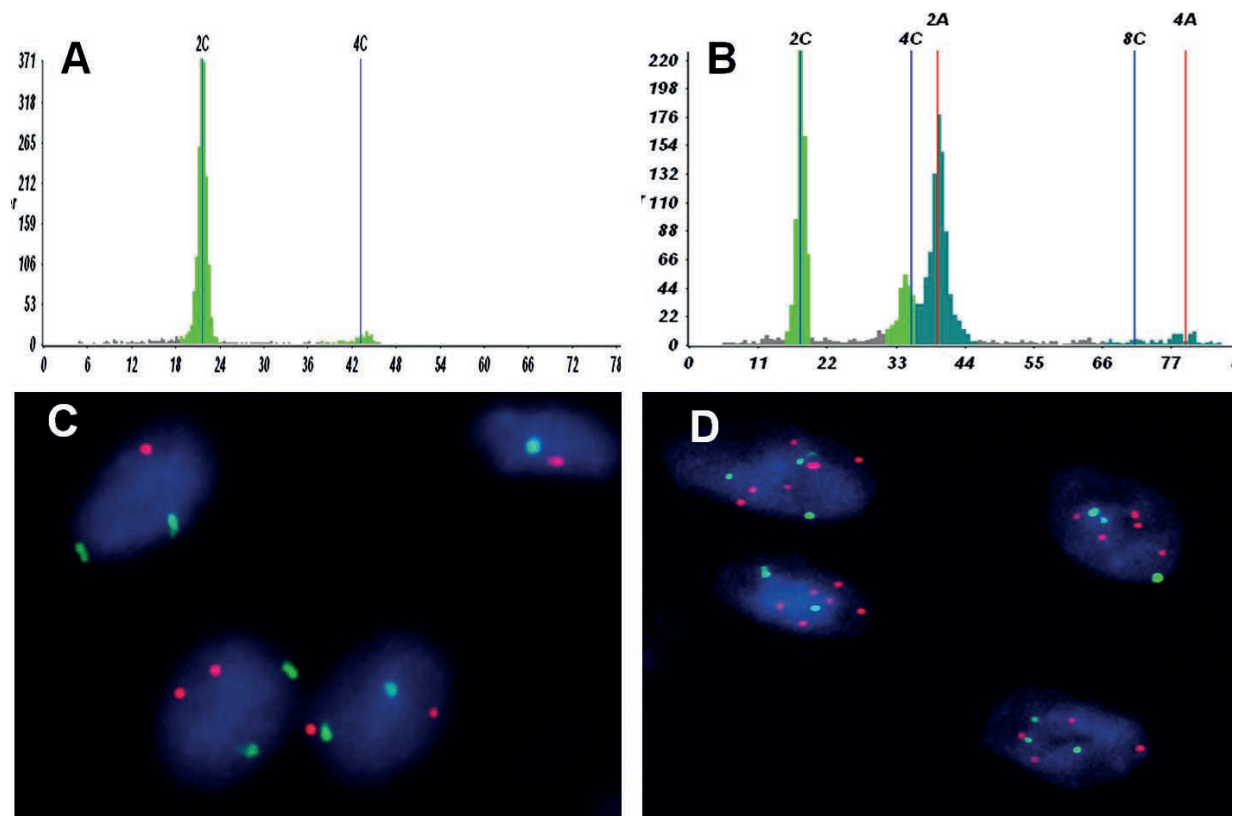

Figure 4.1 Examples of ICM ploidy histograms A) diploid pattern, B) typical aneuploidy pattern. C, D. Representative examples of FISH results using centromere probes specific for chromosome 1 (green) and 7 (red) in cell nuclei (blue) of head and neck oral mucosa epithelium. C) Nuclei showing disomy for both chromosomes. D) Nuclei showing an imbalance between the copy number of chromosomes 1 (maximal 4 copies) and 7 (maximal 6 copies). 


\section{Double-target fluorescence in situ hybridisation (FISH) on tissue specimens}

FISH was performed at the University of Maastricht Medical Centre, Department of Molecular Cell Biology. The procedure was performed as described previously. ${ }^{10,25}$ Briefly, $4 \mu \mathrm{m}$ thick paraffin-embedded tissue specimens were first deparaffinised and pretreated with $85 \%$ formic acid $/ 0.3 \%$ $\mathrm{H}_{2} \mathrm{O}_{2}$ at room temperature $1 \mathrm{M}$ sodium thiocyanate $(\mathrm{NaSCN})$ at $80^{\circ} \mathrm{C}$ and $0.4 \mathrm{~g}$ pepsin (800 to $1200 \mathrm{U} / \mathrm{mg}$ protein porcine stomach mucosa (Sigma Aldrich, St Louis, MO, USA) per $\mathrm{ml} 0.02 \mathrm{NHCl}$ at $37^{\circ} \mathrm{C}$. Slides were post-fixed with $1 \%$ formaldehyde in PBS and dehydrated with an ascending series of ethanol. The probes for chromosome 1 and 7 were prepared by labelling with biotin- and digoxigenin-dUTPs and dissolved at a concentration of $1 \mathrm{ng} / \mu \mathrm{l}$ in $60 \%$ formamide, $2 x$ standard saline citrate (SSC, $\mathrm{pH} 7.0$ ), 10\% dextran sulphate, and 50 times excess of carrier DNA (salmon testis DNA; Sigma Chemical Co, St Louis, MO). After denaturation of probe and tissue at $80^{\circ} \mathrm{C}$ for $5 \mathrm{~min}$ and overnight hybridization the tissue specimens were washed stringently in $2 x$ SSC containing $0.05 \%$ Tween-20 (Acros Organics, Geel, Belgium) two times for $5 \mathrm{~min}$ at $42^{\circ} \mathrm{C}$, followed by $0.1 \times S S C$ two times for $5 \mathrm{~min}$ at $60^{\circ} \mathrm{C}$ and $4 \times S S C / 0.05 \%$ Tween-20 at room temperature.

Detection of the hybridised probes was established with the following antibody combinations diluted in 4xSSC containing $5 \%$ non-fat dry milk powder: FITClabeled avidin (Vector, 1:100)/ anti-digoxigenin monoclonal antibody (1:200, Mannheim); Biotinylated Goat Anti-Avidin (Vector, 1:100)/ rabbit anti mouse TRITC (Vector, 1:1000) and FITC-labeled avidin (1:100)/ swine anti rabbit TRITC (Vector, 1:100). Following the final wash and dehydration, slides were mounted in Tris glycerol, containing 2\% DACO Antifade (Glostrup, Denmark) and $0.5 \mu \mathrm{g} / \mathrm{ml}$ of the nuclear DNA counterstain DAPI. An example of FISH results is shown in Figures $1 \mathrm{C}$ and D. Evaluation of the FISH results was carried out as described in our previous studies. ${ }^{10,22,25}$

\section{Data analysis}

Clinical data, histopathological characteristics and ICM and FISH scores of all lesions were statistically analysed using SPSS version 17.0.1 software (SPSS Inc., Chicago, USA). The progression into carcinoma was analysed using uniand multivariate Cox regression analyses and hazard ratios (HR) including its 95\% confidence intervals $(\mathrm{Cl})$ and associated p-values were calculated. Cumulative progression towards malignancy analysis was performed by means of the Kaplan Meier method. In all analyses the p-value for significance was set at 0.05 . To assess the degree of agreement between ICM and FISH k-statistics were calculated. 


\section{Results}

\section{Patient characteristics and outcome}

Of the 102 patients diagnosed with leukoplakia, $48(47 \%)$ were female and 54 $(53 \%)$ were male (Table 4.1$)$. The duration of follow-up after the first biopsy ranged from 6 to 246 months (median 91.5). Malignant progression occurred in 16 patients ( 5 developed carcinoma in situ and 11 invasive carcinoma). The median follow-up time of these patients was 27.0 months (range: 7-151). Progressive lesions were located on the floor of mouth $(n=2)$, tongue $(n=10)$, buccal mucosa $(n=3)$ and inferior alveolar rim $(n=1)$. Carcinomas developed at the same location as the preceding leukoplakias $(n=13)$, or within a range of 2 centimetres of the initial lesion $(n=3)$ (Warren and Gates criteria). ${ }^{26}$

\section{Clinical parameters}

Table 4.3 gives an overview of the HRs of different clinical parameters. Location was associated with risk of malignant development: leukoplakia of the floor of mouth or tongue had a significantly higher risk of malignant progression $(\mathrm{HR}=3.2 ; P=0.047)$. Older patients were slightly more susceptible to malignant transformation with a HR of $1.1(P=0.025)$. No correlation was found between the type of treatment and developed SCC (data not shown).

Table 4.1 Patient characteristics based upon primary premalignancies.

\begin{tabular}{llcc}
\hline Patient data & & \multicolumn{2}{c}{ Malignant } \\
No & Transformation \\
\hline Number of patients & & 86 & 16 \\
Age & Mean (years) & 51.9 & 57.8 \\
& Cl (95\%) & $(49.6-54.2)$ & $(50.9-64.7)$ \\
Sex & Female & 41 & 7 \\
& Male & 45 & 9 \\
Smoking & Yes & 54 & 9 \\
& No & 32 & 5 \\
& In history & 9 & 1 \\
& Data NA & 2 & 1 \\
Alcohol & Yes & 39 & 7 \\
& No & 40 & 8 \\
\multirow{3}{*}{ Follow-up } & Data NA & 4 & 1 \\
& Median (months) & 98.0 & 27.0 \\
\hline
\end{tabular}

\section{Histopathology}

An overview of the histological diagnosis for each case of leukoplakia related to malignant progression can be found in Table 4.2 (first two columns). Because of the low number of severe dysplasias $(n=3)$, in the present study these 
lesions were pooled with moderate dysplasias for further analyses. This is in accordance with the review by Warnakulasuriya et al. ${ }^{27}$ In univariate Cox regression, histopathological diagnosis was associated with malignant transformation with a hazard ration $(\mathrm{HR})$ of $6.3(\mathrm{Cl}: 2.3-17.3 ; P<0.001$; Table 4.3) comparing the combination of hyperplasia and mild dysplasia with moderate and severe dysplasia. Figure 4.2 shows the corresponding survival curves.

Table 4.2 Fraction of hyperplastic and dysplastic lesions transformed into malignancies

\begin{tabular}{lccccc}
\hline Histopathology & $\begin{array}{c}\text { Number of } \\
\text { SCC after } \\
\text { leukoplakia }\end{array}$ & $\begin{array}{c}\text { Number of } \\
\text { SCC after } \\
\text { diploid } \\
\text { leukoplakia } \\
(\text { ICM) }\end{array}$ & $\begin{array}{c}\text { Number of SCC } \\
\text { after aneuploid } \\
\text { leukoplakia } \\
\text { (ICM) }\end{array}$ & $\begin{array}{c}\text { Number of } \\
\text { SCC after } \\
\text { diploid } \\
\text { leukoplakia } \\
(\text { FISH) }\end{array}$ & $\begin{array}{c}\text { Number of SCC } \\
\text { after aneuploid } \\
\text { leukoplakia } \\
\text { (FISH) }\end{array}$ \\
\hline All & $16 / 102$ & $6 / 79(7.6 \%)$ & $10 / 23(43.5 \%)$ & $8 / 85(9.4 \%)$ & $8 / 17(47.1 \%)$ \\
HP & $(15.7 \%)$ & & & & \\
D+ & $5 / 66(7.6 \%)$ & $4 / 59(6.8 \%)$ & $1 / 7(14.3 \%)$ & $4 / 63(6.3 \%)$ & $1 / 3(33.3 \%)$ \\
D++ & $7 / 16(18.8 \%)$ & $0 / 11(0.0 \%)$ & $3 / 5(60.0 \%)$ & $0 / 11(0.0 \%)$ & $3 / 5(60.0 \%)$ \\
D+++ & $1 / 3(41.2 \%)$ & $2 / 9(22.2 \%)$ & $5 / 8(62.5 \%)$ & $3 / 10(30.0 \%)$ & $4 / 7(57.1 \%)$ \\
\hline
\end{tabular}

$\mathrm{HP}=$ hyperplastic, $\mathrm{D+=}$ ild dysplasia, $\mathrm{D++=}$ oderate dysplasia, $\mathrm{D+++=}$ +evere dysplasia.

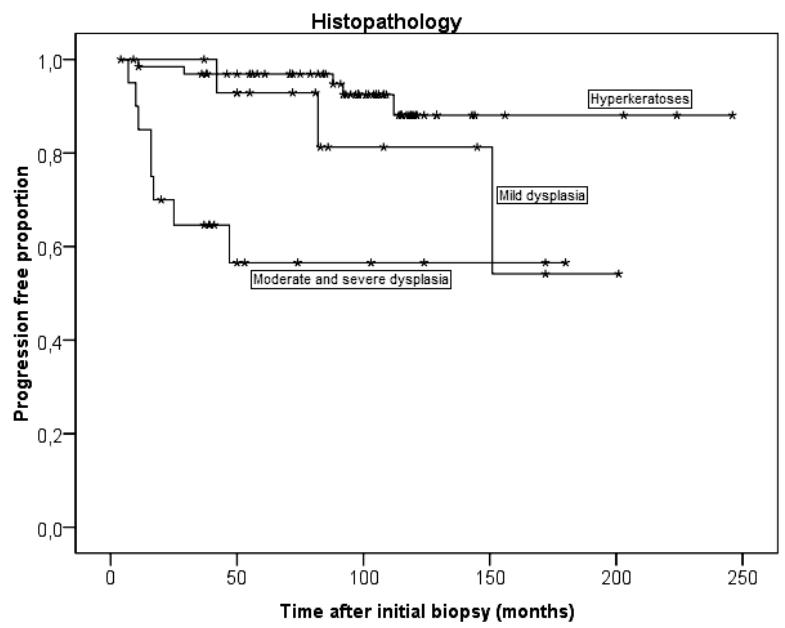

Figure 4.2 Outcome of patients with leukoplakia of the oral cavity, based upon histopathology. Comparing the combination of hyperplasia and mild dysplasia with moderate dysplasia and severe dysplasia results in $\mathrm{HR}=6.3(\mathrm{Cl}: 2.32-17.25)(P<0.001)$. 
Table 4.3 Progression-free period and different assays as well as clinical parameters determined by uni- and multivariate Cox regression analyses. Floor of mouth and tongue were considered to be high-risk locations, all other sites low-grade.

\begin{tabular}{|c|c|c|c|c|c|}
\hline \multirow[b]{2}{*}{ Variable } & \multicolumn{2}{|c|}{$\begin{array}{c}\text { Univariate Cox regression } \\
\text { Analysis }\end{array}$} & \multicolumn{3}{|c|}{ Multivariate Cox regression analysis } \\
\hline & Hazard Ratio & $p$-Value & \multicolumn{3}{|c|}{ Hazard Ratio } \\
\hline & & & \multicolumn{3}{|c|}{ Corrected for: } \\
\hline & & & Histopath. & ICM & FISH \\
\hline Histopathology & $\begin{array}{c}6.3 \\
(2.32-17.25)\end{array}$ & $<0.001$ & - & $\begin{array}{c}4.1 \\
(1.42-11.80) \\
(P=0.009)\end{array}$ & $\begin{array}{c}3.9 \\
(1.31-11.50) \\
(P=0.014)\end{array}$ \\
\hline $\begin{array}{l}\text { DNA image } \\
\text { cytometry }\end{array}$ & $\begin{array}{c}7.2 \\
(2.61-20.03)\end{array}$ & $<0.001$ & $\begin{array}{c}5.4 \\
(1.82-15.77) \\
(P=0.002)\end{array}$ & - & $\begin{array}{c}4.2 \\
(0.99-17.59) \\
(P=0.052\end{array}$ \\
\hline FISH & $\begin{array}{c}6.8 \\
(2.53-18.30)\end{array}$ & $<0.001$ & $\begin{array}{c}4.4 \\
(1.50-13.08) \\
(P=0.007)\end{array}$ & $\begin{array}{c}2.3 \\
(0.57-9.27) \\
(P=0.24)\end{array}$ & - \\
\hline Age & $\begin{array}{c}1.1 \\
(1.01-1.10)\end{array}$ & 0.025 & & & \\
\hline Sex & $\begin{array}{c}1.2 \\
(0.42-3.11)\end{array}$ & 0.79 & & & \\
\hline Location & $\begin{array}{c}3.2 \\
(1.02-9.82)\end{array}$ & 0.047 & & & \\
\hline Treatment & $\begin{array}{c}0.9 \\
(0.29-2.93)\end{array}$ & 0.88 & & & \\
\hline Alcohol & $\begin{array}{c}1.1 \\
(0.98-1.23)\end{array}$ & 0.098 & & & \\
\hline Tobacco & $\begin{array}{c}0.9 \\
(0.32-2.73)\end{array}$ & 0.74 & & & \\
\hline Pack Years & $\begin{array}{c}1.0 \\
(0.94-1.02)\end{array}$ & 0.29 & & & \\
\hline
\end{tabular}

$\mathrm{Cl}=95 \%$ confidence interval

\section{Chromosome instability}

As tetraploid lesions ( $\mathrm{n}=3$ for both ICM and FISH) harbour an abnormal DNA content, ${ }^{28,29,30}$ these lesions were included in the aneuploid group. ICM analysis revealed 23 aneuploid vs. 79 diploid lesions (23\%) and FISH showed 17 aneuploid vs. 85 diploid lesions (16\%). Comparison of FISH and ICM revealed an identical outcome in 90 out of 102 leukoplakia (Table 4.4). The kappa statistic for this comparison was 0.63 , which indicates a substantial agreement between both methods. ( $\mathrm{Cl}$ : 0.44-0.82). The percentage of aneuploidy increased with advancing histopathological classification. Of the aneuploid lesions detected by respectively ICM and FISH, 10 of $23(43.5 \%)$ and 8 of 17 $(47.1 \%)$ showed malignant progression. In contrast, only 6 out of $79(7.6 \%)$ and 8 of $85(9.4 \%)$ of diploid leukoplakia showed malignant progression for ICM and FISH, respectively (Table 4.2). Univariate Cox regression analysis 
revealed an increased risk of malignant progression for aneuploid lesions (both ICM (HR=7.2; $P<0.001)$ and FISH (HR=6.8; $P<0.001)$; Table 4.3). This is also reflected in the progression-free survival curves based on $\mathrm{Cl}$ detection, showing a significantly shorter survival for aneuploid lesions (Figure 4.3-4.4). Including both FISH and ICM in multivariate Cox regression analysis showed decrease of the HR for both techniques (ICM: HR=4.2; $P=0.052$ respectively FISH: $\mathrm{HR}=2.3$; $P=0.240$; Table 4.3) for ICM and $\mathrm{FISH}$, respectively), indicating that both techniques yield comparable information.

Table 4.4 Correlation-table ICM and FISH.

\begin{tabular}{lcccc}
\hline & & FISH & \\
& & Diploid & Aneuploid & Total \\
\hline ICM & Diploid & 76 & 3 & 79 \\
& Aneuploid & 9 & 14 & 23 \\
& Total & 85 & 17 & 102 \\
\hline
\end{tabular}

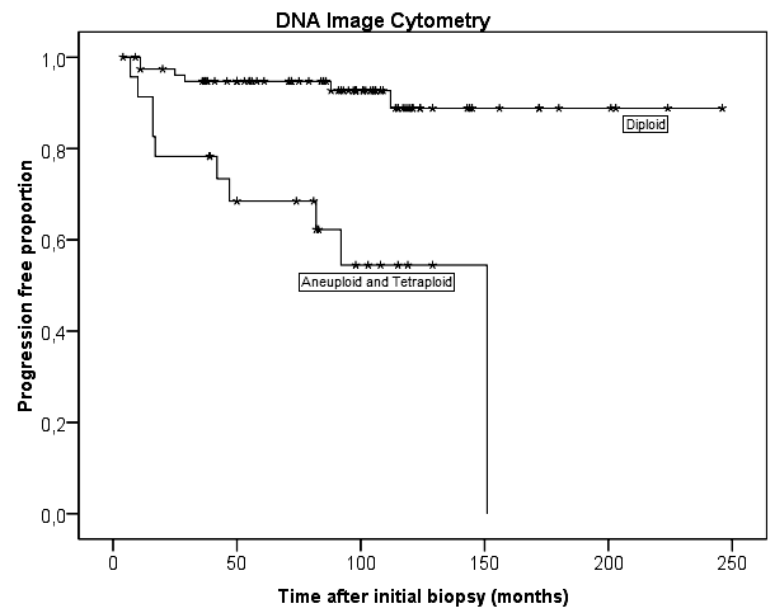

Figure 4.3 Kaplan-Meier curve of the progression free proportion of based upon ICM. HR=7.2 (Cl: 2.61-20.03) $(P<0.001)$.

\section{Combining histopathology and $\mathrm{Cl}$}

In multivariate Cox regression analysis, ICM adjusted for histopathology showed a HR of $5.4(\mathrm{Cl}$ : 1.82-15.8; $P=0.002$; Table 4.3). In this analysis histopathology and ICM appeared to be rather independent, complementary factors. Therefore, multivariate analysis was also performed by comparing 4 combined classes i.e.: low-grade diploid, high-grade diploid, low-grade aneuploid and high-grade aneuploid lesions (high grade being defined as moderate or severe dysplasia, low grade encompassing the other 
histopathological categories). Taking diploid low grade lesions as the reference category, the HR of aneuploid high-grade lesions was found to be as high as 22.0 (Cl: 5.78-83.45); $P<0.001$ ), with lesions being either high-grade diploid or low-grade aneuploid showing HR of $4.3(\mathrm{Cl}: 0.76-23.92 ; P=0.101)$ and 5.5 (Cl: 1.37-21.96; $P=0.016$ ), respectively (Table 4.5). Because the latter two groups showed comparable HRs they were combined in progression-free survival analysis (Figure 4.5).

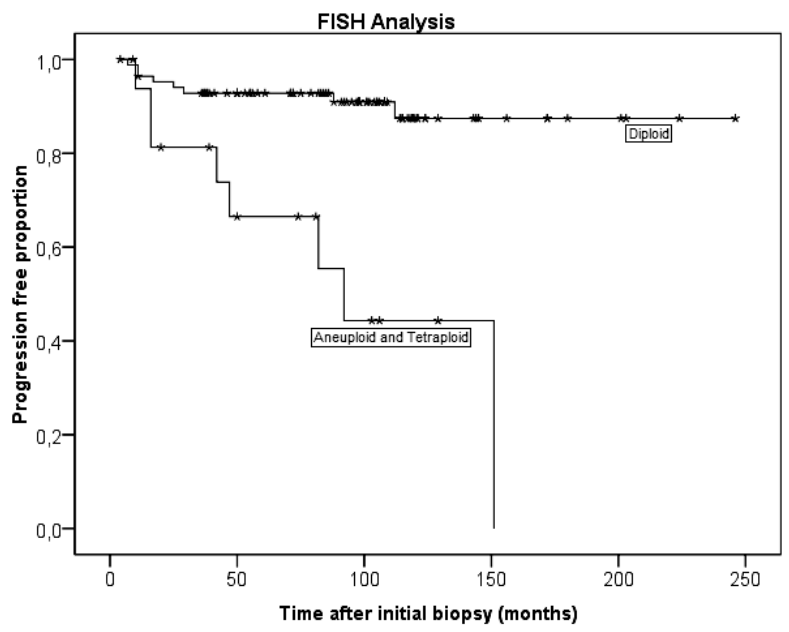

Figure 4.4 Kaplan-Meier curve of the progression free proportion of based upon FISH. HR=6.8 (Cl: 2.53-18.30) $(P<0.001)$.

FISH adjusted for histopathology showed a HR of $4.4(\mathrm{Cl}: 1.5-13.1 ; P<0.01$; Table 4.3). Combining histopathology and FISH in multivariate Cox regression in a manner comparable to that described above for ICM and histopathology, similar results were obtained (Table 4.5). Aneuploid high-grade lesions show a HR of 16.3 ( $\mathrm{Cl}$ : 3.90-68.18; $p<0.001$ ) compared to low grade diploid lesions, with lesions being either high-grade diploid or low-grade aneuploidy showing HR of 9.0 ( $\mathrm{Cl}: 2.21-36.9 ; P=0.002$ ) and 10.1 ( $\mathrm{Cl}: 2.52-40.4 ; P=0.001)$. When the latter two groups were combined a HR of 9.5 ( $\mathrm{Cl}: 2.85-32.00 ; P<0.001)$ was found in progression-free survival analysis as compared to low grade diploid lesions, but was not significantly different from aneuploid high-grade lesions (HR 1.71 with $\mathrm{Cl}: 0.49-6.0 ; P=0.40$ ). 


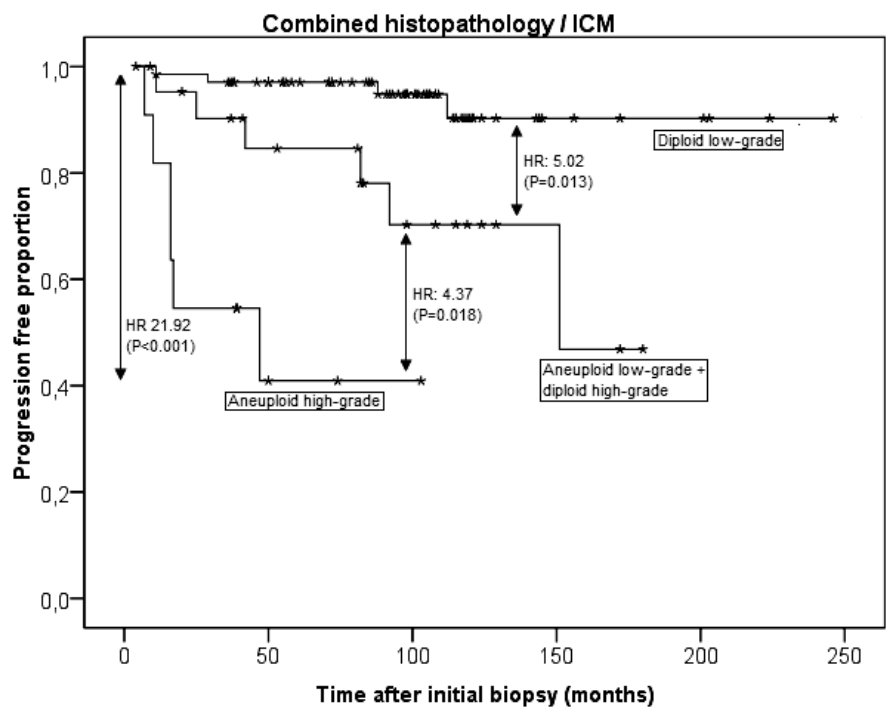

Figure 4.5 Outcome of the ICM combined with histopathological subclasses. Aneuploid low-grade combined with diploid high-grade: HR: $5.0(\mathrm{Cl}: 1.41-17.89)(P=0.013)$ ( adjusted to diploid low-grade). Aneuploid high-grade HR: 21.9 (Cl: 5.78-83.18) $(P<0.001)$ (adjusted to diploid low-grade). Aneuploid high-grade: HR: 4.4 (Cl: 1.29-14.70) $(P=0.018)$ (adjusted to aneuploid low-grade + diploid high-grade).

Table 4.5 Level of association of ICM/FISH and different histopathological classes with progression free survival.

\begin{tabular}{|c|c|c|c|c|}
\hline \multicolumn{5}{|l|}{ Histopathology } \\
\hline DNA Image Cytometry & \multicolumn{2}{|c|}{ Low-grade (HP and D+) } & \multicolumn{2}{|c|}{ High-grade ( $\mathrm{D}++$ and $\mathrm{D}+++)$} \\
\hline Diploid & Reference & $\mathrm{N}=70$ & $\begin{array}{c}\text { HR: } 4.3 \\
(\mathrm{Cl}: 0.76-23.92) \\
(P=0.101)\end{array}$ & $\mathrm{N}=9$ \\
\hline Aneuploid & $\begin{array}{c}\text { HR: } 5.5 \\
(\mathrm{Cl}: 1.37-21.96) \\
(P=0.016)\end{array}$ & $\mathrm{N}=12$ & $\begin{array}{c}\text { HR: } 22.0 \\
(\mathrm{Cl}: 5.78-83.45) \\
(P<0.001)\end{array}$ & $N=11$ \\
\hline \multicolumn{5}{|l|}{ FISH analysis } \\
\hline Diploid & Reference & $\mathrm{N}=74$ & $\begin{array}{c}\text { HR: } 9.04 \\
(\mathrm{Cl}: 2.21-36.9) \\
(P=0.002)\end{array}$ & $N=11$ \\
\hline Aneuploid & $\begin{array}{c}\text { HR: } 10.1 \\
(\mathrm{Cl}: 2.52-40.4) \\
(P=0.001)\end{array}$ & $\mathrm{N}=8$ & $\begin{array}{c}\text { HR: } 16.3 \\
(\mathrm{Cl}: 3.90-68.18) \\
(P<0.001)\end{array}$ & $N=9$ \\
\hline
\end{tabular}

Low-grade: combination of hyperplasia and mild dysplasia. High-grade: combination of moderate and severe dysplasia. 


\section{Monitoring}

ICM revealed that almost all aneuploid malignancies resulted from aneuploid precursor lesions (9 out of 10) and almost all diploid carcinoma had a diploid precursor lesion (5 out of 6 ; FISH showed more variability: 4/8 respectively $5 / 8$ ). Interestingly, two aneuploid leukoplakias developed after 9.3 and 12.6 years into an aneuploid SCC (based on ICM).

Also analysis of intermediate precursor lesions and recurrent SCC was performed (Tables 4.6 and 4.7). From seven initial premalignancies showing progression to SCC, subsequent biopsies were available. Leukoplakia and subsequent malignancies were considered to be related if they were found at the same mucosal location.

Six of seven cases (ICM-based) showed that the ploidy status of the successive lesions (both premalignant lesions and SCC) was identical to the status of the initial lesion. Only one initial aneuploid leukoplakia was followed by both a diploid leukoplakia and a diploid SCC (patient 1; Table 4.6). Interestingly, three initially aneuploid lesions without malignant progression for which subsequent leukoplakia specimens were available, showed transition from aneuploid to diploid lesions (ICM-based) (Table 4.7). Additionally, 6 (ICMbased) diploid initial leukoplakia without malignant progression were followed by diploid leukoplakia on the same location (FISH: 4 diploid; 2 not available). (data not shown). Five patients treated for SCC developed new leukoplakia at the same location (Table 4.6).

Table 4.6 Sequential ploidy scores represent mucosal disorders developed subsequently.

\begin{tabular}{lccccc}
\hline Patient & $\begin{array}{c}\text { Initial } \\
\text { premalignancy }\end{array}$ & $\begin{array}{c}\text { Intermediate } \\
\text { premalignancies }\end{array}$ & SCC & $\begin{array}{c}\text { Intermediate } \\
\text { premalignancies }\end{array}$ & $\begin{array}{c}\text { Recurrent } \\
\text { SCC(s) }\end{array}$ \\
\hline 1 & $\mathrm{~A}$ & $\mathrm{D}$ & $\mathrm{D}$ & $\mathrm{A}$ & $\mathrm{A}$ \\
2 & $\mathrm{~A}$ & $\mathrm{AA}$ & $\mathrm{A}$ & & $\mathrm{A}$ \\
3 & $\mathrm{~A}$ & $\mathrm{~A}$ & $\mathrm{~A}^{\mathrm{a}} \mathrm{D}$ & $\mathrm{A}^{\mathrm{a}} \mathrm{AA}$ & $\mathrm{A}^{\mathrm{b}}$ \\
4 & $\mathrm{~A}$ & $\mathrm{~A}$ & $\mathrm{~A}$ & & $\mathrm{~A}^{\mathrm{a}}$ \\
5 & $\mathrm{D}$ & $\mathrm{D}$ & $\mathrm{D}$ & & \\
6 & $\mathrm{D}$ & & $\mathrm{D}$ & $\mathrm{D}^{\mathrm{b}} \mathrm{D}^{\mathrm{b}}$ & \\
7 & $\mathrm{~A}$ & $\mathrm{~A}$ & $\mathrm{~A}$ & $\mathrm{~A}$ & $\mathrm{AA}$ \\
8 & $\mathrm{~A}$ & $\mathrm{~A}$ & $\mathrm{~A}^{\mathrm{a}}$ & & \\
9 & $\mathrm{D}$ & & $\mathrm{D}$ & $\mathrm{D}$ & \\
\hline
\end{tabular}

$A=$ aneuploid lesion; $D=$ diploid lesion. All values represent the same scores for ICM and FISH except the cases marked with ${ }^{a}$ (ICM is aneuploid and FISH diploid). ${ }^{b} \mathrm{FISH}$ data not available. 
Table 4.7 Monitoring of three patients with multiple leukoplakia without malignant transformation.

\begin{tabular}{|c|c|c|c|c|c|c|}
\hline Patient & $\begin{array}{l}\text { Biopsy } \\
\text { year }\end{array}$ & Biopsy Site & Histopathology & ICM & $\mathrm{FISH}$ & Treatment \\
\hline \multirow[t]{4}{*}{10} & 1999 & FOM front & D+++ & A & A & Laser \\
\hline & 2000 & FOM front & D+++ & D & A & Laser \\
\hline & 2002 & FOM front & $\mathrm{D}+++$ & D & D & Laser \\
\hline & 2006 & \multicolumn{5}{|c|}{ End of follow-up } \\
\hline \multirow[t]{2}{*}{11} & 2004 & Buccal mucosa left & $\mathrm{D}+++$ & A & A & Surgery \\
\hline & $\begin{array}{l}2007 \\
2010\end{array}$ & $\begin{array}{l}\text { Buccal mucosa left } \\
\text { End of follow up }\end{array}$ & $\mathrm{D}+++$ & $\mathrm{D}$ & D & Expectative \\
\hline \multirow[t]{3}{*}{12} & 1997 & Trig. Retromolare right & D++ & A & D & Expectative \\
\hline & 1997 & Trig. Retromolare right & HP & D & A & Expectative \\
\hline & 2001 & \multicolumn{4}{|c|}{ Patient died because of heart failure } & \\
\hline
\end{tabular}

FOM=floor of mouth; Trig=trigonum; HP =hyperplasia; $\mathrm{D++=moderate} \mathrm{dysplasia;} \mathrm{D+++=}$ severe dysplasia; $D=$ diploid; $A=$ aneuploid). Precursor lesions described in bold is the first biopsied lesion.

\section{Discussion}

In this study we analysed the added value of $\mathrm{Cl}$ for the assessment of the malignant potential of oral leukoplakia, using two techniques (ICM and dual target FISH for chromosomes 1 and 7). Previous studies established that histopathology is only partly successful in predicting future behaviour of premalignant oral lesions. ${ }^{8,9,11,12}$ Data of the present study show that $\mathrm{Cl}$ assessed by the two different approaches is an independent prognosticator, providing valuable information in addition to the histopathological diagnosis. Combining these sources of information, three groups of leukoplakia possessing respectively low, intermediate and high risk for malignant transformation may be discriminated. Moreover, it was found that $\mathrm{Cl}$ detected by ICM might be a useful tool to monitor lesions over time. Generally, successive aneuploid premalignancies ultimately resulted in (aneuploid) tumours, whereas a shift from an aneuploid to a diploid status suggested a favourable prognosis.

Our data concerning the prognostic value of the ploidy status of oral leukoplakia are largely concordant with existing literature. ${ }^{14,16,17}$ In the present study, aneuploid oral lesions showed malignant progression in $43.5 \%$ to $47.1 \%$ (detected by ICM and FISH, respectively). Similar percentages are found in other studies. ${ }^{14,16,17}$ Also in line with these studies, not all aneuploid leukoplakia transformed into malignancies. The results might be explained by the fact that these studies (including the present study) are based upon retrospective data, harbouring different intervention modalities (both radical and irradical) which ranged from watchful waiting to surgical excision or laser ablation. As reported by Torres-Rendon et al, $^{14}$ we observed that aneuploid premalignancies are able to transform into SCC after a long time span (in this study one case even 
after 12.6 years). Also, the fact that diploid lesions may progress to SCC was repeatedly found ${ }^{14,16,17}$

In this study, $37.5 \%$ of the developed SCC were found to be diploid (FISH $56.3 \%$ ), which may (at least partly) be explained by the assessment method used. Previous studies found a large variability in the percentage of diploid oral SCC (8-70\%). ${ }^{14,15,31,32}$ The lowest number of diploid SCC (8\%) was found using a very sensitive method ( $\mathrm{CV}$ values as low as $1 \%$ ) applying $\mathrm{FCM} .^{15}$ In the present study using ICM, CV values of approximately $5 \%$ were found, making distinction between diploid and near-diploid populations hazardous. Okafuji et al concluded that sensitive techniques such as comparative genomic hybridisation showed that all oral carcinomas were aneuploid, but that many are not detected as such by techniques as FCM or ICM because of their detection limit. ${ }^{33,35}$ Another factor to consider when assessing ploidy status is heterogeneity within oral lesions as reported before. ${ }^{33,34}$

Baretton et al. showed increased sensitivity for ICM based ploidy assessment, measuring 'in situ' in histological sections, rather than isolating whole nuclei from paraffin blocks. ${ }^{32}$ Apparently, the possibility of selective sampling of nuclei in suspicious regions enables detection of small aneuploid subpopulations, even when applying a less sensitive measurement procedure. In the present study, three of the initial premalignancies were diploid in ICM but aneuploid in $\mathrm{FISH}$. Besides sampling error an explanation might be the inability of ICM (on whole nuclei) to detect small aneuploid subpopulations in the biopsy specimen. In this study, FISH analysis, which is also applied to selective tissue section areas, identified in general less aneuploid cases compared to ICM, resulting in decreased sensitivity for predicting progression (with a corresponding increase in specificity). This may be explained by sampling bias or by the fact that FISH only assesses copy number variations of two centromere probes.

The results of Baretton et al. ${ }^{32}$ are in accordance with our previously published data, in which ploidy assessment in tissue sections was combined with assessment of expression of biomarkers Ki67, p53 and yH2AX. ${ }^{10}$ Despite a sufficiently high sensitivity of ICM and FISH also diploid precursor lesions as well as their subsequent tumours may be found. It has been shown previously that a minority of oral lesions follow an alternative genetic pathway, ultimately resulting in an invasive phenotype not harbouring large copy number alterations or chromosome instability. ${ }^{36}$ This phenomenon may also explain the results found in the present study. Further study is therefore recommended. Combining ploidy data with analysis of biomarkers relevant for this alternative pathway even may yield additional information and increase sensitivity. ${ }^{10}$

Subdivision of leukoplakia into three risk levels, based on the combined histopathology and $\mathrm{Cl}$ analysis may lead to a more appropriate patient 
treatment. Both ICM as well as FISH are suitable for this approach. In this study, aneuploid high grade dysplasia (comprising $11 \%$ of cases) had a progression free survival of approximately $40 \%$ after 4 years (HR of 22.0 compared to low histological grade diploid cases). Similar results were published previously (HR of 19.3 for aneuploid high grade dysplasias, which constituted $8 \%$ of the population). ${ }^{17}$ In comparison, $37.5 \%$ of OSCC patients showed recurrence in a comparable time interval after treatment. ${ }^{37}$ Therefore, considering these lesions to be similar to OSCC in terms of treatment options may be considered. On the other end, diploid low grade leukoplakia are largely devoid of malignant transformation ( $<3 \%$ after 6 years), justifying a 'wait and see' policy. Especially for cases of mild and moderate dysplasia, $\mathrm{Cl}$ analysis may be used to tune clinical management. Results from this study suggest that an aneuploid mild dysplasia is comparable to a diploid moderate dysplasia in terms of progression free survival. On the other hand, a diploid mild dysplasia may be eligible for a 'wait and see' policy whereas an aneuploid moderate dysplasia may demand treatment comparable to an OSCC. In this way, $\mathrm{Cl}$ analysis may greatly reduce the number of cases of intermediate malignant potential, which are inherently difficult to manage.

With regard to the option of using $\mathrm{Cl}$ analysis for monitoring patients over time, promising results were obtained. Considering the low number of cases for which data were available, however, a prospective study is required to confirm this hypothesis.

In conclusion, assessment of $\mathrm{Cl}$ in oral leukoplakia yields independent prognostic information, which may contribute to individual patient management. Different assays may be applied to establish the $\mathrm{Cl}$ status, having their own merits and weaknesses. In the present study the combination of histopathology and $\mathrm{Cl}$ (both ICM and FISH) improved the assessment of the malignant potential and may enable the monitoring of (treated) oral leukoplakia over time. $\mathrm{Cl}$ analysis can help to select patients with a high risk of malignant progression and therefore may identify a subset of leukoplakia suited for stricter follow-up as well as a group of leukoplakia eligible for more aggressive treatment. 


\section{References}

1. Parkin DM, Bray F, Ferlay J, Pisani P. Global cancer statistics, 2002. CA Cancer J Clin 2005;55(2);74-108

2. Mao L, Hong WK, Papadimitrakopoulou VA. Focus on head and neck cancer. Cancer Cell 2004;5:311-6.

3. Mashberg, A. Diagnosis of early oral and oropharyngeal squamous carcinoma: obstacles and their amelioration. Oral Oncol 2000;36:253-5.

4. Reiter R, Gais P, Steuer-Vogt MK, Boulesteix AL, Deutschle T, Hampel R, et al. Centrosome abnormalities in head and neck squamous cell carcinoma (HNSCC). Acta Otolaryngol 2009;129: 205-13.

5. Van der Waal I, Schepman KP, van der Meij EH, Smeele LE. Oral leukoplakia: a clinicopathological review. Oral Oncol 1997;33:291-301.

6. Van der Waal I. Potentially malignant disorders of the oral and oropharyngeal mucosa, classification and present concepts of management. Oral Oncol 2009; 45:317-23.

7. Napier SS, Speight PM. Natural history of potentially malignant oral lesions and conditions: an overview of the literature. J Oral Pathol 2008;37:1-10.

8. Holmstrup P, Vedtofte P, Reibel J, Stoltze K. Long-term treatment outcome of oral premalignant lesions. Oral Oncol 2006;42:461-74.

9. Lumerman $H$, Freedman $P$, Kerpel $S$. Oral epithelial dysplasia and the development of invasive squamous cell carcinoma. Oral Surg Oral Med Oral Pathol Oral Radiol Endod 1995;79:321-9.

10. Fleskens SJ, Takes RP, Otte-Höller I, van Doesburg L, Smeets A, Speel EJ, et al. Simultaneous assessment of DNA ploidy and biomarker expression in paraffinembedded tissue sections. Histopathology 2010;57:14-26.

11. Holmstrup $P$, Vedtofte $P$, Reibel J, Stoltze K. Oral premalignant lesions: is a biopsy reliable? J Oral Pathol Med 2007;36:262-6.

12. Tabor MP, Braakhuis BJ, van der Wal JE, van Diest PJ, Leemans CR, Brakenhoff $\mathrm{RH}$, et al. Comparative molecular and histological grading of epithelial dysplasia of the oral cavity and the oropharynx. J. Pathol 2003;199:354-60.

13. Hanahan D, Weinberg RA. Hallmarks of cancer: the next generation. Cell 2011;144:646-74.

14. Torres-Rendon A, Stewart R, Craig GT, Wells M, Speight PM. DNA ploidy analysis by image cytometry helps to identify oral epithelial dysplasias with a high risk of malignant progression. Oral Oncol 2009;45:468- 73.

15. Donadini A, Maffei M, Cavallero A, Pentenero M, Malacarne D, Di Nallo E, et al. Oral cancer genesis and progression: DNA near-diploid aneuploidization and endoreduplication by high resolution flow cytometry. Cell Oncol 2010;32:373-83.

16. Bradley G, Odell EW, Raphael S, Ho J, Le LW, Benchimol S, et al. Abnormal DNA content in oral epithelial dysplasia is associated with increased risk of progression to carcinoma. Br J Cancer 2010;103:1432-42.

17. Bremmer JF, Brakenhoff RH, Broeckaert MA, Beliën JA, Leemans CR, Bloemena $E$, et al. Prognostic value of DNA ploidy status in patients with oral leukoplakia. Oral oncol 2011;47:956-60.

18. Veltman JA, Hopman AH, van der Vlies SA, Bot FJ, Ramaekers FC, Manni JJ. Double-target fluorescence in situ hybridization distinguishes multiple genetically aberrant clones in head and neck squamous cell carcinoma. Cytometry 1998; $34: 113-20$. 
19. Veltman JA, Bot FJ, Huynen FC, Ramaekers FC, Manni JJ, Hopman AH. Chromosomal instability as an indicator of malignant progression in laryngeal mucosa. J Clin Oncol 2000;18:1644-51.

20. Voravud N, Shin DM, Ro JY, Lee JS, Hong WK, Hittelman WN. Increased polysomies of chromosomes 7 and 17 during head and neck multistage tumourigenesis. Cancer Res 1993;53:2874-83.

21. Ai H, Barrera JE, Meyers AD, Shroyer KR, Varella-Garcia M. Chromosome aneuploidy precedes morphological changes and supports multifocality in head and neck lesions. Laryngoscope 2001; 111:1853-8.

22. Bergshoeff VE, Hopman AH, Zwijnenberg IR, Ramaekers FC, Bot FJ, Kremer B, et al. Chromosome instability in resection margins predicts recurrence of oral squamous cell carcinoma. J. Pathol 2008;215:347-8.

23. Stephenson RA, Gay H, Fair WR, Melamed MR. Effect of section thickness on quality of flow cytometric DNA content determinations in paraffin-embedded tissues. Cytometry 1986;7:41-4.

24. Haroske G, Baak JP, Danielsen H, Giroud F, Gschwendtner A, Oberholzer M, et al. Fourth updated ESACP consensus report on diagnostic DNA image cytometry. Anal Cell Pathol 2001;23:89-95.

25. Hopman AH, Kamps MA, Speel EJ, Schapers RF, Sauter G, Ramaekers FC. Identification of chromosome 9 alterations and p53 accumulation in isolated carcinoma in situ of the urinary bladder versus carcinoma in situ associated with carcinoma. Am J Pathol 2002;161:1119-25.

26. Warren S, Gates O. Multiple primary malignant tumours. A survery of the literature and statistical study. Am J Cancer 1932;16:1358-414.

27. Warnakulasuriya S, Reibel J, Bouquot J, Dabelsteen ES. Oral epithelial dysplasia classification systems: predictive value, utility, weaknesses and scope for improvement. J Oral Pathol Med 2008;37:127-33.

28. Nguyen HG, Ravid K. Tetraploidy/aneuploidy and stem cells in cancer promotion: The role of chromosome passenger proteins. J Cell Physiol 2006;208:12-22.

29. Olaharski AJ, Sotelo R, Solorza-Luna G, Gonsebatt ME, Guzman P, Mohar A, et al. Tetraploidy and chromosomal instability are early events during cervical carcinogenesis. Carcinogenesis 2006;27: 337-43.

30. Storchova Z, Kuffer $\mathrm{C}$. The consequences of tetraploidy and aneuploidy. J Cell Sci 2008;121:3859-66.

31. Das SN, Khare P, Patil A, Pandey RM, Singh M, Shukla NK. Association of DNA pattern of metastatic lymph node with disease free survival in patients with intraoral squamous cell carcinoma. Indian J Med Res 2005;122:216-23.

32. Baretton G, Li X, Stoll C, Fischer-Brandies E, Schmidt M, Löhrs U. Prognostic significance of DNA ploidy in oral squamous cell carcinomas. A retrospective flow and image cytometric study with comparison of DNA ploidy in excisional biopsy specimens and resection specimens, primary tumors and lymph node metastases. Oral Surg Oral Med Oral Pathol Oral Radiol Endod 1995;79:68-76.

33. Diwakar N, Sperandio M, Sherriff M, Brown A, Odell EW. Heterogeneity, histological features and DNA ploidy in oral carcinoma by image-based analysis. Oral Oncol 2005;41:416-22.

34. Slootweg PJ, Giessen MC, Rutgers DH, Wils IS. DNA heterogeneity in metastasizing squamous cell head and neck cancer. J Craniomaxillofac Surg 1993;21:348-50. 
35. Okafuji M, Ita M, Oga A, Hayatsu Y, Matsuo A, Shinzato Y, et al. The relationship of genetic aberrations detected by comparative genomic hybridization to DNA ploidy and tumor size in human oral squamous cell carcinomas. J Oral Pathol Med 2000;29:226-31.

36. Bhattacharya A, Roy R, Snijders AM, Hamilton G, Paguette J, Tokuyasu T, et al. Two distinct routes to oral cancer differing in genome instability and risk for cervical node metastasis. Clin Cancer Res 2011;17:7024-34.

37. Iyer SG, Pradhan SA, Pai PS, Patil S. Surgical treatment outcomes of localized squamous carcinoma of buccal mocosa. Head Neck 2004;26:897-902. 


\section{Chapter}

\section{CHROMOSOME INSTABILITY IN}

RESECTION MARGINS PREDICTS RECURRENCE OF ORAL SQUAMOUS CELL CARCINOMA

Verona E Bergshoeff, Anton H.N. Hopman, Iris R. Zwijnenberg, Frans C.S. Ramaekers, Fredrik J. Bot, Bernd Kremer, Johannes J. Manni,

Ernst-Jan M. Speel

The Journal of Pathology 2008;215(3):347-348 
Oral squamous cell carcinoma (OSCC) has a poor prognosis with a 5-years survival of approximately $50 \%$, partly due to the development of (loco)regional recurrences in $10-30 \%$ of surgically treated patients. ${ }^{1,2}$ These recurrences may arise from histopathologically undetected residual cancer cells and precursor lesions (minimal residual disease) in resection margins. The presence of (pre)malignant cells in resection margins that were apparently tumor-free after histopathological examination can be demonstrated by the use of various molecular and cytochemical assays, including p53 mutation and expression analysis as well as chromosome 1 and 7 copy number detection by the use of in situ hybridization (ISH). ${ }^{3,4}$ Mutations in p53 and chromosome 1 and 7 alterations are common in (pre)malignant head and neck lesions and have been used successfully for risk-assessment of premalignancies. ${ }^{1,5-7}$

In 2001 we have reported on the molecular detection of residual (pre)malignant cells in the resection margins of 20 oral cancers that were radically resected between 1994 and $1997 .{ }^{4}$ None of these patients did receive any additional treatment and no follow-up data were reported at that time. Resection margins were examined by ISH for chromosome instability $(\mathrm{Cl})$, defined as the presence of chromosome 1 and 7 copy number imbalances and/or polysomy, and by immunohistochemistry for nuclear p53 overexpression in squamous epithelial cells. Table 5.1 summarizes these molecular data, showing 8 out of 19 cases with (pre)malignant cell nuclei harboring $\mathrm{Cl}$ (see Figure 5.1) and 8 cases with nuclear p53 immunostaining (with 6 cases overlapping).
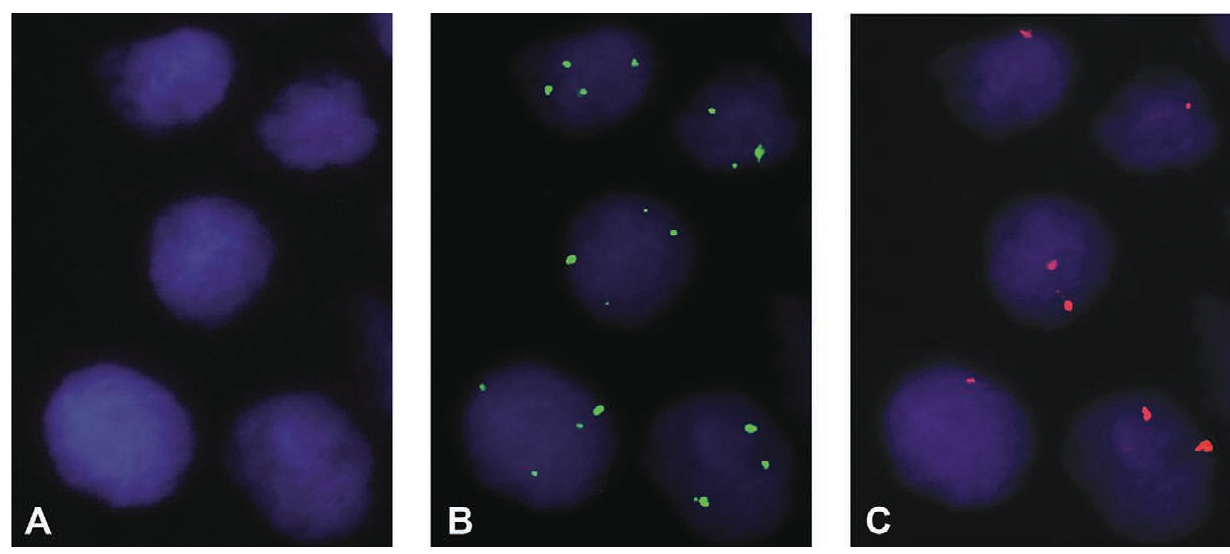

Figure 5.1 Representative image of a FISH analysis on an OSCC resection margin of patient 17, showing A) blue DAPI-stained nuclei, B) 3-4 fluorescein-stained copies of the chromosome 7 centromere per nucleus (green), and C) 1-2 rhodamine-stained copies of the chromosome 1 centromere per nucleus (red). 
In order to examine the predictive value of these molecular markers, we have now re-evaluated the histopathological and clinical patient files and collected follow-up data of these 19 patients over a period of 10-13 years (see Table 5.1). One patient is excluded from the current study because of a retrospectively proven irradical resection of the primary tumor. Our study revealed that all 11 patients without $\mathrm{Cl}$ in their resection margins showed no evidence of disease during follow-up. In contrast, 4 out of 8 patients with $\mathrm{Cl}$ developed disease during follow-up, two showing local recurrence within 5 years, and two additional patients developed local/locoregional tumours after 10 and 11 years. Four patients remained tumour-free.

Table 5.1 Clinical follow-up data of 19 patients with OSCC, whose primary tumour resection margins were histopathologically tumour-free and analysed for $\mathrm{Cl}$ and p53 overexpression.

\begin{tabular}{|c|c|c|c|c|c|c|}
\hline \multirow[t]{2}{*}{$\begin{array}{l}\text { Patient } \\
\text { number }\end{array}$} & \multirow[t]{2}{*}{ Location of primary tumour } & \multirow[t]{2}{*}{ TNM $^{*}$} & \multicolumn{2}{|c|}{$\begin{array}{l}\text { Molecular results } \\
\text { in } \\
\text { resection margins }\end{array}$} & \multirow[t]{2}{*}{$\begin{array}{l}\text { Follow-up } \\
\text { time } \\
\text { (years) }\end{array}$} & \multirow[t]{2}{*}{ Progression } \\
\hline & & & $\mathrm{Cl}$ & p53 & & \\
\hline 1 & Trigonum retromolare (right) & T2N0M0 & - & - & 12.5 & - \\
\hline 2 & Lateral tongue (left) & T1N0M0 & - & - & 11 & - \\
\hline 3 & Floor of mouth (left) & T1N0M0 & - & - & 12 & - \\
\hline 4 & Floor of mouth anteromedial & T2NOMO & - & - & 12.5 & - \\
\hline 5 & Lateral tongue (right) & T2NOMO & - & - & 12 & - \\
\hline 6 & Floor of mouth anteromedial & T2N0M0 & - & - & 10 ** & - \\
\hline 7 & Lateral tongue (left) & T1N0M0 & - & - & 11.5 & - \\
\hline 8 & Inferior alveolar proc. (left) & T1N0M0 & - & - & 11 & - \\
\hline 9 & Lateral tongue (left) & T1N0M0 & - & - & 11.5 & - \\
\hline 10 & Lateral tongue (left) & T2N0M0 & - & + & 2 ** & - \\
\hline 11 & Lateral tongue (left) & T3NOMO & - & + & $8^{* *}$ & - \\
\hline 12 & Lateral tongue (left) & T2NOMO & + & - & 12 & - \\
\hline 13 & Floor of mouth (right) & T1N0M0 & + & + & 10.5 & - \\
\hline 14 & Floor of mouth (left) & T1N0M0 & + & + & 12 & - \\
\hline 15 & Floor of mouth (right) & T2NOMO & + & + & 11.5 & - \\
\hline 16 & Lateral tongue (right) & T1N0M0 & + & - & 1.5 & $+(\mathrm{LT})$ \\
\hline 17 & Lateral tongue (right) & T1N0M0 & + & + & 2 & $+(\mathrm{LT})$ \\
\hline 18 & Floor of mouth (left) & T1N0M0 & + & + & 10 & $+(\mathrm{LT})$ \\
\hline 19 & Lateral tongue (right) & T1N0M0 & + & + & 11 & $+(\mathrm{LRT}+\mathrm{DM})$ \\
\hline
\end{tabular}

*Tumors were classified according to the TNM-classification criteria of malignant tumors (UICC). **These patients died during follow-up due to a non-OSCC related cause. Cl: Chromosome Instability measured by ISH for chromosomes 1 and 7 , defined as the presence of chromosome 1 and 7 copy number imbalances and/or polysomy. p53: Lesions were classified as either p53negative, when no or only a few cells with positive nuclear staining were observed, or p53-positive, when multiple cells with positive nuclear staining were present ${ }^{21}$. LT: Local tumor growth. LRT: Locoregional tumor growth. DM: Distant metastasis.

While all 4 recurrent cases showed $\mathrm{Cl}$, only 3 of these were positive for p53. As a result $\mathrm{Cl}$ detection is strongly associated with (loco)regional tumor outgrowth during follow-up as indicated by a $P$-value of 0.018 in the Fisher's exact test, 
whereas p53 immunostaining does not significantly correlate with recurrence of OSCC. We therefore advise to perform a $\mathrm{Cl}$ analysis in histopathologically radical resection margins of OSCC. A re-resection or additional treatment should be considered in case of $\mathrm{Cl}$ detection. 


\section{References}

1. Mao L, Hong WK, Papadimitrakopoulou VA. Focus on head and neck cancer. Cancer Cell 2004;5:311-6.

2. Sutton DN, Brown JS, Rogers SN, Vaughan ED, Woolgar JA. The prognostic implications of the surgical margin in oral squamous cell carcinoma. Int $\mathrm{J}$ Oral Maxillofac Surg 2003;32:30-4.

3. van Houten VM, Leemans CR, Kummer JA, Dijkstra J, Kuik DJ, van den Brekel $\mathrm{MW}$, et al. Molecular diagnosis of surgical margins and local recurrence in head and neck cancer patients: a prospective study. Clin Cancer Res 2004;10:3614-20.

4. van der Toorn PP, Veltman JA, Bot FJ, de Jong JM, Manni JJ, Ramaekers FC, et al. Mapping of resection margins of oral cancer for p53 overexpression and chromosome instability to detect residual (pre)malignant cells. J Pathol 2001;193:66-72.

5. Cruz IB, Snijders PJ, Meijer CJ, Braakhuis BJ, Snow GB, Walboomers JM, et al. P53 expression above the basal cell layer in oral mucosa is an early event of malignant transformation and has predictive value for developing oral squamous cell carcinoma. J Pathol 1998;184:360-8.

6. Veltman JA, Bot FJ, Huynen FC, Ramaekers FC, Manni JJ, Hopman AH, et al. Chromosome instability as an indicator of malignant progression in laryngeal mucosa. J Clin Oncol 2000;18:1644-51.

7. Poh CFY, Zhu Y, Sun R, Tseng I-L, Zhang L, Rosin MP. Unique FISH patterns associated with biological aggressiveness of potentially malignant oral lesions. Proc AACR 2006;47:212 (Abstract 900). 


\section{Chapter}

EVALUATION CRITERIA FOR CHROMOSOME INSTABILITY DETECTION BY FISH TO PREDICT MALIGNANT PROGRESSION IN PREMALIGNANT GLOTTIC LARYNGEAL LESIONS

Verona E. Bergshoeff, Maschenka C. A. Balkenhol, Annick Haesevoets, Andrea Ruland, Michelene N. Chenault, Rik C. Nelissen, Carine J. Peutz, Ruud Clarijs, Jeroen A.W.M. Van der Laak, Piet J. Slootweg, Robert P. Takes, Michiel W. Van den Brekel, Marie-Louise F. Van Velthuysen, Frans C.S. Ramaekers, Bernd Kremer, Ernst Jan M. Speel 


\begin{abstract}
Chromosome instability $(\mathrm{Cl})$ detected by Fluorescence in Situ Hybridization (FISH) for chromosome 1 and 7 centromeres predicts malignant progression in premalignant head and neck lesions in which routine histopathological evaluation does not provide sufficient information. The aim of this study was to determine objective, clinically applicable evaluation criteria for $\mathrm{Cl}$ detection. We performed dual-target FISH for chromosome 1 and 7 centromeres on $4 \mu \mathrm{m}$ formalin-fixed, paraffin embedded tissue sections of 87 laryngeal premalignancies (severe dysplasia and carcinoma in situ (CIS) excluded) to detect copy number variations (CNVs). Thirty-five randomly selected, normal head and neck squamous cell samples were used as a control. The chromosome 7:1 ratio (CR) and percentage of aberrant nuclei (PAN) were established in each lesion. The normal range of CRs $(\geq 0.84 \leq 1.16)$ was based on the mean $C R+/-3$ $x$ SD found in the normal population, the cut-off value for PAN was set at $\geq 10 \%$. PAN showed a stronger correlation with malignant progression than CR (resp. OR 5.6, $P=0.001$ and OR 3.8, $P=0.009$ ). PAN combined with dichotomized histopathological diagnosis (HP) resulted in a prognostic model with an area under the ROC curve (AUC) of 0.75 (s.e. 0.061 , sensitivity $71 \%$, specificity $70 \%$ ). Evaluation criteria for FISH 1c/7c based on $\mathrm{PAN} \geq 10 \%$ provide the best prognostic information in the risk-management of premalignant laryngeal lesions.
\end{abstract}




\section{Introduction}

Head and neck squamous cell carcinoma (HNSCC) belongs to the 10 most common cancers worldwide. ${ }^{1}$ Well-established oncogenic risk factors include alcohol and tobacco consumption as well as infection with Human Papilloma Virus (HPV) especially in oropharyngeal cancer. ${ }^{2-6}$ Curative treatment consists of surgical excision, radiation therapy with or without chemotherapy and/or targeted therapy. Approximately $25 \%$ of all HNSCC are located in the larynx. ${ }^{1}$ Despite medical oncological progress HNSCC is associated with a poor 5-year survival of approximately $50 \%$, which can partially be explained by 1) a late onset of symptoms and thus presentation at late-stage disease 2) association of HNSCC with second (or thirth) primary malignancies in the digestive or respiratory tract 3 ) tumor recurrence due to minimal residual disease (MRD) in resection margins and/ or locoregional recurrence and 4) poor results of chemotherapy by a lack of therapeutic (onco)target genes. Furthermore, difficulties in the differentiation between potentially harmful (progressive) and non-harmful (non-progressive) premalignant head and neck lesions make the choice for appropriate treatment difficult. ${ }^{7-10}$ The current gold standard is histopathological examination of the epithelium and underlying stroma, in most cases on tissue biopsy material. However, it has been shown that histopathological classification, especially in low-grade lesions, is hampered by a high inter- and intra-observer variability, which has implications on clinical decision making and the prognosis of patients. ${ }^{11,12}$ The oncogenic molecular changes which lead to an increased rate of chromosome mis-segregation in mitosis, failure to maintain a correct chromosomal content (euploidy) and the status of chromosome instability $(\mathrm{Cl})$ and thus to malignant progression of a lesion do not always lead to histomorphological changes that can be detected by the pathologist. ${ }^{13-16}$ This makes the application of other, objective and more reliable molecular markers, which can detect $\mathrm{Cl}$ in an early stage necessary.

Our previous studies on $\mathrm{Cl}$ detection showed that the assessment of numerical aberrations of chromosome 1 and 7 using dual target centromere FISH probes for chromosomes 1 and 7 can predict malignant progression in oral and laryngeal premalignant lesions. ${ }^{17,18}$ These chromosomes were chosen because in HNSCC chromosome 1 copy numbers in general reflect the ploidy status of the nucleus whereas chromosome 7 shows very frequently gain, also in relation to chromosome 1 copy number. ${ }^{18,19}$ Recent genomic studies on head and neck lesions also report extensive $\mathrm{Cl}$ with frequent gain of chromosome $7^{16,20}$ This FISH approach requires only small tissue amounts, which is an advantage in e.g. laryngeal lesions, in contrast to other molecular diagnostics (loss of heterozygosity analysis (LOH), DNA flow- and image cytometry and array comparative genomic hybridization). Furthermore, the tissue architecture 
remains unaffected which allows a thorough impression of an often heterogeneous lesion. Moreover, this technique is relatively easy to perform with low costs, in comparison to e.g. more complex approaches such as microarray analysis or next-generation sequencing (NGS). ${ }^{16,21-25}$

The fact that in premalignant head and neck lesions with $\mathrm{Cl}$ predominantly chromosome gain for one or both chromosomes is found (especially for chromosome 7), generally allows easy visualization of aberrant nuclei and gives a quick impression of the presence of $\mathrm{Cl}$ in a lesion. ${ }^{17,18}$ Until now the evaluation of our FISH results was carried out by two independent investigators who performed a global screening of a lesion and assessed the presence of aberrant copy numbers of chromosomes 1 and 7 . In this way a lesion could be labeled as disomic, trisomic, tetrasomic or polysomic ( $>4$ signals per nucleus) for one or both chromosomes, based on the highest copy number of both chromosomes per nucleus present in $\geq 20 \%$ of nuclei (with a minimum of 50 nuclei and a maximum of 500 nuclei, depending on the size of the lesion), and categorization as either "stable" (configuration 2/2) or "instable" (configuration other than 2/2, including a "balanced" chromosome $7 / 1$ status e.g. 4/4 or tetrasomy). However, FISH analysis on tissue sections for the assessment of the number of signals per nucleus is hampered by 1) cutting artifacts, which can lead to loss of signals and 2) fortuitous overlap of nuclei, which could both lead to misinterpretation of the correct number of signals per nucleus. ${ }^{26}$ Taking into account these technical limitations we intended in this study to define stricter and reproducible evaluation criteria for the assessment of FISH lesions in order to obtain a maximum of objectivity. These new evaluation criteria should also be implementable in future computerized tissue analysis.

Based on FISH analyses in tumor diagnostics for other entities than HNSCC, which detect numerical chromosomal aberrations or copy number variations (CNV), chromosome re-arrangements, amplifications or deletions in a certain number of analyzed nuclei ${ }^{27-30}$ (Table 6.1), and our previous results, 14,15,17,18,23 we compared in this study: 1) the Chromosome Ratio (CR) between chromosomes 7 and 1, and 2) the percentage of aberrant nuclei (PAN) based on the absolute number of nuclei per 100 with $>2$ signals for one or both chromosomes. We compared both criteria in terms of reliability in the assessment of malignant progression-risk and clinical applicability in a series of 87 premalignant laryngeal lesions. Furthermore, we used a normal control population as a reference in order to reduce the possible influence of cutting and overlap of nuclei on the interpretation of data. 
Table 6.1 Evaluation criteria currently used for routine FISH analysis of tumors.

\begin{tabular}{|c|c|c|c|c|c|c|}
\hline Tumor entity & $\begin{array}{l}\text { DNA } \\
\text { Probe(s) for }\end{array}$ & Tissue & $\begin{array}{l}\text { Evaluation } \\
\text { criterium }\end{array}$ & Cut-off value & $\begin{array}{l}\mathrm{N}=\text { nuclei } \\
\text { to be } \\
\text { scored }\end{array}$ & References \\
\hline \multirow[t]{6}{*}{ Lung cancer } & ALK & $\mathrm{FFPE}^{\&}$ & rearrangment & PAN $\geq 50 \%$ & $\mathrm{n}=50$ & Jurmeister et al. ${ }^{27}$ \\
\hline & & cyto & & $\mathrm{PAN} \geq 15 \%$ & $n=100$ & \\
\hline & ROS1 & $\mathrm{FFPE}^{\&}$ & rearrangment & $\mathrm{PAN} \geq 50 \%$ & $\mathrm{n}=50$ & Jurmeister et al. ${ }^{27}$ \\
\hline & & cyto & & $P A N \geq 15 \%$ & $n=100$ & \\
\hline & RET & $\begin{array}{l}\text { FFPE }^{\&} \\
\text { cyto }\end{array}$ & rearrangment & $\begin{array}{l}P A N \geq 20 \% \\
P A N \geq 4 \%\end{array}$ & $n=50$ & Tsuta et al. ${ }^{35}$ \\
\hline & MET & $\begin{array}{l}\text { FFPE }^{\&} \\
\text { cyto }\end{array}$ & amplification & $\begin{array}{l}\text { MET/ CEP7- } \\
\text { ratio } \geq 2\end{array}$ & & Jurmeister et al. ${ }^{27}$ \\
\hline \multirow[t]{3}{*}{$\begin{array}{l}\text { Different types of } \\
\text { lymphomas }\end{array}$} & $\mathrm{Bcl} 2$ & $\begin{array}{l}\text { FFPE }^{\&} \\
\text { cyto }\end{array}$ & translocation & $\begin{array}{l}\mathrm{PAN} \geq 10 \% \\
\text { staining intensity }\end{array}$ & $n=200$ & Haralanbieva et al. \\
\hline & Bcl6 & $\begin{array}{l}\text { FFPE }^{\&} \\
\text { cyto }\end{array}$ & translocation & $P A N \geq 10 \%$ & & Haralanbieva et al. \\
\hline & Myc & $\begin{array}{l}\text { FFPE } \\
\text { cyto }\end{array}$ & translocation & $\begin{array}{l}\mathrm{PAN} \geq 10 \% \\
\text { staining intensity }\end{array}$ & & Haralanbieva et al. \\
\hline Breast cancer & $\begin{array}{l}\text { ERBB2/ } \\
\text { CEP17 }\end{array}$ & $\begin{array}{l}\text { FFPE }^{\&} \\
\text { cyto }\end{array}$ & $\begin{array}{l}\text { amplification/ } \\
\mathrm{CNG}^{+}\end{array}$ & $\begin{array}{l}\text { ERBB2/ CEP } 17 \\
\text { Copy Ratio } \geq 2.0 \\
\text { or }<2\end{array}$ & $\mathrm{n}=20$ & $\begin{array}{l}\text { Orsaria et al. }^{36} \\
\text { ASCO/ CAP } \\
\text { guidelines }^{37}\end{array}$ \\
\hline Melanoma & $\begin{array}{l}11 q 13 / \\
6 q 23 / 6 p 25 / C \\
\text { EP6 }\end{array}$ & FFPE $^{\&}$ & loss $/ \mathrm{CNG}^{+}$ & $\begin{array}{l}\mathrm{PAN} \geq(29-55 \%) / \\
\text { multiparameter } \\
\text { model/ CR }\end{array}$ & $n=30$ & Gerami et al. ${ }^{38}$ \\
\hline Bladder cancer & $\begin{array}{l}\text { Urovysion } \\
\text { (chrom. } \\
3,7,9 \mathrm{p} 21,17 \text { ) }\end{array}$ & $\begin{array}{l}\text { Urine } \\
\text { cytology }\end{array}$ & $\mathrm{CNV}^{\S}$ & $\begin{array}{l}\mathrm{CNG}^{*} \text { for } \\
\text { chromosomes } \\
3,7,17(\geq 4) ; 9 p 21 \\
\text { loss in } \geq 12\end{array}$ & $n=25$ & Huysentruyt et al. ${ }^{39}$ \\
\hline Liposarcoma & $\begin{array}{l}\text { MDMD2/CD } \\
\text { K4/CEP12 }\end{array}$ & FFPE $^{\&}$ & amplification & $\begin{array}{l}\text { MDMD2/ CEP12- } \\
\text { ratio } \geq 2 ; \\
\text { CDK4/CEP12 } \\
\text { ratio } \geq 2\end{array}$ & $n=20$ & Sirvent et al. ${ }^{40}$ \\
\hline $\begin{array}{l}\text { Different sarcoma } \\
\text { types }\end{array}$ & $\begin{array}{l}\text { DDIT3, } \\
\text { EWSR1, } \\
\text { FOXO1, } \\
\text { FUS SS18, } \\
\text { MDM2 }\end{array}$ & FFPE $^{\&}$ & rearrangement & PAN $\geq 10-13 \%$ & $n=100$ & Horn et al. 2014 \\
\hline Oligodendroglioma & $1 p / 19 q$ & $\mathrm{FFPE}^{\&}$ & Loss/CNG & $\begin{array}{l}1 p / 1 q \text { and } 19 q / \\
19 p \text { ratio } \leq 0.8 \\
\text { PAN } \geq 30 \%\end{array}$ & $n=20$ & Van der Bent et al. \\
\hline
\end{tabular}

${ }^{\&}$ FFPE: Formalin Fixed Paraffin Embedded. "GCN: Gene copy numbers, †CNG: Copy Number Gain, ${ }^{\S} \mathrm{CNV}$ : Copy Number Variation, ${ }^{\&} \mathrm{CEP}{ }^{\mathrm{X}}$ : centromere probe for chromosome $\mathrm{x},{ }^{\& \&} \mathrm{CR}$ Chromosome Ratio

\section{Materials and methods}

\section{Patient data and tissue material}

Formalin-fixed, paraffin-embedded (FFPE) tissue biopsies from glottic premalignant lesions were obtained from the Radboud University Medical Center Nijmegen, the Netherlands, Zuyderland Medical Center Heerlen, the 
Netherlands and The Netherlands Cancer Institute, Amsterdam, the Netherlands.

Patient material was obtained by microlarynx-surgery between 1984 and 2007. 87 out of 220 lesions were eligible for this study. We excluded 1) lesions harboring severe dysplasia or carcinoma in situ (CIS), 2) patients that had previously undergone radiation therapy of the larynx, 3) patients that had undergone a radical excision biopsy or vocal cord "stripping" (chordectomy type I), 4) laryngeal lesions other than glottic and 5) patients with a follow-up time from initial biopsy until malignant progression shorter than 6 months. None of the patients were included in previous studies of our department. $\mathrm{N}=33$ patients could not be included because of a lack of representative patient material. Thirty-five at random selected, head and neck squamous cell tissue samples from 35 healthy, non-cancer related patients were used as a control population. The patient material was treated according to the Code for Proper Secondary Use of Human Tissue (Federation of Medical Scientific Societies, The Netherlands; 2003) and the study protocol was approved by the institutional ethical committee. In case of multiple available biopsies the last biopsy preceding SCC or CIS was chosen, taking into account a 6-months follow-up period as a minimum. Patient information including the follow-up data on malignant progression was collected from the medical records. Lesions were classified "progressive" in case of the development of carcinoma in situ (CIS) or squamous cell carcinoma (SSC) at the same localization site as the primary biopsy site within five years of follow-up.

\section{Histopathological assessment}

$4 \mu \mathrm{m}$ thick haematoxylin-eosin stained tissue sections of all lesions were thoroughly histopathologically classified according to the WHO classification system.

\section{Detection of chromosome 1 and 7 alterations by FISH analysis}

All lesions were submitted to $\mathrm{FISH}$ on $4 \mu \mathrm{m}$ thick tissue sections, using centromere-specific probes for chromosomes 1 and 7 according to our earlier described protocol. ${ }^{17}$ Briefly, sections were deparaffinized, pretreated with $85 \%$ formic acid $/ 0.3 \% \mathrm{H}_{2} \mathrm{O}_{2}, 1 \mathrm{M} \mathrm{NaSCN}$ and $4 \mathrm{mg} / \mathrm{ml}$ pepsin in $0.01 \mathrm{M} \mathrm{HCl}$, postfixed in $1 \%$ formaldehyde in phosphate-buffered saline (PBS), dehydrated in an ethanol series and hybridized with a mixture of digoxigenin-labeled human centromere 1-specific and biotin-labeled centromere 7-specific DNA probes [1 $\mathrm{ng} / \mathrm{\mu l}$ 60\% formamide, 2x sodium-saline citrate (SSC), 10\% dextran sulphate and 50x excess salmon sperm carrier DNA]. After hybridization the preparations were washed stringently in $2 x \mathrm{SSC}$ at $42^{\circ} \mathrm{C}$ (two times for $5 \mathrm{~min}$ ) and $0.1 \mathrm{x} \mathrm{SSC}$ at $60^{\circ} \mathrm{C}$ (two times for $5 \mathrm{~min}$ ). The probes were detected by 
application of (i) mouse anti-digoxin (Sigma) / avidin fluorescein (Vector Laboratories, Burlingame, CA, USA), (ii) rabbit anti-mouse rhodamin (Dako, Glostrup, Denmark)/biotinylated goat anti-avidin (Vector) and (iii) swine antirabbit rhodamin (Dako)/ avidin fluorescein. Preparations were mounted in Vectashield (Vector Laboratories) containing 4,6-diamidino-2-phenyl indole (Sigma; $0.2 \mu \mathrm{g} / \mathrm{ml}$ ). Microscope images were recorded with the Leica DC 300 Fx camera (Leica, Wetzlar, Germany) mounted on top of a Leica DM 500 B fluorescence microscope (Leica), equipped with fluorescein-, rhodamine- and DAPI-specific filter sets for single-color analysis and a double bandpass filter set (fluorescein, rhodamine) for simultaneous dual-color analysis.

\section{Evaluation of FISH results}

All FISH stained lesions were examined independently, by two observers (VEB and MB). FISH signals in 100 nuclei were counted per color to determine chromosome 1 and 7 copy numbers. Nuclei containing other than 0,1 or 2 signals per chromosome (e.g. tri-, tetra-, or polysomy) were considered aberrant. In all cases the entire tissue section was thoroughly screened for aberrant nuclei and counts were performed in a region which showed most aberrant nuclei. In order to discriminate between premalignant laryngeal lesions with or without $\mathrm{Cl}$, the following two approaches were applied and compared:

1) the assessment of the chromosome $7 / 1$ ratio (CR-FISH), based on the absolute amount of signals of both chromosomes in 100 nuclei. Cut-off values for $\mathrm{Cl}$ were defined as $\mathrm{CR}-\mathrm{FISH} \leq 0.84$ or $\geq 1.16$, based on the ratios found in the normal control population (further description in the Results section).

2) the assessment of the amount of aberrant nuclei, counted in a total of 100 , defined as the percentage of aberrant nuclei (PAN-FISH). The PAN cut-off value for $\mathrm{Cl}$ in premalignant laryngeal lesions was set at $\geq 10 \%$ based on the optimal sensitivity and specificity in relation to prediction of malignant progression.

\section{Statistical analysis}

All data were analyzed using SPSS 22.0. Patients with non-progressive lesions were censored at the date of last follow-up (with a minimum of 5 years of follow-up from the date of biopsy) or date of death, provided that death was not related to laryngeal malignancy. Differences in patient characteristics between subgroups in the study population were evaluated with a two-tailed T-test for continuous variables and the Chi-square test or Fisher's Exact test for categorical variables. 
Logistic regression analysis was performed for histopathological diagnosis, CR and PAN. Taking into account the influence of possible confounders, multivariate logistic regression analysis was carried out, which resulted in a predictive model based on the combination of the different prognostic markers, including ROC curves. Progression-free survival analysis was calculated using the Kaplan-Meier method. A log rank test was performed to compare the progression-free survival of subgroups, classified according to histopathology, $\mathrm{CR}$ and PAN. In all analyses the $P$-value for significance was set at 0.05 .

\section{Results}

\section{Patient characteristics}

The patient group consisted of 34 females and 53 males. The lesions were histopathologically classified as 27 hyperplasias, 38 mild dysplasias and 22 moderate dysplasias. Twenty-four out of $87(27.3 \%)$ lesions showed malignant progression with a mean malignant progression time of 23.9 months (range 654). Patient characteristics are found in Table 6.2.

Table 6.2 Clinicopathological characteristics of the patient group.

\begin{tabular}{|c|c|c|c|c|c|c|c|c|c|}
\hline \multirow[t]{3}{*}{ Patient population } & \multicolumn{3}{|c|}{ Histopathology } & \multicolumn{3}{|c|}{$\mathrm{CR}$} & \multicolumn{3}{|c|}{ PAN } \\
\hline & $\mathrm{HP}+\mathrm{MD}$ & MDD & P-value & Normal & Aberrant & $P$-value & $<10 \%$ & $\geq 10 \%$ & $P$-value \\
\hline & & & & $\mathrm{N}=62$ & $\mathrm{~N}=25$ & & $\mathrm{~N}=51$ & $\mathrm{~N}=36$ & \\
\hline Gender & & & $P$ NS & & & $P=\mathrm{NS}$ & & & $P=\mathrm{NS}$ \\
\hline Male $(n=53)$ & 39 & 14 & & 36 & 17 & & 30 & 23 & \\
\hline Female $(n=34)$ & 26 & 8 & & 25 & 9 & & 24 & 10 & \\
\hline \multirow[t]{2}{*}{ Age (mean, (SD) } & 57.7 & 60.7 & $P$ NS & 57.6 & 61.35 & $P=\mathrm{NS}$ & 57.8 & 59.9 & $P=\mathrm{NS}$ \\
\hline & $(11.8)$ & (11.9) & & $(11,18)$ & $(12.96)$ & & $(12.4)$ & $(10.8)$ & \\
\hline Histopathology & & & & & & $P=\mathrm{NS}$ & & & $P=0.02^{*}$ \\
\hline \multirow[t]{2}{*}{ Hyperplasia $(n=27)$} & & & & 19 & 8 & & 17 & 10 & \\
\hline & & & & $(67 \%)$ & $(33 \%)$ & & $(67 \%)$ & $(33 \%)$ & \\
\hline \multirow[t]{2}{*}{ Mild dysplasia $(n=38)$} & & & & 29 & 9 & & 26 & 12 & \\
\hline & & & & $(76 \%)$ & $(24 \%)$ & & $(74 \%)$ & $(26 \%)$ & \\
\hline Moderate dysplasia & & & & 14 & 8 & & $8(36 \%)$ & 14 & \\
\hline$(n=22)$ & & & & $(64 \%)$ & $(36 \%)$ & & & $(64 \%)$ & \\
\hline Outcome & & & $P=0.02^{*}$ & & & $P=0.007^{*}$ & & & $P=0.001^{*}$ \\
\hline No progression $(n=63)$ & 52 & 11 & & 50 & 13 & & 44 & 19 & \\
\hline Progression $(n=24)$ & 13 & 11 & & 12 & 12 & & 7 & 17 & \\
\hline
\end{tabular}

* significant $P$-value; NS= non-significant $P$-value. Abbreviations: CR, Chromosome Ratio between chromosomes 7 and 1; Normal CR $0.84 \leq C R \leq 1.16$; PAN, Percentage of Aberrant Nuclei (nuclei showing other than 0,1 or 2 signals for chromosome 1 and/or 7); HP, hyperplasia, MD, mild dysplasia, MDD, moderate dysplasia. 


\section{Histopathological diagnosis of premalignant laryngeal lesions and malignant progression}

Histopathological diagnosis was dichotomized and the lesions were divided in two categories: hyperplasia and mild dysplasia $(n=64)$ versus moderate dysplasia $(n=23)$. No significant differences between both groups were found for age and gender.

The lesions classified as moderate dysplasia showed significantly more often malignant progression than the lower grade lesions (hyperplasia + mild dysplasia); $(P=0.02$; Table 6.2).

\section{$\mathrm{Cl}$ detection in FFPE tissue sections and application to premalignant laryngeal lesions}

a) Definition of cut-off values for $\mathrm{Cl}$ assessed by CR-FISH in normal head and neck squamous epithelium

Randomly selected normal head and neck squamous cell epithelium samples from 35 healthy, non-cancer related patients were used as a control population and were subjected to CR-FISH analysis. All epithelia showed nuclei containing a maximum of 2 signals per chromosome per nucleus (Figure 6.1A), which is expected in normal tissue and in line with our previous findings ${ }^{17}$. The mean CR was 0.97 (range 0.84-1.07; SD 0.05). As the hypothetical CR between chromosome 7 and 1 would be 1.0, we used for statistical reasons the "distance to 1" as a parameter, which resulted in a mean of 0.045 (range 0.010.16 ; SD 0.04). Based on the mean distance to $1+/-3 \times$ SD we defined the range for a non-aberrant $\mathrm{CR}$ as $0.84 \leq \mathrm{CR} \leq 1.16$.

\section{b) Assessment of CR-FISH in premalignant laryngeal lesions and the association with malignant progression}

CR-FISH analysis performed in 87 premalignant laryngeal lesions showed an aberrant CR in 25 lesions. In most cases (21 out of 25 ; $84 \%$ ) we found a $C R \geq 1.16$ indicating a relative gain of chromosome 7 , which is in agreement with previous studies ${ }^{17}$.

A representative image of a premalignant lesion with an aberrant $C R$ is displayed in Figure 6.1B.

Aberrant CRs were found in all histopathological stages, including hyperplasia, which demonstrates that the morphology of low-grade premalignant lesions does not reflect underlying genetic changes (Table 6.2, Figure 6.1D). There were no significant differences in clinical features including age, gender and histopathology between the group with a normal CR and the group with an aberrant CR (Table 6.2). 

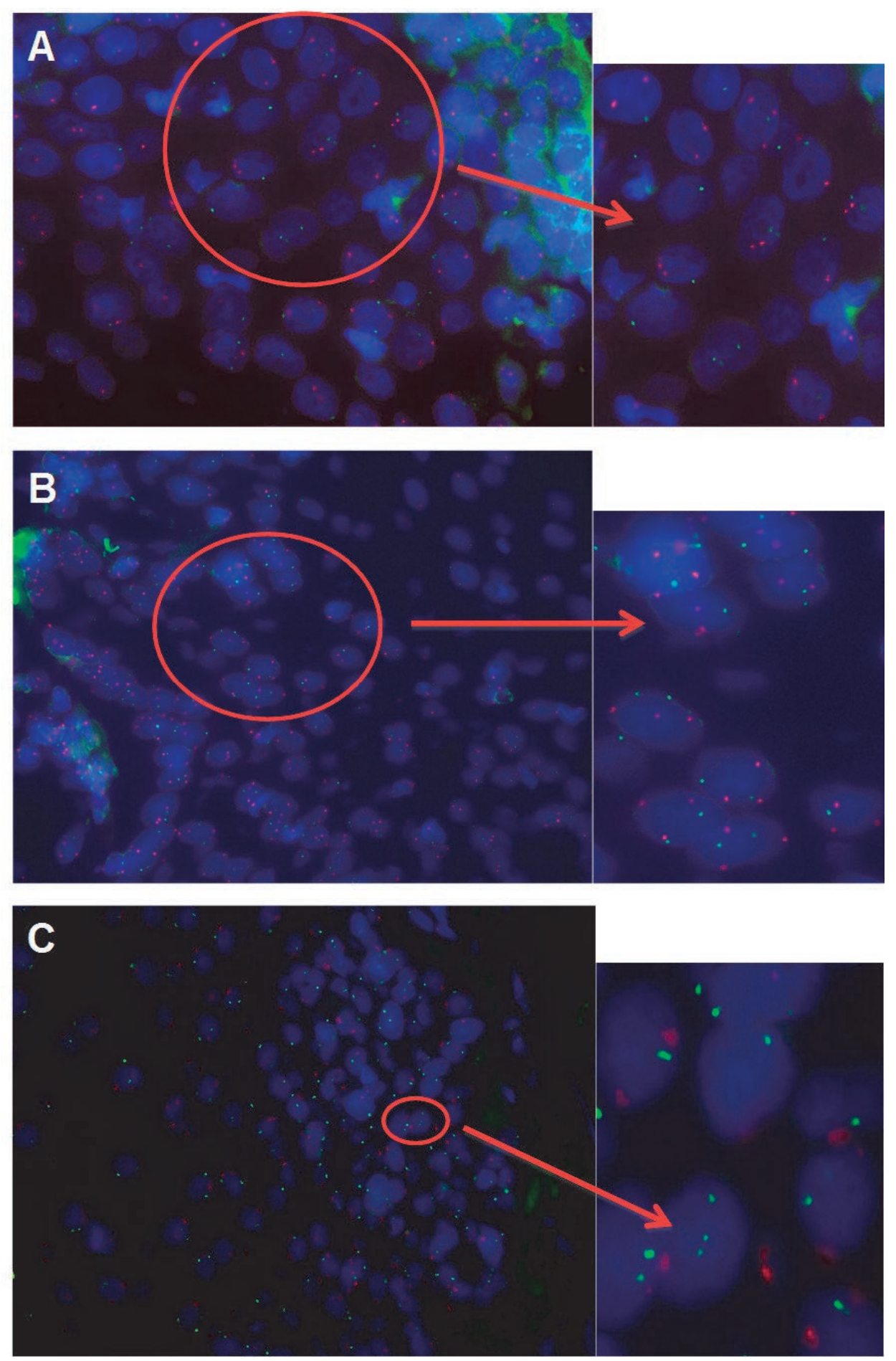

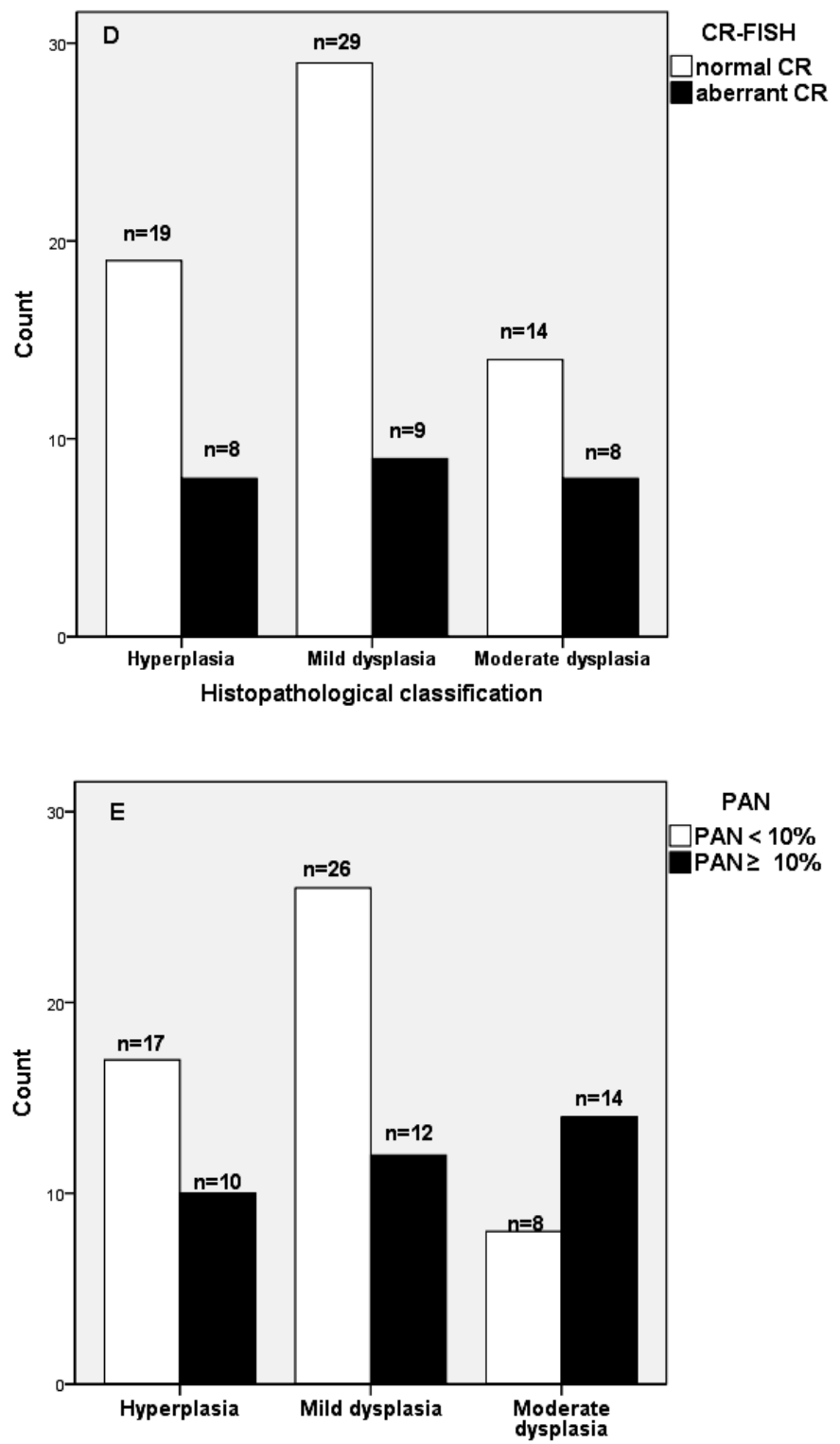

PAN

PAN $<10 \%$

$P A N \geq 10 \%$

Histopathological classification

Figure 6.1 Representative images of tissue sections of premalignant laryngeal lesions, analyzed by FISH $1 / 7$ with centromere probes for chromosome instability $(\mathrm{Cl})$ detection showing disomy for chromosomes 1 (green) and 7 (red) (no $\mathrm{Cl}$ ) (A), trisomy for chromosome 1 and polysomy for chromosome $7(\mathrm{Cl})$ resulting in an aberrant $\mathrm{CR}$ and $\mathrm{PAN} \geq 10 \%(\mathrm{~B})$ and a lesion with only few aberrant nuclei, resulting in a normal CR but PAN $\geq 10 \%$ (C). (D-E): percentage of $\mathrm{Cl}$ in premalignant laryngeal lesions (hyperplasia, mild and moderate dysplasia) as determined by CR-FISH (D) and PAN-FISH (E). 
An aberrant CR was associated with malignant progression (12 out of 25) $(P=0.007$; Table 6.2). However, 12 lesions with a normal $C R$ did progress towards malignancy (12 out of 62), of which 5 lesions showed a trisomy for both chromosomes $(n=3)$, or a relatively low number of nuclei with a trisomy for chromosome $1(n=2)$. The remaining seven lesions showed a disomy for chromosomes 1 and 7, indicating a diploid status. On the other hand 13 lesions with an aberrant CR did not progress towards malignancy.

c) PAN-FISH in premalignant laryngeal lesions and the association with malignant progression

PAN-FISH analysis performed on 87 premalignant laryngeal lesions showed a $P A N \geq 10 \%$ in 36 lesions, thus identified 11 additional lesions with chromosome alterations as compared to $\mathrm{CR}-\mathrm{FISH}$. A representative image with a $\mathrm{PAN} \geq 10 \%$ (and normal CR) is shown in Figure 6.1C.

The group of lesions with a PAN $\geq 10 \%$ contained significantly more lesions with moderate dysplasia and the percentage of lesions with a PAN $\geq 10 \%$ increased with advancing histopathological stage (Table 6.2, Figure 6.1E). There were no significant differences in age and gender between the group with a PAN $<10 \%$ and PAN $\geq 10 \%$ (Table 6.2). Furthermore, a PAN $\geq 10 \%$ was strongly associated with malignant progression (17 out of 36) $(P=0.001$; Table 6.2). Seven out of 87 lesions did not contain aberrant nuclei and were nevertheless progressive. On the other hand 19 out of 36 lesions with PAN $\geq 10 \%$ did not undergo malignant transformation within 5 years and were considered as non-progressive. However, four of these patients showed malignant transformation after more than 5 years.

\section{Logistic regression analysis for histopathology, CR and PAN}

Odd's Ratio's for individual parameters are displayed in Table 6.3.

$\mathrm{PAN} \geq 10 \%$ showed the strongest association with malignant progression (OR=5.6; (2.0-15.8); $P=0.001)$, followed by dichotomized histopathological diagnosis, comparing moderate dysplasia with the combined group of hyperplasia and mild dysplasia (OR=4.0; (1.42-11.24); $P=0.009)$, and aberrant CR (OR=3.8 (1.41-10.52); $P=0.009)$.

Table 6.3 Odds Ratios for individual parameters to predict malignant progression.

\begin{tabular}{lcc}
\hline Parameter & OR $(95 \%$ Confidence Interval) & $P$-value \\
\hline Histopathology & $4.0(1.42-11.24)$ & $0.009^{*}$ \\
HP and MD vs MDD & & \\
CR & $3.8(1.41-10.52)$ & $0.009^{*}$ \\
PAN $(\geq 10 \%)$ & $5.6(2.0-15.8)$ & $0.001^{*}$ \\
\hline
\end{tabular}

* significant $P$-value. OR, Odds Ratio; CR, Chromosome Ratio; PAN, Percentage of Aberrant Nuclei; HP, hyperplasia; MD, mild dysplasia; MDD, moderate dysplasia. 


\section{Kaplan Meier progression-free survival analysis}

Patients with moderate dysplasia showed a significantly shortened 5-years progression-free survival as compared with lesions containing hyperplasia or mild dysplasia $(P=0.009)$. No significant difference in survival was found between lesions containing hyperplasia or mild dysplasia (Figure 6.2A.). Kaplan Meier survival analysis showed a significantly shortened 5-years progression-free survival for patients with lesions harboring $\mathrm{Cl}(P=0.003)$ (Figure 6.2B), and even more pronounced with lesions harboring a $\mathrm{PAN} \geq 10 \%$ $(P=0.0001$; Figure $6.2 \mathrm{C})$, in which PAN-FISH outperformed CR-FISH analysis.
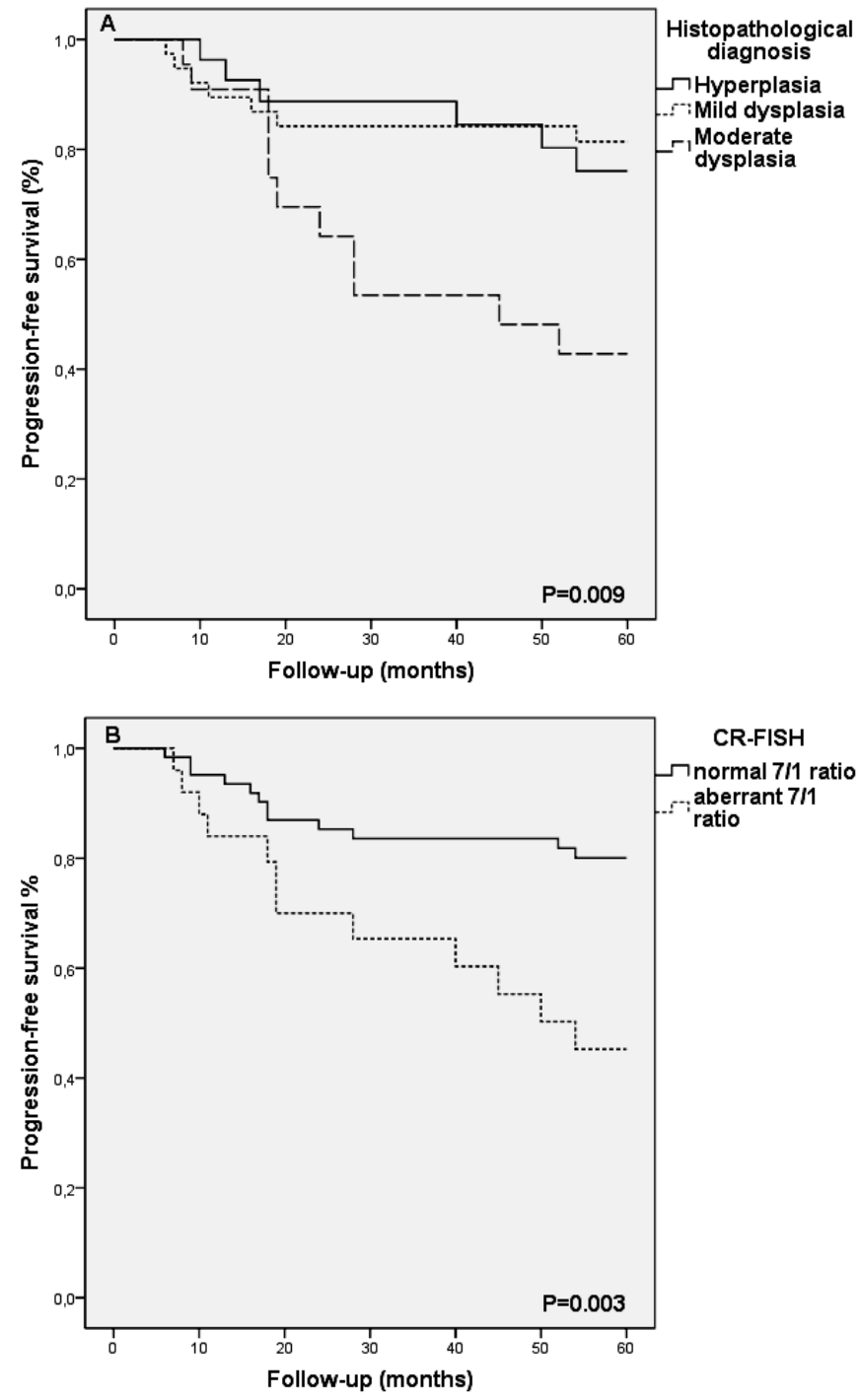


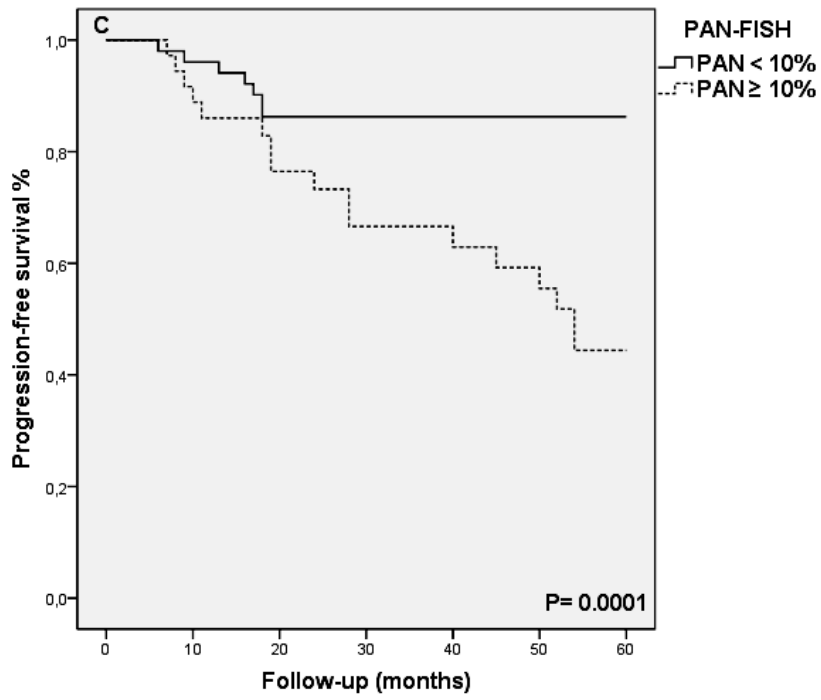

Figure 6.2 Kaplan Meier survival analyses for histopathology, CR-FISH and PAN-FISH. A) Progression-free survival according to histopathological diagnosis, patients with moderate dysplasia show a significantly shortened progression-free survival as compared to the patients diagnosed with hyperplasia or mild dysplasia; $(P=0.009)$. The diagnosis of hyperplasia or mild dysplasia does not provide additional information on progression-risk. B) Progression-free survival according to $\mathrm{CR}-\mathrm{FISH}$. Patients with an aberrant $C R$ show a significantly shortened progression-free survival $(P=0.004)$. C) Progression-free survival according to PAN-FISH. Patients with PAN $\geq 10 \%$ show a significantly shortened progression-free survival $(P=0.0001)$

\section{Multivariate predictive model, ROC curves}

In order to evaluate the prognostic information provided by dichotomized histopathological diagnosis, CR-FISH and PAN-FISH a multivariate regression analysis was performed and Receiver Operating Curves (ROC) were calculated. The combination of PAN-FISH with dichotomized histopathological diagnosis resulted in a slightly larger area under the curve (AUC=0.75; sensitivity $71 \%$ and specificity $70 \%$ ) (Figure 6.3A) as compared to the combination of $\mathrm{CR}$ - FISH with dichotomized histopathological diagnosis (AUC $=0.73$; sensitivity $75 \%$ and specificity 66\%) (Figure 6.3B). Histopathological diagnosis alone resulted in an AUC of 0.64 . 

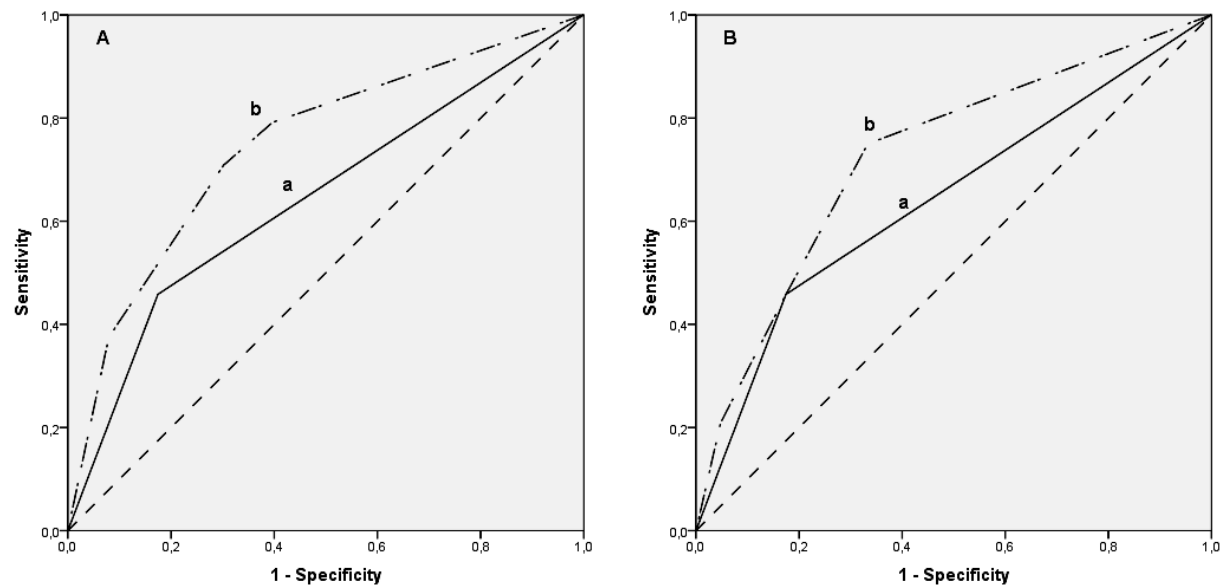

Figure 6.3 A) Receiver Operating Curve $(\mathrm{ROC})$ for dichotomized histopathological diagnosis only (black line a) and in combination with $P A N \geq 10 \%$ (upper dotted line b), AUC $=0.75$, optimal sensitivity $71 \%$, specificity $70 \%$. B) Receiver Operating Curve (ROC) for dichotomized histopathological diagnosis only (black line a) and in combination with CR (upper dotted line b), AUC $=0.73$, optimal sensitivity $75 \%$, specificity $66 \%$.

\section{Discussion}

In previous studies we have shown that the analysis of $\mathrm{Cl}$ in premalignant head and neck lesions by detection of CNVs of chromosomes 1 and 7 using FISH contributes to a more reliable risk assessment for cancer outgrowth. ${ }^{8,14,17,18} \mathrm{Cl}$ detection can be particularly useful in low-grade lesions (hyperplasia, mild and moderate dysplasia), because in these lesions the gold standard of histopathological assessment does not provide sufficient prognostic information. ${ }^{17}$ This poses the clinician for the diagnostic dilemma which lesions require treatment and which do not.

The aim of this study was to determine objective and easily applicable evaluation criteria for $\mathrm{Cl}$ detection by $\mathrm{FISH}$ in a new, independent patient population of low-grade premalignancies. For this purpose, two $\mathrm{Cl}$ detection methods were compared, i.e. 1) determination of the ratio between chromosome 7 and 1 copy numbers (CR) counted in 100 nuclei (CR-FISH) and 2 ) the determination of the percentage of aberrant nuclei (showing $>2$ signals for one or both chromosomes) in 100 nuclei (PAN-FISH). We found that $\mathrm{Cl}$ detected by CR-FISH and especially PAN-FISH (cut-off $\geq 10 \%$ aberrant nuclei) was strongly associated with malignant progression (OR 3.8 and 5.6, respectively). A multiparameter model with ROC curves combining respectively PAN-FISH with dichotomized histopathological diagnosis (hyperplasia and mild 
dysplasia vs. moderate dysplasia) resulted in an AUC of 0.75 , which was slightly higher than when combining CR-FISH with histopathology (AUC 0.73).

\section{PAN-FISH is more favorable than CR-FISH for $\mathrm{Cl}$ detection}

The CR-FISH approach is suitable for an objective, quantitative analysis of chromosome 1 and 7 copy number variations. However, if only few aberrant nuclei are present in a lesion, as a consequence, the CR may not exceed the defined range for normal squamous cell epithelium. The same issue is encountered in case of a numerically balanced chromosome status (trisomy/ tetrasomy), resulting in a potentially false negative test result (no $\mathrm{Cl}$ detected). In both examples thus CR-FISH will not detect $\mathrm{Cl}$ while PAN-FISH will (if $\geq 10 \%$ aberrant nuclei). In addition, scoring of a minimal amount of abnormal nuclei (PAN-FISH) in between a large amount of normal nuclei is easier to perform than assessing the $\mathrm{CR}$ in such a situation (CR-FISH). Indeed, PAN-FISH is also often used for the diagnostics of CNVs and gene rearrangements in other tumors (see Table 6.1.).

\section{FISH not always correctly predicts outcome}

Despite the strong correlation between $\mathrm{Cl}$ and malignant progression, both FISH approaches did not always correctly predict outcome. For example, lesions with $\mathrm{Cl}$ did not always progress to cancer, which can be explained by a possibly radical excision of a small laryngeal lesion containing $\mathrm{Cl}$, during the primary biopsy. Seven patients with a premalignant lesion containing $\mathrm{Cl}$ showed malignant progression $>5$ years after biopsy (range 63-208 months). Because a 5-year follow-up is generally considered as an endpoint for outcome we considered these cases as non-progressive in this study, although malignant progression of lesions after a relatively long period ( $>5$ years) has been reported earlier ${ }^{8}$. Statistical analysis taking into account the clinical outcome of patients with or without the 5-years endpoint of follow-up however, showed comparable results in terms of prognostic values of the tested parameters (data not displayed).

On the other hand, lesions without $\mathrm{Cl}$ and harboring a disomy for chromosome 1 and 7 sometimes show malignant progression, as has been previously reported. Also the recent ATCG sequencing study reported a subgroup of HNSCC with a stable genome. ${ }^{20}$ In diploid precursor lesions carcinogenesis may be induced by other factors e.g. oncogenic viruses, methylation or LOH at $9 \mathrm{p} 21$, which may not always result in numerical aberrations of chromosome 1 and/ or $7.22,31-33$ In order to recognize this particular group of diploid, progressive lesions, probably the supplementary application of other markers, such as LOH for 9p21, could be useful. Particularly PAN-FISH will determine lesions with tri-or tetrasomies as well as lesions with only small groups of 
aberrant nuclei, in contrast with CR-FISH. Finally, a false-negative (nonrepresentative) tissue biopsy should always be considered. ${ }^{7,17,18}$

\section{The role of histopathological diagnosis}

The histopathological classification of laryngeal biopsies remains the gold standard for the risk assessment of malignant outgrowth. The evaluation of squamous cell epithelium may lead to diagnoses varying from e.g. hyperplasia to CIS, according to the WHO criteria. Severe dysplasia and CIS are classifications which are in general univocally posed by different pathologists and correlate strongly with the presence of $\mathrm{Cl}$ and malignant progression of a lesion. However, this is not the case for the lower-grade histopathological classifications (hyperplasia, mild and moderate dysplasia), which do not always reflect the underlying genetic changes. ${ }^{34}$ In this study histopathology contributed only positively to the risk-assessment if applied in a dichotomized way, (hyperplasia and mild dysplasia v.s. moderate dysplasia), resulting in a better OR than expected on the basis of our previous results. ${ }^{17}$ This might be explained by the study design, in which inter-observer variability was reduced by the assessment of the lesions by two experienced head and neck pathologist (PJS and CJP), which is not the case in daily clinical practice.

In conclusion, our data provide evidence that $\mathrm{Cl}$ in premalignant lesions predicts malignant progression. $\mathrm{Cl}$ analysis based on FISH analysis for the detection of chromosomes 1 and $7 \mathrm{CNVs}$ can best be performed using a cut-off value of $\geq 10 \%$ nuclei with aberrant chromosome copy numbers. 


\section{References}

1. Ferlay J, Soerjomataram I, Dikshit R, et al. Cancer incidence and mortality worldwide: sources, methods and major patterns in GLOBOCAN 2012. Int J Cancer 2015;136:E359-86.

2. Hashibe M, Brennan P, Chuang SC, et al. Interaction between tobacco and alcohol use and the risk of head and neck cancer: pooled analysis in the International Head and Neck Cancer Epidemiology Consortium. Cancer Epidemiol Biomarkers Prev 2009, 18:541-50.

3. Maxwell JH, Grandis JR, Ferris RL. HPV-Associated Head and Neck Cancer: Unique Features of Epidemiology and Clinical Management. Annual review of medicine 2015.

4. Hafkamp HC, Mooren JJ, Claessen SM, et al. P21 Cip1/WAF1 expression is strongly associated with HPV-positive tonsillar carcinoma and a favorable prognosis. Mod Pathol 2009, 22:686-98.

5. Hunter KD, Parkinson EK, Harrison PR. Profiling early head and neck cancer. Nat Rev Cancer 2005; 5:127-35.

6. Pezzuto F, Buonaguro L, Caponigro F, et al. Update on Head and Neck Cancer: Current Knowledge on Epidemiology, Risk Factors, Molecular Features and Novel Therapies. Oncology 2015;89:125-36.

7. Leemans $\mathrm{CR}$, Braakhuis BJ, Brakenhoff $\mathrm{RH}$. The molecular biology of head and neck cancer. Nat Rev Cancer 2011;11:9-22.

8. Bergshoeff VE, Hopman AH, Zwijnenberg IR, et al. Chromosome instability in resection margins predicts recurrence of oral squamous cell carcinoma. J Pathol 2008;215:347-8.

9. Agrawal N, Frederick MJ, Pickering CR, et al. Exome sequencing of head and neck squamous cell carcinoma reveals inactivating mutations in NOTCH1. Science 2011;333:1154-7.

10. Mao L, Hong WK, Papadimitrakopoulou VA. Focus on head and neck cancer. Cancer Cell 2004;5:311-6.

11. Fleskens SA, Bergshoeff VE, Voogd AC, et al. Interobserver variability of laryngeal mucosal premalignant lesions: a histopathological evaluation. Mod Pathol 2011;24:892-8.

12. Fleskens S, Slootweg P. Grading systems in head and neck dysplasia: their prognostic value, weaknesses and utility. Head Neck Oncol 2009;1:11.

13. $\mathrm{Ai} \mathrm{H}$, Barrera JE, Meyers $\mathrm{AD}$, et al. Chromosomal aneuploidy precedes morphological changes and supports multifocality in head and neck lesions. Laryngoscope 2001;111:1853-8.

14. Veltman JA, Bot FJ, Huynen FC, et al. Chromosome instability as an indicator of malignant progression in laryngeal mucosa. J Clin Oncol 2000;18:1644-51.

15. Veltman JA, Hopman AH, van der Vlies SA, et al. Double-target fluorescence in situ hybridization distinguishes multiple genetically aberrant clones in head and neck squamous cell carcinoma. Cytometry 1998;34:113-20.

16. Garnis C, Chari R, Buys TP, et al. Genomic imbalances in precancerous tissues signal oral cancer risk. Mol Cancer 2009, 8:50.

17. Bergshoeff VE, Van der Heijden SJ, Haesevoets A, et al. Chromosome instability predicts progression of premalignant lesions of the larynx. Pathology 2014;46: 216-24. 
18. Siebers TJ, Bergshoeff VE, Otte-Holler I, et al. Chromosome instability predicts the progression of premalignant oral lesions. Oral Oncol 2013;49:1121-8.

19. Soder Al, Hopman AH, Ramaekers FC, et al. Distinct nonrandom patterns of chromosomal aberrations in the progression of squamous cell carcinomas of the head and neck. Cancer Res 1995;55:5030-7.

20. Cancer Genome Atlas N. Comprehensive genomic characterization of head and neck squamous cell carcinomas. Nature 2015;517:576-82.

21. Sethi N, MacLennan K, Wood HM, et al. Past and future impact of next-generation sequencing in head and neck cancer. Head Neck 2016;38 Suppl 1:E2395-402.

22. Zhang L, Poh CF, Williams $M$, et al. Loss of heterozygosity (LOH) profiles-validated risk predictors for progression to oral cancer. Cancer Prev Res 2012;5:1081-9.

23. Fleskens SJ, Takes RP, Otte-Holler I, et al. Simultaneous assessment of DNA ploidy and biomarker expression in paraffin-embedded tissue sections. Histopathology 2010;57:14-26.

24. Abou-Elhamd KE, Habib TN. The flow cytometric analysis of premalignant and malignant lesions in head and neck squamous cell carcinoma. Oral Oncol 2007;43:366-72.

25. Saintigny $\mathrm{P}$, Zhang L, Fan $\mathrm{YH}$,et al. Gene expression profiling predicts the development of oral cancer. Cancer Prev Res 2011;4:218-29.

26. Herbergs J, Speel EJ, Ramaekers FC, et al. Combination of lamin immunocytochemistry and in situ hybridization for the analysis of chromosome copy numbers in tumor cell areas with high nuclear density. Cytometry 1996;23: 1-7.

27. Jurmeister P, Lenze D, Berg E, et al. Parallel screening for ALK, MET and ROS1 alterations in non-small cell lung cancer with implications for daily routine testing. Lung Cancer 2015;87:122-9.

28. Horn $\mathrm{H}$, Allmanritter J, Doglioni $\mathrm{C}$, et al. Fluorescence in situ analysis of soft tissue tumor associated genetic alterations in formalin-fixed paraffin-embedded tissue. Pathol Res Pract 2014; 210:804-11.

29. Fiskvik I, Beiske K, Delabie J, et al. Combining MYC, BCL2 and TP53 gene and protein expression alterations improves risk stratification in diffuse large B-cell lymphoma. Leuk Lymphoma 2015; 56:1742-9.

30. Horn $\mathrm{H}$, Ziepert M, Becher $\mathrm{C}$, et al. MYC status in concert with BCL2 and BCL6 expression predicts outcome in diffuse large B-cell lymphoma. Blood 2013;121:2253-63.

31. Califano J, van der Riet P, Westra W, et al. Genetic progression model for head and neck cancer: implications for field cancerization. Cancer research 1996;56:2488-92.

32. Hall GL, Shaw RJ, Field EA, et al. p16 Promoter methylation is a potential predictor of malignant transformation in oral epithelial dysplasia. Cancer Epidemiol Biomarkers Prev 2008;17:2174-9.

33. Moore PS, Chang Y. Why do viruses cause cancer? Highlights of the first century of human tumour virology. Nat Rev Cancer 2010;10:878-89.

34. van Hulst AM, Kroon W, van der Linden ES, et al. Grade of dysplasia and malignant transformation in adults with premalignant laryngeal lesions. Head Neck 2016;38 Suppl 1:E2284-90. 
35. Tsuta K, Kohno T, Yoshida A, et al. RET-rearranged non-small-cell lung carcinoma: a clinicopathological and molecular analysis. $\mathrm{Br} J$ Cancer 2014;110:1571-8.

36. Orsaria M, Khelifa S, Buza N, et al. Chromosome 17 polysomy: correlation with histological parameters and HER2NEU gene amplification. J Clin Pathol 2013;66:1070-5.

37. Wolff AC, Hammond ME, Hicks DG, et al. Recommendations for human epidermal growth factor receptor 2 testing in breast cancer: American Society of Clinical Oncology/College of American Pathologists clinical practice guideline update. Arch Pathol Lab Med 2014;138:241-56.

38. Gerami P, Jewell SS, Morrison LE, et al. Fluorescence in situ hybridization (FISH) as an ancillary diagnostic tool in the diagnosis of melanoma. Am J Surg Pathol 2009;33:1146-56.

39. Huysentruyt CJ, Baldewijns MM, Ruland AM, et al. Modified UroVysion scoring criteria increase the urothelial carcinoma detection rate in cases of equivocal urinary cytology. Histopathology 2011; 58:1048-53.

40. Sirvent N, Coindre JM, Maire G, et al. Detection of MDM2-CDK4 amplification by fluorescence in situ hybridization in 200 paraffin-embedded tumor samples: utility in diagnosing adipocytic lesions and comparison with immunohistochemistry and realtime PCR. Am J Surg Pathol 2007;31:1476-89. 


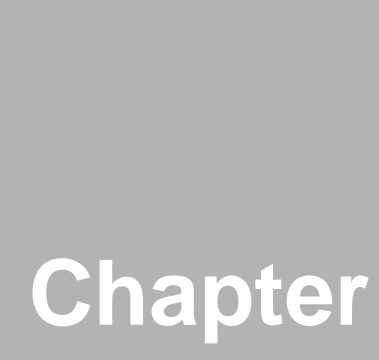

GENERAL DISCUSSION 


\section{General discussion}

The development of HNSCC is a multistep process in which the head and neck mucosa undergoes molecular and histomorphological changes which finally result in cancer. In this process, precursor lesions are often encountered and the clinical management of these lesions comprises local treatment (surgery and/or radiation therapy) or a wait and see policy. ${ }^{1,2}$ The gold standard for risk assessment is histopathological classification of these lesions, which however remains a major challenge. The main aim of the studies in this thesis was to identify reliable molecular indicators for malignant outgrowth. For this purpose we investigated three approaches i.e. FISH for copy number analysis of chromosome 1 and 7, Image Cytometry (ICM) to detect DNA aneuploidy and immunohistochemistry $(\mathrm{IHC})$ to evaluate expression of proteins involved in the cell cycle and apoptosis.

First, we investigated which histopathological classification method for premalignant laryngeal lesions provides the most uniform diagnosis, and which level of uniformity can be reached (Chapter 2). We found a large interobserver variability for all 3 investigated classification systems. A reduction of the grading systems towards a 2 or 3-grade system resulted in a better concordance between observers. Nevertheless, only moderate agreement was achieved. Simultaneous assessment of lesions by three pathologists did also result in an improvement of the concordance level.

In the next chapter (Chapter 3), we compared the value of chromosome instability $(\mathrm{Cl})$, detected by FISH and defined as CNV for chromosome 1 and 7 , with immunohistochemical analysis of p53, FADD, pFADD and Cyclin D1 expression for the prediction of malignant progression in premalignant laryngeal lesions. $\mathrm{Cl}$ detection proved to be a strong prognostic marker of malignant progression. In addition, detection of p53 and FADD overexpression can be helpful in the identification of progressive, Cl-negative lesions.

In Chapter 4 we compared the prognostic value of $\mathrm{Cl}$ determined by $\mathrm{FISH}$ and aneuploidy by ICM in oral premalignant lesions. The presence of $\mathrm{Cl} /$ aneuploidy detected by both methods was strongly associated with malignant progression.

In Chapter 5 we found that $\mathrm{Cl}$ detection by FISH also can be of value for the prediction of tumor recurrence in histopathologically tumor free resection margins of Oral Squamous Cell Carcinoma (OSCC). In this follow-up study resection margins with $\mathrm{Cl}$ showed to be associated with tumor recurrence. The presence of p53 overexpression as detected by IHC was unreliable for this purpose.

In order to establish objective evaluation criteria for $\mathrm{Cl}$ detection by $\mathrm{FISH}$, two approaches were compared and applied on a new series of premalignant 
laryngeal lesions in Chapter 6 . The first approach determined the chromosome 7:1 copy number ratio in 100 nuclei (CR-FISH), whereas the second assessed the number of $\mathrm{Cl}$-containing nuclei in 100 nuclei, with a cut-off value of $\geq 10 \%$ for Cl-positivity (PAN-FISH). The latter approach provided the most reliable prognostic information in the risk-management of these lesions.

\section{Interpretation of study findings}

\section{The role of histopathology in risk-assessment of head and neck premalignancies}

Different histopathological grading systems have been developed for premalignant head and neck lesions. The most commonly used systems include the WHO-, SIN-, and Ljubljana classification. The reported percentages of lesions that show malignant progression for each classification-subclass however differ substantially in literature. ${ }^{3-5}$

In this thesis we evaluated the value of histopathological assessment to predict malignant progression of premalignant head and neck lesions. In chapter 2 we compared the WHO, SIN and Ljubljana classification systems on premalignant laryngeal lesions. Disappointing k-values for interobserver agreement were found for each classification system, and no significant differences between the $\mathrm{K}$-values of the three systems were found. A reduction of the grading systems to a 2 or 3-grade system resulted in an improvement of the $\mathrm{k}$-values and the percentage of concordance between pathologists. However, only a moderate (and clinically insufficient) agreement between observers was achieved. Simultaneous assessment of lesions by three pathologists resulted in an improvement of the concordance level. This underlines the fact that the histomorphological assessment of premalignant lesions remains difficult and subjective, which makes a prediction of the malignant progression risk based on the histomorphological features hazardous. Thus, histopathological diagnoses of one head and neck precursor lesion posed by different pathologists are inconsistent.

In Chapter 3, 4 and 6 we have analyzed the prognostic value of histopathological diagnosis, including all different degrees of dysplasia, based on the WHO criteria. We found that for both laryngeal and oral lesions histopathological diagnosis was not able to reliably differentiate between progressive and non-progressive lesions, especially in the lower-grade lesions (hyperplasia, mild and moderate dysplasia). Only the diagnosis severe dysplasia distinguished clearly between progressive and non-progressive lesions, i.e. a significant difference in disease-free survival was found. For the lower-grade lesions statistical significance could only be reached by the use of 
a two-degree dichotomization (hyperplasia + mild dysplasia versus moderate dysplasia). This underlines the fact that the grade of dysplasia does not accurately predict the risk for progression of premalignant head and neck lesions.

On the basis of our data we would like to propose regular training of head and neck pathologists as well as pathology residents for the assessment of head and neck precursor lesions. Furthermore, histopathological assessment of premalignant head and neck lesions by more than one pathologist and the introduction of a two-degree classification system for the category of lesions comprising hyperplasia, mild and moderate dysplasia should be considered. Finally, it is highly recommended to combine histopathological assessment with the application of molecular biomarkers to improve the risk assessment of head and neck premalignancies, ${ }^{2}$ Chapter $3,4,6$.

\section{The role of molecular biomarkers in risk assessment of head and neck premalignancies}

In this thesis we focused on FISH analysis to detect $\mathrm{Cl}$ and ICM to detect aneuploidy, as well as overexpression of p53, cyclin D1, FADD and pFADD proteins, all being potential biomarkers for progression of head and neck premalignancies. ${ }^{6-8}$

\section{Chromosome instability detection by FISH}

FISH using chromosome 1 and 7 centromere probes to detect CNVs for one or both chromosomes is a relatively straight-forward approach, which can be easily implemented in a clinical diagnostic setting. It has been earlier applied in a pilot study on premalignant laryngeal lesions, which showed an association between chromosome 1 and $7 \mathrm{CNVs}$ and malignant progression. ${ }^{9}$ Analogue to this study, in this thesis we applied FISH for chromosome 1 and 7 centromeres in premalignant laryngeal and oral lesions to detect $\mathrm{Cl}$ and studied its value as a prognosticator (Chapter 3 and 4). The FISH approach showed to be ideal for premalignant head and neck lesions, especially for the larynx, where small biopsies are common. We found numerical aberrations of one or both chromosomes in hyperplasia, the different grades of dysplasia and CIS. Copy number gain was found for both chromosomes, however especially for chromosome 7 .

$\mathrm{Cl}$, including tri,- and tetrasomy for both chromosomes (balanced chromosome-status), showed a strong association with malignant progression in both laryngeal and oral lesions. 
Furthermore, in a minority of low-grade lesions an isolated trisomy for chromosome 1 with a disomic chromosome 7 status was observed. In the more advanced histopathological stages a majority of lesions with chromosome instability showed copy number gains for both chromosomes, which most probably reflects the occurrence of aneuploidy in the cell.

In Chapter 5 we showed in a small retrospective study, that $\mathrm{Cl}$ detection by FISH applied on resection margins of histopathologically radically resected OSCC $(n=19)$ is able to predict local tumor recurrence. Four patients showed tumor recurrence and all cases showed CNVs for one or both chromosomes in at least one resection margin. Three out of these 4 lesions showed also p53 overexpression. This pilot study shows that resection margins, which are considered as histopathologically tumor free, may contain (groups of) cells with $\mathrm{Cl}$, which may be associated with later tumor recurrence. In a subsequent study on 42 patients with resected OSCC, FISH analysis showed that in nine out of the eleven cases with tumor relapse within 5 years, $\mathrm{Cl}$ could be detected in at least one of the surgical margins of the previously resected primary tumor. Thus, this study further underlines the prognostic value of $\mathrm{Cl}$ detection to identify patients at risk for developing local recurrence, which has been further explored in a recent extended study on resection margins of OSCC. ${ }^{10}$

\section{Comparison of FISH results with DNA ploidy analysis by ICM}

In oral premalignant lesions (Chapter 4), in which larger tissue amounts were available, DNA ploidy detection by DNA image cytometry was performed in addition to the FISH approach, in order to compare both techniques. The presence of $\mathrm{Cl}$ as detected by both FISH and ICM was strongly associated with malignant progression. While the assessment of chromosome instability by $\mathrm{FISH}$ is based on the analysis of CNVs of only two chromosomes, ICM comprises the whole DNA content and ploidy status. Both techniques have their merits and limitations, resulting in false positive and false negative results. For example, in case of an aneuploid lesion without CNVs for chromosomes 1 and/ or $7 \mathrm{FISH}$ results will show a disomy for both chromosomes, while ICM analysis will show an abnormal DNA content. On the other hand, small areas with aneuploid nuclei in lesions can be detected by FISH, while these lesions would be classified as normal by ICM. Nevertheless, the kappa analysis showed a "substantial" agreement between ICM and FISH. Multivariate analysis including both techniques showed a decrease of both Hazard Ratios, indicating that both techniques yield comparable information and that FISH gives a reliable indication of the ploidy status of the cell.

Comparable with the results in laryngeal premalignant lesions, also in oral lesions the histopathological diagnosis did only have prognostic value if the different histopathological subclasses were pooled into low-grade vs. high- 
grade (hyperplasia and mild dysplasia vs. moderate dysplasia and severe dysplasia). This lead to a clinically relevant categorization of lesions in 1) lesions with a good prognosis (diploid low-grade), 2) lesions with an intermediate prognosis (diploid high-grade or aneuploid low-grade), and 3) lesions with a poor prognosis (aneuploid high-grade), the latter showing the poorest disease-free survival.

\section{$\mathrm{Cl}$ detection in precursor lesions over time}

The ploidy status of oral precursor lesions and the subsequent tumor lesion was investigated in 9 patients who had undergone several tissue biopsies (Chapter 4). In five cases all precursor lesions as well as the tumor were aneuploid. In 3 out of 9 patients a diploid precursor lesion and diploid tumor was found (detected by both FISH and ICM analysis). This indicates that in order to identify this special entity of diploid, progressive lesions, other additional markers are required. In diploid precursor lesions carcinogenesis may be induced by other factors e.g. oncogenic viruses, methylation, Micro Satellite Instability (MSI) or $\mathrm{LOH}$ at 9p21, which may not always result in numerical aberrations of chromosome 1 and/ or $7 .^{11-15}$ In order to recognize this particular group of diploid, progressive lesions, probably the supplementary application of other markers, such as LOH for 9p21, could be useful.

One case showed an aneuploid precursor lesion, followed by a diploid precursor lesion and a diploid SCC. This might be explained by the existence of field cancerization, in which several genetically different clones may develop in a cancerous lesion. ${ }^{16}$ On the other hand, the localization of tissue biopsies might differ slightly, which may result in the detection of precursor lesions with a genetically different profile (biopsy bias).

\section{The role of cell-cycle and apoptosis related genes as markers of progression}

\section{P53}

P53 is probably the most frequently mutated tumor suppressor gene in smoking and alcohol induced HNSCC. ${ }^{17,18}$ However, the role of p53 as an indicator of progressing premalignancies remains issue of debate. ${ }^{19-22}$ P53 overexpression can even be found in non-cancerous lesions, e.g. Reinkes oedema of the larynx, ${ }^{23}$ which may also be induced by non-cancer related factors or simply be a sign of cellular stress. ${ }^{24}$ P53 overexpression in (pre)cancerous lesions is generally the result of gene mutation, but the interpretation and clinical relevance of p53 overexpression remains difficult. ${ }^{24}$ 
Furthermore, gene mutation without detectable protein overexpression may occur in case of truncation of the protein, as well as p53 overexpression without detectable gene mutation. ${ }^{25}$ The p53 overexpression pattern we found in premalignant laryngeal lesions (Chapter 3 ) as well as in histopathologically tumor free oral squamous cell (OSCC) resection margins (Chapter 5 ) was not sufficiently powerful as an individual marker of progression or predictor of tumor recurrence, although other studies report the contrary. ${ }^{20}$ However, most other p53-studies were performed on oral lesions, in which TP53 mutation and overexpression is far more common than in laryngeal lesions. ${ }^{26}$ Additional mutation analysis for TP53 might differentiate between gene mutation induced p53 protein overexpression and non-oncogenic overexpression. Probably, additional events along with TP53 mutation are required to induce progression towards cancer.

\section{Cyclin D1, FADD and pFADD}

Amplification and overexpression of the 11q13-related genes and proteins of Cyclin D1, FADD and its phosphorylated isoform pFADD is frequently found in head and neck cancer and has also been described as a marker of progression for premalignant lesions. ${ }^{8,27}$ However, our study in Chapter 3 could not confirm this in premalignant laryngeal lesions. We observed Cyclin D1 and FADD overexpression in a minority of cases of the study population (32\% and $15 \%$ respectively), which might reflect a situation of impairment of cell cycle control and apoptosis induction, which does not necessarily lead towards cancer. Nuclear pFADD overexpression was very commonly found (93\%), however without clinical significance.

\section{A multi-parameter progression model combining $\mathrm{Cl}$, p53 and FADD detection and histopathology for the risk-assessment of premalignant head and neck lesions}

The individually tested markers P53, Cyclin D1, FADD and pFADD were not sufficiently powerful to be used as single predictors of malignant progression, which is in line with other reports. ${ }^{19}$

p53 and FADD overexpression was only clinically relevant in a multiparameter model combined with histopathology and FISH, which reduced the false negative cases, including a part of the diploid precursor lesions which were progressive but were "missed" by FISH detection alone. FADD and pFADD overexpression is probably clinically less relevant in head and neck premalignancies than in HNSCC, where overexpression of this protein can be 
used for therapeutic purposes and differentiate between tumors that are more sensitive to radiation therapy or chemotherapy. ${ }^{28,29}$

\section{Optimization of the evaluation criteria for $\mathrm{Cl}$ detection by FISH in risk assessment of premalignant head and neck lesions}

The evaluation criteria for the assessment of $\mathrm{Cl}$ by $\mathrm{FISH}$ were further investigated in Chapter 6 , in order to achieve a maximum of objectivity, reliability and time efficiency. Based on the evaluation criteria used in FISH diagnostics for other tumors (Chapter 6, Table 6.1) , $^{30-37}$ we tested and compared the chromosome 7:1 ratio (CR), based on the total of FISH signals for both chromosomes in 100 nuclei, with the percentage of aberrant nuclei (PAN), defined as the percentage of nuclei harboring more than 2 signals per chromosome. The use of PAN with a cut-off value of $\geq 10 \%$ aberrant nuclei showed the best association with malignant progression. Furthermore, this assessment method can be easily implemented in tissue diagnostics and is less time-consuming than $\mathrm{CR}$ assessment. Aberrant nuclei are relatively easily detected because copy number gain is nearly always observed. In this study we combined PAN with dichotomized histopathological diagnoses (hyperplasia vs. mild and moderate dysplasia), which resulted in an improvement of the AUC of the ROC curve, e.g. a slightly better predictive model.

\section{The role of FISH in the risk-counseling of premalignant head and neck lesions: limitations of the studies of this thesis}

As has been shown by the studies on premalignant laryngeal and oral lesions, FISH is a strong additional prognostic tool in the risk counselling of these lesions. Although it has been shown to be much more reliable than the traditional histopathology, large prospective studies are required for validation. There are some weaknesses, which should be addressed in future. The genetic diversity of premalignant lesions makes that, in order to identify also those lesions that have a diploid DNA status, it might be necessary to assess additional molecular markers, such as p53 and FADD overexpression and/ or $3 p$ and $9 p$ deletion analysis.

The results of our studies might, despite all efforts, be negatively influenced by 1) biopsy bias (the biopsy of the precursor lesion has been not exactly taken from the same localization as the tumor lesion), 2) the biopsy that has been taken has radically resected all aberrant cells, 3) the tissue slices analyzed for 
histopathology, FISH, ploidy assessment and immunohistochemistry possibly harbored slightly different regions (especially when only small areas of aneuploidy cells are present and 4) a lack of representative tissue which has reduced the number of eligible patients for the studies.

However, based on the currently reported other markers of progression for premalignant head and neck lesions, which all give poorer predictive results, we believe that the introduction of FISH in the diagnostic management of these lesions may be of value and should be implemented in clinical practice.

\section{Future perspectives in the management of premalignant head and neck lesions}

The diagnostic dilemma of how to manage premalignant head and neck lesions remains an issue for further research. In this thesis we studied the value of other potential biomarkers for progression besides histopathological diagnosis. Numerical aberrations of chromosomes 1 and 7 have been shown to be useful as a strong marker of progression.

To achieve better treatment results in terms of reduction of morbidity and mortality due to prevention of progression to HNSCC, early detection and appropriate treatment remain indispensable.

Prevention should include awareness of individuals of the carcinogenic risks of especially smoking and alcohol consumption. Systematic screening for aberrant cells by cellular mouth-brushes could be done in individuals with an increased risk for the development of HNSCC, however, this would probably be cost-ineffective due to the relatively low incidence of HNSCC as compared to other types of cancer such as breast cancer, where population broad detection has been proved effective.

For the early detection of asymptomatic oral lesions increased alertness of dentists, who carry out periodic dental controls could be helpful. In case of a mucosal lesion, which could require further investigation early referral to a specialist could then be established. Biopsies of a mucosal lesion could be (intra-operatively) guided by Narrow Band Imaging, which could better identify regions at risk in a lesion. ${ }^{38}$

Once a biopsy has been taken, based on our data a dichotomized histopathological classification dividing lesions in low-risk and high-risk (which could comprise the WHO classifications hyperplasia and mild dysplasia vs. moderate dysplasia and severe dysplasia) should be applied. Additional assessment of chromosome instability by the detection of CNVs of chromosomes 1 and 7 by FISH in combination with FADD and p53 immunohistochemistry may lead to a diagnostic model. In this light, also other 
biomarkers, such as $3 p$ and $9 p$ loss and $8 q$ gain might be relevant alternatives. ${ }^{12,39}$

This approach could also be extrapolated to the assessment of resection margins of resected OSCC. A multi-center prospective study should provide final validation of these results and facilitate implementation of a new diagnostic protocol in the daily clinical practice.

\section{Conclusion}

$\mathrm{Cl}$ detection by FISH is a powerful biomarker of malignant progression in laryngeal and oral premalignant lesions, which can also be applied on resection margins of OSCC to assess risk for local recurrence. This marker overrules the subjectivity of histopathological assessment and can detect those lesions which are at risk despite a normal histopathological appearance. However, the development of HNSCC is a complex process, in which different genetic pathways to cancer play a role. This makes a multiparameter approach for premalignant lesions indispensable in order to reduce false-negative cases and reduce patient morbidity and mortality. p53 and FADD may play a role as supplementary markers for the detection of diploid, progressive lesions, where FISH stainings may show chromosome 1 and 7 disomy. A prospective study design should provide data on the benefits in terms of a patients prognosis, cost-effectiveness and evaluation of future clinical implementation. 


\section{References}

1. Leemans CR, Braakhuis BJ, Brakenhoff RH. The molecular biology of head and neck cancer. Nat Rev Cancer 2011;11:9-22.

2. Dionne $\mathrm{KR}$, et al. Potentially malignant disorders of the oral cavity: current practice and future directions in the clinic and laboratory. Int J Cancer 2015;136:503-15.

3. Fleskens S, Slootweg P. Grading systems in head and neck dysplasia: their prognostic value, weaknesses and utility. Head Neck Oncol 2009;1:11.

4. Eversole LR. Dysplasia of the upper aerodigestive tract squamous epithelium. Head Neck Pathol 2009; 3:63-8.

5. Sperandio $\mathrm{M}$, et al. Predictive value of dysplasia grading and DNA ploidy in malignant transformation of oral potentially malignant disorders. Cancer Prev Res (Phila) 2013;6:822-31.

6. Pignataro L, et al. The predictive value of p53, MDM-2, cyclin D1 and Ki67 in the progression from low-grade dysplasia towards carcinoma of the larynx. J Laryngol Otol 1998;112:455-9.

7. Jeannon JP, et al. Molecular markers in dysplasia of the larynx: expression of cyclin-dependent kinase inhibitors p21, p27 and p53 tumour suppressor gene in predicting cancer risk. Clin Otolaryngol Allied Sci 2004;29:698-704.

8. Papadimitrakopoulou V, et al. Cyclin D1 and cancer development in laryngeal premalignancy patients. Cancer Prev Res (Phila Pa) 2009;2:14-21.

9. Veltman JA, et al. Chromosome instability as an indicator of malignant progression in laryngeal mucosa. J Clin Oncol 2000;18:1644-51.

10. Pierssens DD, et al. Chromosome instability in tumor resection margins of primary OSCC is a predictor of local recurrence. Oral Oncol 2017;66:14-21.

11. Califano J, et al. Genetic progression model for head and neck cancer: implications for field cancerization. Cancer Res 1996;56:2488-92.

12. Zhang $\mathrm{L}$, et al. Loss of heterozygosity (LOH) profiles--validated risk predictors for progression to oral cancer. Cancer Prev Res (Phila) 2012;5:1081-9.

13. Hall GL, et al. p16 Promoter methylation is a potential predictor of malignant transformation in oral epithelial dysplasia. Cancer Epidemiol Biomarkers Prev 2008;17:2174-9.

14. Moore PS, Chang Y. Why do viruses cause cancer? Highlights of the first century of human tumour virology. Nat Rev Cancer 2010;10:878-89.

15. Ha PK, et al. Progression of microsatellite instability from premalignant lesions to tumors of the head and neck. Int J Cancer 2002;102:615-7.

16. Braakhuis BJ, et al. A genetic explanation of Slaughter's concept of field cancerization: evidence and clinical implications. Cancer Res 2003;63:1727-30.

17. Chung $\mathrm{CH}$, et al. Genomic alterations in head and neck squamous cell carcinoma determined by cancer gene-targeted sequencing. Ann Oncol 2015;26:1216-23.

18. Agrawal $\mathrm{N}$, et al. Exome sequencing of head and neck squamous cell carcinoma reveals inactivating mutations in NOTCH1. Science 2011;333:1154-7.

19. Nankivell $P$, et al. Biomarkers in laryngeal dysplasia: a systematic review. Head Neck 2011;33:1170-6.

20. Graveland AP, et al. Molecular screening of oral precancer. Oral Oncol 2013;49:1129-35.

21. Nylander K, Dabelsteen E, Hall PA. The p53 molecule and its prognostic role in squamous cell carcinomas of the head and neck. J Oral Pathol Med 2000;29: 413-25. 
22. Hittelman WN. Genetic instability in epithelial tissues at risk for cancer. Ann $N$ Y Acad Sci 2001;952: 1-12.

23. Moz LE, et al. Comparative study of the behavior of p53 immunoexpression in smoking associated lesions: Reinke's edema and laryngeal carcinoma. Inhal Toxicol 2013;25:17-20.

24. Vousden KH, Lane DP. p53 in health and disease. Nat Rev Mol Cell Biol 2007;8:275-83.

25. Hafkamp $\mathrm{HC}$, et al. A subset of head and neck squamous cell carcinomas exhibits integration of HPV 16/18 DNA and overexpression of p16INK4A and p53 in the absence of mutations in p53 exons 5-8. Int J Cancer 2003;107:394-400.

26. Bosch FX, et al. Head and neck tumor sites differ in prevalence and spectrum of p53 alterations but these have limited prognostic value. Int J Cancer 2004;111: 530-8.

27. Izzo JG, et al. Dysregulated cyclin D1 expression early in head and neck tumorigenesis: in vivo evidence for an association with subsequent gene amplification. Oncogene 1998;17:2313-22.

28. Schrijvers ML, et al. FADD expression as a prognosticator in early-stage glottic squamous cell carcinoma of the larynx treated primarily with radiotherapy. Int J Radiat Oncol Biol Phys 2012;83: 1220-6.

29. Gibcus $\mathrm{JH}$, et al. Amplicon mapping and expression profiling identify the Fasassociated death domain gene as a new driver in the 11q13.3 amplicon in laryngeal/pharyngeal cancer. Clin Cancer Res 2007; 13:6257-66.

30. Jurmeister P, et al. Parallel screening for ALK, MET and ROS1 alterations in nonsmall cell lung cancer with implications for daily routine testing. Lung Cancer 2015;87:122-9.

31. Tsuta K, et al. RET-rearranged non-small-cell lung carcinoma: a clinicopathological and molecular analysis. Br J Cancer 2014;110:1571-8.

32. Orsaria $\mathrm{M}$, et al. Chromosome 17 polysomy: correlation with histological parameters and HER2NEU gene amplification. J Clin Pathol 2013;66:1070-5.

33. Sirvent N, et al. Detection of MDM2-CDK4 amplification by fluorescence in situ hybridization in 200 paraffin-embedded tumor samples: utility in diagnosing adipocytic lesions and comparison with immunohistochemistry and real-time PCR. Am J Surg Pathol 2007;31:1476-89.

34. Horn $\mathrm{H}$, et al. Fluorescence in situ analysis of soft tissue tumor associated genetic alterations in formalin-fixed paraffin-embedded tissue. Pathol Res Pract 2014;210: 804-11.

35. Huysentruyt CJ, et al. Modified UroVysion scoring criteria increase the urothelial carcinoma detection rate in cases of equivocal urinary cytology. Histopathology 2011;58:1048-53.

36. Gerami $\mathrm{P}$, et al. Fluorescence in situ hybridization (FISH) as an ancillary diagnostic tool in the diagnosis of melanoma. Am J Surg Pathol 2009;33:1146-56.

37. van den Bent MJ. How to use molecular markers when caring for a patient with brain cancer: $1 \mathrm{P} / 19 \mathrm{Q}$ as a predictive and prognostic marker in the neuro-oncology clinic. Am Soc Clin Oncol Educ Book, 2013:114-6.

38. De Vito A, Meccariello G, Vicini C. Narrow band imaging as screening test for early detection of laryngeal cancer: a prospective study. Clin Otolaryngol 2017;42: 347-53.

39. Cancer Genome Atlas N. Comprehensive genomic characterization of head and neck squamous cell carcinomas. Nature 2015;517:576-82. 
SUMMARY

$$
\text { I }
$$




\section{Summary}

In Chapter 1 a general introduction on the carcinogenesis of head and neck squamous cell carcinoma (HNSCC) and the etiological, clinical, epidemiological, histopathological and genetic features is given. HNSCC is a disease with a poor overall survival rate of approximately $50 \%$. The factors that contribute to this disappointing survival rate are outlined. One of these is the existence of multiple precursor lesions in the head and neck mucosa or field cancerization, which may lead to tumor outgrowth. The importance of early detection and appropriate treatment of premalignant head and neck lesions is emphasized. The currently available diagnostic detection methods are described. Histopathological assessment of head and neck tissue biopsies remains until now the gold standard for the assessment of premalignant and malignant head and neck lesions. However, the histopathological approach, for which three internationally accepted classification systems do exist, has limitations due to inter observer variation in the assessment of lesions. This results in poor prognostic information in terms of an unreliable prediction of the risk of malignant progression for head and neck premalignancies. Due to the lack of a reliable prognostic tool for these lesions, the clinician may have difficulties in decision-making concerning the treatment or follow-up strategy of a lesion. The need for additional, more reliable, molecularly based and clinically applicable markers of progression, especially based on chromosome instability $(\mathrm{Cl})$ detection is highlighted, with a focus on clinically implementable diagnostic methods. The aims of the present thesis are described.

The inter observer agreement between the three internationally accepted histopathological classification systems i.e. the WHO-, SIN- and Ljubljana classification in premalignant laryngeal lesions is compared in Chapter 2. We found a disappointing high interobserver variability for all three systems. A modification of the grading systems towards a 2 or 3 grade system resulted in an improvement of the agreement between observers, reflected in a "moderate" kappa value. Furthermore, an improvement of the inter-observer consensus was achieved when a lesion was simultaneously assessed by more than one pathologist. In order to achieve a maximum of interobserver agreement, a simplification of the existing histopathological grading systems towards a 2- or 3- degree profiling of lesions, i.e. low-risk, intermediate risk and high-risk as well as simultaneous histopathological assessment could lead to a more consistent histopathological diagnosis.

In order to acquire more reliable prognostic information on the malignant potential of premalignant head and neck lesions, $\mathrm{Cl}$ detection can be applied. 
This principle is highlighted in Chapter 3, where we investigated the potential role of $\mathrm{Cl}$, defined as Copy Number Variations (CNV) of chromosomes 1 and 7 , as a marker for malignant progression in laryngeal precursor lesions. Based on earlier reports by Veltman et al. on the presence of CNVs of chromosome 1 and 7 in premalignant head and neck lesions, which showed to be associated with malignant progression, we further investigated this approach on a new series of laryngeal precursor lesions. Chromosome 1 and $7 \mathrm{CNVs}$ were assessed by Fluorescent in Situ Hybridization (FISH) on centromere probes. Furthermore, the expression of the protein markers p53, Fass Associated Death Domain (FADD), pFADD and Cyclin D1 was immunohistochemically assessed. We observed that a large majority of the lesions with $\mathrm{Cl}$ showed copy number gain, i.e. trisomy, tetrasomy or polysomy. Lesions with $\mathrm{Cl}$ showed a strongly increased risk for malignant progression. Interestingly, $\mathrm{Cl}$ was found in all histopathological grades, e.g. also in the WHO classification hyperplasia, however, more frequently in the more advanced histopathological degrees. None of the protein markers showed to be useful as an individual marker of progression. Histopathological diagnosis showed to be unable to differentiate between progressive and non-progressive lesions, especially when only lesions containing hyperplasia, mild and moderate dysplasia were analyzed. Dichotomization of the histopathological diagnosis to low-grade (hyperplasia and mild dysplasia) and high-grade lesions (moderate dysplasia) improved the prognostic value of histopathology. This findings lead to a proposed multiparameter prognostic model based on the markers $\mathrm{Cl}$, dichotomized histopathological diagnosis, p53 and FADD. The combination of these markers showed to be a useful prognostic tool for laryngeal premalignancies.

In Chapter 4 we investigated the prognostic information provided by $\mathrm{Cl}$ in oral premalignant lesions. $\mathrm{Cl}$ detection was performed by both FISH analysis, based on the detection of CNVs of chromosome 1 and 7 and DNA Image Cytometry (ICM). The presence of $\mathrm{Cl}$ as detected by both methods was strongly associated with malignant progression. Both ICM and FISH yielded comparable prognostic information in terms of malignant progression risk. This suggests that the analysis of CNVs of chromosome 1 and 7 by FISH can give a reliable impression of the general ploidy status of a lesion. Both techniques have their merits and disadvantages. The FISH approach is ideal for the detection of especially small lesions and visualizes small groups of aberrant cells, which are not always detected by ICM. Furthermore, FISH is also applicable on small tissue biopsies such as laryngeal biopsies, which do not contain sufficient DNA for ICM analysis. In this study, the prognostic information provided by histopathological examination of lesions was also analyzed. Only if dichotomization of the four included histopathological grades, 
i.e. hyperplasia and mild dysplasia (low-grade) versus moderate and severe dysplasia (high-grade), was applied, a significant discrimination between nonprogressive and progressive lesions was found. This is comparable with the results found in premalignant laryngeal lesions, as reported in Chapter 3.

Furthermore, in a series of oral premalignant lesions of which different, consecutive tissue biopsies were available, we retrospectively analyzed the ploidy status over time (ICM and FISH 1c/7c). This analysis showed that almost all aneuploid tumors had an aneuploid precursor lesion and nearly all diploid precursor lesions resulted in a diploid tumor. Furthermore, in two cases an aneuploid tumor developed out of a aneuploid precursor lesion after a timespan of more than 9 years. On the basis of the information provided by $\mathrm{Cl}$ detection ( $\mathrm{Cl}$ or no $\mathrm{Cl}$ ) and histopathological grade (low-grade or high-grade), a three steps risk-profile for premalignant lesions was proposed, containing 1) diploid low-grade (low risk of malignant progression), 2) diploid high-grade and 3) aneuploid-low-grade (intermediate risk of malignant progression) and aneuploid high-grade (high risk of malignant progression). This subdivision of lesions could be useful to enable the discrimination of premalignant head and neck lesions that do not need follow-up, do require strict follow-up or do require immediate treatment.

While the prognosis of HNSCC patients largely depends on whether tumor relapse occurs or not, we analyzed the potential role of $\mathrm{Cl}$ detection in the search for residual, potentially malignant (groups of) cells in resection margins of oral squamous cell carcinomas (OSCC). In Chapter 5 we retrospectively analyzed resection margins in a set of 19 histopathologically radically resected OSCC for the presence of $\mathrm{Cl}$, assessed by FISH analysis, based on the detection of CNVs of chromosome 1 and or 7 , and p53 protein overexpression assessed by IHC. We correlated these data to the clinical outcome in terms of (loco)regional tumor recurrence. $\mathrm{Cl}$ in resection margins showed to be associated with tumor recurrence. Also long term recurrences, up to eleven years after primary resection, were found. P53 was not significantly associated with malignant progression. This pilot study indicates that additional $\mathrm{Cl}$ analysis should be considered in resection margins of histopathologically radically resected OSCC to minimalize the risk of tumor relapse. This has been recently confirmed in an extended study on OSCC resection margins (Pierssens et al. 2017).

In order to develop a maximum of objectivity in the $\mathrm{Cl}$ analysis in premalignant head and neck lesions, we described in Chapter 7 the definition of objective, clinically applicable evaluation criteria for $\mathrm{Cl}$ detection. We performed dualtarget FISH for chromosomes 1 and 7 centromeres on $4 \mu \mathrm{m}$ formalin-fixed, 
paraffin embedded tissue sections of 87 laryngeal premalignancies (severe dysplasia and carcinoma in situ (CIS) excluded) to detect CNVs. A set of normal head and neck squamous cell samples was used as a control population. Two approaches, derived from generally accepted tumor diagnostics based on CNV detection, were compared. First, the chromosome $7: 1$ ratio (CR), based on the objective count of chromosome signals of both chromosomes per nucleus in 100 nuclei was assessed. Second, the percentage of aberrant nuclei (PAN), based on the amount of aberrant nuclei (containing more than 2 signals per chromosome) in 100 analyzed nuclei, was established in each lesion. Based on the CRs found in the control population, we defined a normal range of CRs $(\geq 0.84 \leq 1.16)$, furthermore, the cut-off value for abnormal PAN was set at $\geq 10 \%$. Data were correlated with the clinical outcome of patients. Both evaluation methods were reliable for the prediction of malignant progression, however, PAN showed the strongest correlation with malignant progression especially in combination with dichotomized histopathological diagnosis. These evaluation criteria for $\mathrm{Cl}$ detection based on PAN, with a cut-off value of $\geq 10 \%$ aberrant nuclei, are also recommendable because of the possibility of a relatively quick, easy to perform assessment of lesions. This study provides information for a standardized, clinically applicable protocol for $\mathrm{FISH}$-based $\mathrm{Cl}$ detection in premalignant head and neck lesions.

Chapter 8 comprises the general discussion and the conclusion of the results described in this thesis. Future perspectives are discussed. 
SAMENVATTING

$$
\text { I }
$$




\section{Samenvatting}

Hoofdstuk 1 bevat een algemene introductie in de carcinogenese van hoofdhals kanker (HNSCC) en de etiologie, klinische presentatie, histopathologische en genetische kenmerken van deze aandoening. HNSCC kenmerkt zich door een slechte 5 -jaars overleving van circa $50 \%$. Factoren die bijdragen aan deze slechte prognose worden toegelicht. Een van de belangrijkste hiervan is de frequente aanwezigheid van multiple mucosale laesies die voorstadia van HNSCC bevatten (dysplasie), en zich kunnen ontwikkelen tot HNSCC. Het belang van vroege detectie van deze potentieel maligne laesies wordt toegelicht, alsmede een overzicht van de huidige, meest frequent gebruikte detectie methoden hiervoor. Histopathologische beoordeling van weefsel coupes uit biopten is tot op heden de gouden standaard voor de analyse van premaligne en maligne hoofd-hals laesies. Echter, histopathologische beoordeling, waarvoor drie internationaal geaccepteerde classificaties bestaan, kenmerkt zich door een hoge variabiliteit in diagnoses indien een coupe door verschillende onafhankelijke pathologen wordt beoordeeld (inter-observer variabiliteit). Dit resulteert in een onbetrouwbare diagnose met betrekking tot het risico op maligne ontaarding en leidt tot onduidelijkheid voor de behandelend arts omtrent welke beslissing hij/zij dient te nemen ten aanzien van eventuele behandeling of follow-up van de betreffende laesie. De noodzaak voor het aan de diagnostiek van premaligne hoofd-hals laesies toevoegen van additionele, meer betrouwbare, moleculaire markers wordt benoemd. Een belangrijke potentiele marker voor het voorspellen van maligne progressie van een laesie is Chromosomale Instabiliteit $(\mathrm{Cl})$, welke gebaseerd is op de genotypische kenmerken van een laesie, losstaand van fenotypische veranderingen. De verschillende methoden om $\mathrm{Cl}$ aan te tonen, waaronder de detectie van veranderingen in kopie aantal (CNV) van de chromosomen 1 en 7 door middel van Fluorescente In Situ Hydridizatie (FISH), worden belicht, met de nadruk op klinische toepasbaarheid. Ten slotte volgt een nadere toelichting op de doelen van dit proefschrift.

De inter-observer variabiliteit bij het toepassen van de drie internationaal geaccepteerde histopathologische classificatie systemen, te weten de WHO-, SIN- en Ljubljana classificatie, wordt in Hoofdstuk 2 geanalyseerd en onderling vergeleken in een groep premaligne larynx laesies. Het blijkt dat de drie classificatie systemen zich alle kenmerken door een hoge inter-observer variabiliteit. Een vereenvoudigende modificatie van deze classificatie systemen naar een twee of drie-graads indeling resulteert in een verbetering van de overeenkomst tussen de beoordelingen van de verschillende pathologen, uitgedrukt in een "redelijke" Kappa-waarde. Daarnaast blijkt dat er meer 
consensus ten aanzien van de diagnose wordt bereikt indien meerdere pathologen tegelijk een weefselcoupe beoordelen. Door het introduceren van een histopathologische indeling voor premaligne hoofd-hals laesies, bestaande uit twee of drie keuzemogelijkheden, kan de inter-observer variabiliteit worden gereduceerd, een positief effect zal hebben op de prognostische informatie geleverd door histopathologische beoordeling.

In Hoofdstuk 3 wordt $\mathrm{Cl}$ detectie, gebaseerd op de detectie van CNV's van chromosoom 1 en 7 door middel van FISH met behulp van chromosoom 1- en 7- specifieke centromeer DNA-probes (FISH 1c/7c) op een serie premaligne larynxlaesies beschreven. Deze techniek werd reeds eerder toegepast in een eerdere pilot-studie op premaligne larynxlaesies door Veltman et al. (2000). De betrouwbaarheid van deze potentiële marker in het kader van voorspelling van maligne progressie werd retrospectief geanalyseerd. Daarnaast werd immunohistochemisch aangetoonde overexpressie van de eiwitten p53, FADD, pFADD en Cycline D1 gecorreleerd met eventuele maligne progressie op basis van de beschikbare klinische patiëntendata. De laesies waarin $\mathrm{Cl}$ werd gedetecteerd, vertoonden vrijwel alle een verhoogd kopie aantal van chromosoom 1 en/of 7 (gain), te weten trisomie, tetrasomie en polysomie. Laesies met $\mathrm{Cl}$ bleken een sterk verhoogde kans te hebben op maligne ontaarding. Een opvallende bevinding was dat in alle voorloper stadia, variërend van hyperplasie tot ernstige dysplasie, $\mathrm{Cl}$ werd gedetecteerd, in een min of meer oplopende mate, al naar gelang de ernst van de histopathologische diagnose. Geen van de onderzochte eiwit-markers bleek significant geassocieerd met maligne progressie in de univariate analyse. Ook histopathologie (WHO-classificering) bleek geen significante voorspeller van maligne progressie, met name voor de lagere histopathologische classificeringen, te weten hyperplasie, geringe en matige dysplasie. De prognostische betrouwbaarheid van histopathologie nam toe door een gedichotomiseerde indeling toe te passen, bestaande uit twee keuzemogelijkheden, waarbij hyperplasie en geringe dysplasie versus matige en ernstige dysplasie respectievelijk werden beschouwd als laesies met "laag risico" en "hoog risico". Logistische regressie analyse toonde aan dat de combinatie van $\mathrm{Cl}$, gedichotomiseerde histopathologische diagnose, p53 en FADD samen gebruikt kan worden als een bruikbaar, betrouwbaar model voor de voorspelling van maligne progressie in premaligne larynx laesies. De laatste twee eiwit-markers dragen positief bij aan de reductie van het aantal foutnegatieven.

De waarde van $\mathrm{Cl}$ bepaling in het kader van het voorspellen van maligne progressie in premaligne mondholtelaesies werd onderzocht in Hoofdstuk 4. $\mathrm{Cl}$ detectie vond hier plaats door middel van $\mathrm{FISH} 1 \mathrm{c} / 7 \mathrm{c}$ alsmede door analyse van de DNA ploidie status door middel van DNA Image Cytometrie (ICM), 
waarbij alle ploidie configuraties buiten de normale diploide status werden beschouwd als $\mathrm{Cl}$. Met beide methoden kon $\mathrm{Cl}$ worden aangetoond en was significant geassocieerd met maligne progressie. Beide methoden toonden maligne progressie-kans aan met een vergelijkbare Hazard Ratio (HR), hetgeen aanduidt dat beide technieken vergelijkbare prognostische informatie leveren. Dit geeft aan dat $\mathrm{Cl}$ detectie met FISH 1c/7c, waarbij er slechts twee chromosomen worden geanalyseerd, een betrouwbare indruk geeft van de algemene ploidie status van een laesie. Beide methoden kennen voor- en nadelen. FISH 1c/7c kan bijvoorbeeld kleine groepjes celkernen met $\mathrm{Cl}$ detecteren, welke niet zouden leiden tot een afwijkende ploidie status bij ICM analyse. Daarnaast is deze techniek geschikt voor kleine weefselbiopten (zoals van de larynx) waarbij vaak te weinig materiaal bestaat voor ICM bepaling.

De prognostische informatie van de histopathologische diagnose bleek niet afdoende om te discrimineren tussen progressieve en niet progressieve laesies, met name in de WHO classificaties hyperplasie, geringe en matige dysplasie. Dichotomisatie, waarbij hyperplasie en geringe dysplasie werden gebundeld tot een "laag risico" groep en matige en ernstige dysplasie tot een "hoog risico" groep, leidde tot een betere prognostische waarde van histopathologie als parameter, uitgedrukt in een significant slechtere ziektevrije overleving voor de laatste groep. Deze uitkomst was vergelijkbaar met de bevindingen in premaligne larynx laesies, zoals beschreven in Hoofdstuk 3.

Vervolgens werden van 12 patiënten verschillende weefselbiopten, afkomstig van dezelfde localisatie, door middel van FISH 1c/7c en ICM geanalyseerd, met als doel de ploidie status in de voorstadia in de tijd tot aan maligne ontaarding te meten. Het bleek dat vrijwel alle aneuploide tumoren aneuploide voorlopers hadden en het merendeel van de diploide tumoren diploide voorlopers. Tevens werden enkele gevallen gezien waarbij een aneuploide status werd gevolgd door een diploide status en vice versa. Ook werd een uitzonderlijk lange tijdspanne tot maligne ontaarding van meer dan 9 jaar waargenomen in twee gevallen.

Op basis van de gegevens verkregen door middel van $\mathrm{Cl}$ detectie (FISH 1c/7c en ICM) en histopathologische beoordeling werd een risicoprofiel-indeling gemaakt bestaande uit drie categorieën: 1) diploid-laag risico (lage ontaardingskans), 2) diploid-hoog risico en aneuploid-laag risico (intermediaire ontaardingskans) en 3) aneuploid-hoog risico (hoge ontaardingskans). Deze indeling van premaligne laesies zou de basis kunnen zijn voor een klinische indeling met betrekking tot de behandeling van laesies respectievelijk: geen follow-up, strikte follow-up en (chirurgische) behandeling.

De prognose van patiënten met HNSCC wordt sterk negatief beïnvloed door het wel of niet optreden van een (loco)regionaal recidief door de aanwezigheid 
van achtergebleven tumorcellen (minimal residual disease) of premaligne cellen, die potentieel kunnen uitgroeien tot HNSCC. In dit kader werd in Hoofdstuk 5 retrospectief een kleine groep mondholtetumoren geanalyseerd, welke histopathologisch radicaal waren gereseceerd. Klinische gegevens met betrekking tot tumor recidief werden verzameld. Door middel van FISH 1c/7c werd onderzocht of er in de resectievlakken van de betreffende preparaten $\mathrm{Cl}$ aanwezig was en of dit geassocieerd was met later tumor recidief. Daarnaast werd door middel van immunohistochemie p53 eiwit overexpressie gemeten in de resectievlakken en de associatie met maligne progressie bepaald. $\mathrm{Cl}$ bleek significant geassocieerd met het optreden van tumor recidief. P53 was niet significant geassocieerd met tumor recidief. Op basis van deze gegevens en naar aanleiding van de bevestiging van deze resultaten in een recent gepubliceerde vervolg studie over $\mathrm{Cl}$ in resectieranden (Pierssens et al. 2017), dient $\mathrm{Cl}$ detectie in resectieranden te worden overwogen.

Hoofdstuk 7 bevat een nadere analyse van de evaluatie criteria voor FISH $1 \mathrm{c} / 7 \mathrm{c}$ in het kader van $\mathrm{Cl}$ detectie in premaligne hoofd-hals laesies. Deze criteria dienen maximaal objectief te zijn en goed klinisch toepasbaar. FISH $1 \mathrm{c} / 7 \mathrm{c}$ werd toegepast op $4 \mu \mathrm{m}$ formaline-gefixeerde paraffine coupes op een groep premaligne larynxlaesies (ernstige dysplasie en carcinoma in situ werden geëxcludeerd), met als doel het aantonen van veranderingen in kopie aantal van één of beide chromosomen (CNV). Voor het bepalen van CNV's wordt in het algemeen in de diagnostiek van diverse soorten kanker gebruik gemaakt van 1) het bepalen van een chromosoom ratio tussen de twee chromosomen in een bepaald aantal te beoordelen celkernen, of 2) het objectief aantal afwijkende celkernen (die CNVs bevatten voor een of beide chromosomen) per vastgesteld aantal celkernen. Hierbij wordt gebruik gemaakt van een afkappunt, uitgedrukt in een percentage afwijkende celkernen.

In de studiepopulatie werd de chromosoom 7: chromosoom 1 ratio (CR) berekend op basis van het totaal aantal getelde signalen per 100 celkernen. Normaalwaarden voor de CR $(\geq 0.84 \leq 1.16)$ werden berekend vanuit de CRs gevonden in een serie van 25 coupes van normaal plaveiselcelepitheel. Vervolgens werd volgens de tweede gangbare methode het percentage afwijkende celkernen (geteld per 100 celkernen) vastgesteld per laesie (PAN). Het optimale afkappunt werd vastgesteld op $\geq 10 \%$ afwijkende celkernen. De uitkomsten werden gecorreleerd met de klinische patiëntendata en de associatie met maligne progressie werd berekend. Hieruit bleek met name bij het gebruik van PAN een sterke associatie met maligne progressie. CR en PAN werden ook gebruikt in combinatie met gedichotomiseerde histopathologische diagnose (hyperplasie versus geringe en matige dysplasie 
samengevoegd) in een multivariate regressie analyse, waarbij de betrouwbaarheid van de test toenam.

Voor de beoordeling van FISH 1c/7c lijkt op basis van deze data PAN de meest betrouwbare en minst complexe beoordelingsmethode voor weefselcoupes.

De gedichotomiseerde histopathologische diagnose in combinatie met PAN (met een afkappunt van $\geq 10 \%$ ) levert een positieve bijdrage in de zin van een toename van de sensitiviteit van de test. Deze studie is de basis voor verdere toekomstige implementatie van $\mathrm{Cl}$ detectie door middel van $\mathrm{FISH} 1 \mathrm{c} / 7 \mathrm{c}$ in de diagnostiek van premaligne hoofd-hals laesies en/ of resectieranden van hoofd-halstumoren.

Hoofdstuk 8 bevat de algemene discussie en conclusie van de resultaten van dit proefschrift toekomst perspectieven worden besproken. 
VALORISATION ADDENDUM 


\section{Valorisation addendum}

Early detection of head and neck cancer is of utmost importance for prognosis and preservation of function. In an ideal scenario, progressive premalignant lesions will be detected before malignant progression has taken place. Especially in the field of head and neck cancer, possibilities for early detection are given for a number of subsites: e.g. mucosal alterations of the oral cavity can be visualized at ENT-examination and mucosal alterations of the vocal cords can give early complaints of hoarseness. If mucosal alterations are detected, tissue biopsies will guide the clinician in the decision whether treatment, i.e. surgical excision or radiation therapy, is necessary. In case of malignancy there is no doubt about the need of treatment. However, in case of premalignant lesions that harbor a risk of malignant progression to head and neck squamous cell carcinoma (HNSCC), decisions are more complex. Until now, the risk of malignant progression for different precursor lesions remains unclear. Furthermore, histopathological classifications of these lesions are variable and greatly observer dependent.

The same is the case for resection margins of malignant head and neck tumors: not only (minimal) residual disease, but also groups of premalignant cells in resection margins of tumors can lead to an increased risk of (local) recurrence.

\section{Reliability and clinical value of histopathological diagnosis}

The tissue analysis of mucosal biopsies is generally performed by histopathological assessment. However, the in literature reported malignant progression risks for the different grades of dysplasia differ largely ${ }^{1,2}$ and no internationally accepted guidelines exist for the therapeutic management of these precursor lesions.

Therefore, the studies in this thesis have been performed in order to 1) analyze the reliability of today's histopathologic classification systems in terms of inter observer concordance and prognostic information concerning malignant progression risk and 2) to identify additional markers of malignant progression in premalignant laryngeal and oral lesions. Furthermore, markers for tumor recurrence in resection margins of oral squamous cell carcinomas were investigated.

Our studies showed that the histopathological assessment of premalignant head and neck lesions on the basis of the existing histopathological classifications, leads to an inconsistent diagnosis, related to inter-observer variability. Furthermore, the WHO classifications hyperplasia, mild and moderate dysplasia do not discriminate between progressive and non- 
progressive lesions. An improvement of the reliability can be achieved by the introduction of a two-grade scale modification of the used histopathological WHO-criteria, i.e. a division of premalignant lesions in "low-grade" (hyperplasia and mild dysplasia) and "high-grade" (moderate dysplasia).

\section{Chromosome instability detection and its additional value above the available markers of progression}

While the histopathological diagnosis of a premalignant lesion does not provide reliable prognostic information on the malignant potential of a lesion, the clinician may have difficulties in the decision-making on the therapeutic management of a lesion. Therefore, additional molecular markers for the discrimination of progressive lesions are needed to solve this issue. In this thesis, we applied chromosome instability $(\mathrm{Cl})$ detection as an additional marker of progression in premalignant laryngeal and oral head and neck lesions. Chromosome Instability detection was performed by Fluorescent in Situ Hybridization (FISH) on chromosome 1 and 7 centromere probes. $\mathrm{Cl}$ was defined as the presence of copy number variations (CNVs), e.g. trisomy of polysomy of one or both chromosomes. We proved that $\mathrm{Cl}$ detection can be performed by the count of aberrant cell nuclei in 100 nuclei, with a cut-off value of $\geq 10 \%$ aberrant nuclei (PAN). This approach improves the objectivity of the assessment as compared to histopathological assessment. We combined the information provided by the histopathological diagnosis, which was converted to a two-degree classification, with $\mathrm{Cl}$ and immunohistochemically assessed protein overexpression of p53 and Fass Associated Death Domain (FADD). This lead to a multi-parameter progression model based on the previously mentioned markers, which improved the prognostic value compared to the routine histopathological assessment. This predictive model could be considered as a new tool for clinicians that need a more reliable tool for the discrimination of potentially progressive head and neck precursor lesions. An improvement of the counseling and therefore a more appropriate treatment of head and neck premalignancies will probably lead to a long-term decrease of patients morbidity and mortality, which is in general high in HNSCC. ${ }^{3,4}$

\section{Clinical applications of $\mathrm{Cl}$ detection and additional molecular markers}

The main proposed molecular marker of this thesis is chromosomal instability (Cl), defined as copy CNVs of chromosomes 1 and 7 , which can be easily 
assessed by dual target, centromere probe FISH. The relative low complexity of this detection method makes it very attractive for application in the daily clinical setting of ENT-surgeons, maxillofacial surgeons and other clinicians who encounter patients with potentially malignant head and neck lesions. $\mathrm{Cl}$ detection by FISH can be implemented in a two-day diagnostic procedure and provides a quick and reliable diagnosis, especially if combined with a simplified, two-degree histopathological assessment scale and additional p53 /FADD immunostaining. The application of a quick Cl-detection procedure on freshfrozen intra operative tissue samples is in development.

\section{Cost-effectiveness of the suggested new diagnostic model}

$\mathrm{Cl}$ detection by $\mathrm{FISH}$ and immunohistochemistry can be performed with relatively low costs especially if compared to other, more complex molecular detection methods.

There are no data available on the total costs related to the diagnostic procedure, treatment and follow-up of HNSCC patients. However, it is clear that the health-care related costs of a patient who is treated for HNSCC are high and often include a surgical procedure, hospitalization of the patient, radiation therapy, revalidation, (years of intensive) medical follow-up and sometimes specialized supportive extramural health care in case of progressive and non-curable disease. Secondary costs related to a short-term or long-term decrease of work-productivity should also be taken into account. A global comparison of the costs made in our clinic for the surgical treatment of a premalignant vs. a malignant oral lesion showed that the costs are approximately 10 times higher for the latter (i.e. 1700 euro vs. 17000 euro). The implementation of $\mathrm{Cl}$ detection and immunostainings in the diagnostic procedure will lead to a slight increase of the diagnostic costs which, however, are non-significant as compared to the amount that can be potentially saved by the prevention of the development of HNSCC. However, yet to perform costeffectiveness studies could provide more information on this issue.

\section{Future perspectives- prospective study design}

Today, there is no generally applied diagnostic and treatment protocol for premalignant head and neck lesions, except for lesions containing severe dysplasia or CIS (based on the WHO classification), which are in general treated by radical surgical (laser)excision or radiation therapy ${ }^{5}$ Based on the results of this thesis, future research should focus on the development of a standardized, uniform and validated treatment protocol for premalignant head 
and neck lesions. Currently, we are working on the development of a prospective, clinical multi-center study on the diagnostic and therapeutic approach of head and neck premalignancies with implementation of $\mathrm{Cl}$ detection. Also patient related parameters such as the quality of life in relationship to potential loss of functionality (i.e. voice quality, swallowing) and discomfort after a performed surgical treatment as well as the costeffectiveness of this new approach of head and neck premalignancies will be subject of investigation. This prospective study may finally lead to the definition of the optimal moment for (surgical) intervention in head and neck premalignancies.

Last but not least, it would be of great interest to perform further research based on the same principles, on other premalignant lesions found in the aerodigestive tract, for which comparable diagnostic issues do exist. 


\section{References}

1. Fleskens S, Slootweg P. Grading systems in head and neck dysplasia: their prognostic value, weaknesses and utility. Head Neck Oncol. 2009;1:11.

2. McLaren KM, et al. Consistency of histopathological reporting of laryngeal dysplasia. The Scottish Pathology Consistency Group. Histopathology. 2000;37: 460-3.

3. Xing $\mathrm{Y}$, et al. Relation between the level of lymph node metastasis and survival in locally advanced head and neck squamous cell carcinoma. Cancer. 2016;122: 534-45.

4. O'Sullivan B, Shah J. New TNM staging criteria for head and neck tumors. Semin Surg Oncol. 2003;21:30-42.

5. IKN-Richtlijn Hoofd Halstumoren https://richtlijnendatabase.nl/richtlijn/hoofdhalstumoren 
LIST OF PUBLICATIONS

$$
\text { I }
$$




\section{List of publications}

Bergshoeff VE, Hopman AH, Zwijnenberg IR, Ramaekers FC, Bot FJ, Kremer $B$, Manni JJ, Speel EJ. Chromosome instability in resection margins predicts recurrence of oral squamous cell carcinoma. J Pathol 2008;215:347-8.

Weerkamp NJ, Koehler PJ, Bergshoeff VE. Airhead with auras J Neurol 2010;257:464-465

Fleskens SA*, Bergshoeff VE*, Voogd AC, van Velthuysen ML, Bot FJ, Speel EJ, Kremer B, Takes R, Slootweg P. Interobserver variability of laryngeal mucosal premalignant lesions: a histopathological evaluation. Mod Pathol 2011;24:892-8. (*equally contributed)

Siebers TJ*, Bergshoeff VE*, Otte-Holler I, Kremer B, Speel EJ, Van der Laak JA, Merkx MA, Slootweg PJ. Chromosome instability predicts the progression of premalignant oral lesions. Oral Oncol 2013;49:1121-8 ( ${ }^{*}$ equally contributed)

Bergshoeff VE, Van der Heijden, Haesevoets A, Litjens SG, Bot FJ, Voogd AC, Chenault MN, Hopman AH, Schuuring E, Van der Wal JM, Manni JJ, Ramaekers FC, Kremer B, Speel EJ. Chromosome instability predicts progression of premalignant lesions of the larynx. Pathology 2014;46:216-24

Willems RPP, Busari OJ, Van Waardenburg DA, Bergshoeff VE. OSAS Due to Massive Lingual Tonsillar Hypertrophy in 8-Year-Old Boy with Delta-BetaThalassemia - A Case Report J Pediatr Neonatal Care 2015;2: 00079

Hofland E, Bergshoeff VE, Maes A, Slappendel R. The breathtaking power of money. A case report of an unexpected, impaired intubation by a swallowed coin. Accepted for publication Acta anesthesiologica Belgica

Bergshoeff VE, Balkenhol MCA, Haesevoets A, Ruland A, Chenault MN, Nelissen RC, Van der Laak JAWM, Takes R, Van den Brekel MC, Van Velthuysen MLF, Ramaekers FCS, Kremer B, Speel EJM. Objective evaluation criteria for chromosome Instability detection by FISH to predict malignant progression in premalignant laryngeal lesions. Submitted, J Molec Diagnostics 
DANKWOORD

$$
\text { I }
$$




\section{Dankwoord}

Het ei is gelegd! Trots ben ik dat na een jaren durend onderzoekstraject het eindresultaat -dit proefschrift- nu een feit is. Wat begon als enkele losse A4-tjes met hierop handgeschreven de namen van patiënten die moesten worden geïncludeerd is uitgegroeid tot diverse onderzoekslijnen rondom het hoofdthema chromosomale instabiliteit in (voorstadia van) hoofd-hals kanker. Ik ben trots dat ik aan het begin van dit project heb mogen staan. Mooi is te zien hoe in dit kader een steeds nauwere samenwerking is ontstaan tussen de basale wetenschap, te weten de Moleculaire Celbiologie met de klinische geneeskunde, zijnde de Keel- Neus en Oorheelkunde en in het midden de Klinische Pathologie. Geen van deze drie entiteiten kan floreren zonder de ander.

In de afgelopen jaren hebben velen bijgedragen aan de voortgang van het onderzoek en hiervoor ben ik zeer dankbaar. Enkelen wil ik hierbij in het bijzonder danken.

Als eerste wil ik bedanken Professor Kremer. Beste Bernd, jij bent naast mijn (tweede) opleider in het MUMC een ontzettend toegewijde, integere en altijd enthousiaste persoon. Jouw pragmatische visie op het onderzoek heeft bijgedragen tot het tot stand komen van praktische handvatten waarmee dit onderzoek een duidelijke klinische relevantie heeft gekregen. Ik denk met veel plezier terug aan de vele avonden waarop we, met name in de eindfase van het proefschrift, met de nodige gezelligheid en humor bij jou thuis hebben doorgewerkt richting de afronding. Ik hoop dat we onze goede samenwerking in de toekomst mogen voortzetten.

Professor Speel, beste Ernst-Jan, we hebben er heel wat jaartjes samen opzitten! Wat begon op je kamer op de Moleculaire Celbiologie, werd later de Pathologie. Je hebt mij de kern van het basaal wetenschappelijk onderzoek bijgebracht. Het voelde soms als een detective: het in het donker bekijken van de microscopische coupes, waar ik dan iets meende te zien, en jou vervolgens enthousiast erbij riep. Je bent een enorme duizendpoot en hebt een overvolle agenda, wat onze afspraken soms in de weg stond, maar ik ben je dankbaar dat je in deze drukte toch tijd vrij hebt kunnen maken voor het samen schrijven aan de papers in dit proefschrift, wat ook altijd weer gezellig was.

Professor Ramaekers, beste Frans, je hebt altijd de afgelopen jaren over mijn schouder meegekeken. Ik ben je dankbaar voor je helikopter-visie op het onderzoek. Ondanks het feit, dat je je met zoveel andere projecten bezighoudt, 
kon je feilloos de draad oppakken als je weer eens een definitieve versie onder je neus kreeg. Je ziet altijd de rode draad in het verhaal en streeft naar een tijdsplanning voor afronding, wat zeker beslissend is geweest voor de voortgang van het promotietraject, dank daarvoor!

Professor Manni, beste Hans, mijn eerste opleider Keel-, Neus en Oorheelkunde. Via jou ben ik in dit onderzoeksproject gerold. Zonder jouw rol als initiator was het er niet geweest. Je bent de "oervader" die aan het begin stond van dit onderzoek en had al vele ideeën voordat we er überhaupt aan begonnen. Je bent - ook in je werk als Keel-, Neus- Oorarts- en oncoloogaltijd hard geweest voor jezelf en een enorme doorzetter: "ook na tegenslagen niet opgeven"! Een grondhouding waar ik zeker veel van heb geleerd. Ondanks je pensionering bleef je altijd zeer betrokken en geïnteresseerd in het onderzoek, wat ik enorm waardeer.

Stijn Fleskens en Theke Siebers, dank voor de prettige samenwerking die heeft uitgemond in twee gezamenlijke papers.

Annick en Andrea hartelijk dank voor jullie hulp bij de analyses.

Dr. Chenault, beste Mickey, je hebt mij geweldig geholpen in methodologisch en statistisch opzicht. Je heldere kijk op de data in combinatie met veel humor zijn zeer waardevol.

Dr. Voogd, beste Adri, je hebt onze eerste FISH studie op larynxlaesies vanaf het allereerste begin statistisch begeleid, waarvoor mijn hartelijke dank.

Graag wil ik de leden van de manuscriptcommissie en de corona danken voor hun beoordeling en hun aanwezigheid tijdens de verdediging van het proefschrift.

De stafleden en assistenten KNO gedurende mijn opleidingstijd in het MUMC. We hebben naast een leerzame tijd ook ontzettend veel plezier beleefd samen, dank daarvoor!

Kenneth, ik ben je dankbaar voor alle mooie en humorvolle momenten die we samen hebben beleefd, onder andere als kamergenoten in het Oxford gebouw. Ik ben blij dat je over bent gekomen uit Frankrijk om mijn paranimf te zijn!

Secretaresses van het Oxford gebouw: Edith, Ester, Marèse en Nicole, jullie hebben gezorgd voor de noodzakelijke gezelligheid gedurende de vele uren 
die ik de afgelopen jaren op jullie afdeling heb mogen doorbrengen om het proefschrift af te schrijven, waarvoor dank.

Tiny Wouters, dank voor jouw vliegensvlugge afwerken van dit proefschrift

Mijn maten van de huidige maatschap KNO in het Zuyderland MC: dank voor jullie vertrouwen, geduld en flexibiliteit de afgelopen jaren. Zonder deze factoren was het niet gelukt dit project af te ronden. Jullie zijn mij dierbaar.

Margreet, mijn hardloop-maatje: je relativerende en inspirerende woorden tijdens de vele kilometers die we er op hebben zitten met Juulke onze (leen)hond zijn goud waard!

Mijn tweelingzus Alina, ondanks de reisafstand zijn we nog steeds net zo close als in onze kindertijd. Jouw promotie is al jaren geleden afgerond, waar ik best jaloers op ben. Heerlijk dat jij nu mijn paranimf bent.

Mijn lieve ouders, het doet mij verdriet dat jullie niet meer aanwezig kunnen zijn om mijn promotie mee te maken. Ik ben jullie intens dankbaar voor alles wat jullie mij hebben meegegeven. Doorzettingsvermogen, altijd verdieping zoeken, liefde voor cultuur en wetenschap. Ik hoop dat jullie toch vanuit die andere wereld meegenieten.

Kochana Rodzino z Polski! Grunt to rodzinka! Bardzo cieszę się, że będziecie uczestniczyć w ceremonii obrony mojego doktoratu, serdecznie Wam dziekuję!

Mijn lieve man en kinderen, Hans, Emilia, Josephine en Titus, zonder jullie steun, geduld en acceptatie van de offers waarmee dit gepaard is gegaan, was het zeker niet gelukt dit werk af te maken. Ik ben er weer voor jullie! 
CURRICULUM VITAE 


\section{Curriculum Vitae}

Verona Ewa Bergshoeff werd op 13 maart 1975 geboren te Gouda.

Zij behaalde in 1993 haar Atheneum-B diploma aan het Christelijk Lyceum te Gouda.

In 1993 startte zij met de studie medicijnen aan de Erasmus Universiteit te Rotterdam. Zij volgde buiten de reguliere co-schappen enkele (keuze)coschappen aan het Hôpital Edouard Herriot en Hôpital de l'Hôtel Dieu (Hospices Civiles) te Lyon, Frankrijk.

In 2000 behaalde zij haar artsexamen. Aansluitend was zij tot eind 2001 werkzaam als arts-assistent heelkunde niet in opleiding (AGNIO) in het Albert Schweitzer Ziekenhuis, Zwijndrecht.

Op 1 januari 2002 startte zij, na een korte AGNIO periode, met de opleiding Keel- Neus en Oorheelkunde in het Academisch Ziekenhuis Maastricht (thans MUMC). Zij werd hier opgeleid door aanvankelijk prof. dr. J.J Manni en later prof. dr. B. Kremer. Haar niet-universitaire deel van de opleiding werd gevolgd in het Catharina Ziekenhuis te Eindhoven onder dr. F.C.P.M Adriaansen (opleider) en dr. D.J.M. Mateijsen (plaatsvervangend opleider) en in het Atrium Medisch Centrum (thans Zuyderland Medisch Centrum) te Heerlen onder dr. T.D. Zijlker en (opleider) en drs. H.E.V.M. Brinkhuis (plaatsvervangend opleider). Gedurende haar opleidingstijd werd de basis gelegd voor dit proefschrift. In 2006 ontving zij voor haar onderzoek de derde prijs van het Pélerin Wetenschaps Symposium te Maastricht.

In januari 2007 behaalde zij haar KNO-arts examen. Vervolgens startte zij haar medisch specialistische loopbaan als chef de clinique in het Zuyderland Medisch Centrum, met een deeltijd detachering van twee dagen per week in het MUMC. Per 1 april 2009 is zij toegetreden tot de maatschap Keel- Neus en Oorheelkunde Oostelijk Zuid Limburg in het Zuyderland Medisch Centrum. De daarop volgende jaren heeft zij zich gespecialiseerd in de rhinologie waarbij zij door dr. T.D. Zijlker verder is opgeleid in de plastische- er reconstructieve aangezichtschirurgie, met als zwaartepunt de functionele en esthetische neuschirurgie en neusbijholtenchirurgie. Daarnaast heeft zij als tweede aandachtsgebied binnen het Zuyderland MC de benigne weke delen chirurgie van het hoofd hals gebied en (bedreigde) luchtweg-management. Zij verricht diverse organisatorische taken binnen de maatschap.

Sinds 1 januari 2016 heeft zij dr. T.D. Zijlker opgevolgd als niet-universitair opleider.

Ewa Bergshoeff en haar echtgenoot Hans Leistra wonen samen met hun drie kinderen Emilia, Josephine en Titus te Maastricht. 
